\title{
Sea Surface Salinity Observations from Space with the SMOS Satellite: A New Means to Monitor the Marine Branch of the Water Cycle
}

\author{
Nicolas Reul ${ }^{*}, 1,2$, Severine Fournier ${ }^{1}$, Jaqueline Boutin ${ }^{3}$,Olga Hernandez ${ }^{3}$,Christophe Maes ${ }^{5}$, \\ Bertrand Chapron ${ }^{1}$,Gaël Alory ${ }^{5}$,Yves Quilfen ${ }^{1}$,Joseph Tenerelli ${ }^{4}$, Simmon Morisset ${ }^{3}$, \\ Yann Kerr ${ }^{6}$,Susanne Mecklenburg ${ }^{7}$, Steven Delwart $^{7}$
}

1 Laboratoire d'Océanographie Spatiale, Institut Français de recherche et d'Exploitation de la Mer, Centre Bretagne BP 70, 29280, Plouzané, France

${ }^{2}$ Centre Méditerranée, Zone Portuaire de Brégaillon, BP 330, 83507, La Seyne-sur-Mer Cedex, France

3 Laboratoire d'Océanographie et du Climat: Expérimentation et Approches Numériques, UMR 7159 CNRS/UPMC/IRD/MNHN, Paris, France

${ }^{5}$ LEGOS, OMP, CNAP, Université de Toulouse, Toulouse, France

${ }^{4}$ CLS-Radar Division, Bâtiment Le Ponant, Avenue La Pérouse, Technopôle Brest-Iroise, 29280, Plouzané, France

${ }^{6}$ CESBIO, Toulouse, France

${ }^{7}$ ESA-ESRIN, Frascatti, Italy

*: Corresponding author : Nicolas Reul, email address : $\underline{\text { nreul@ifremer.fr }}$

\begin{abstract}
:
While it is well known that the ocean is one of the most important component of the climate system, with a heat capacity 1,100 times greater than the atmosphere, the ocean is also the primary reservoir for freshwater transport to the atmosphere and largest component of the global water cycle. Two new satellite sensors, the ESA Soil Moisture and Ocean Salinity (SMOS) and the NASA Aquarius SAC-D missions, are now providing the first spaceborne measurements of the sea surface salinity (SSS). In this paper, we present examples demonstrating how SMOS-derived SSS data are being used to better characterize key land-ocean and atmosphere-ocean interaction processes that occur within the marine hydrological cycle. In particular, SMOS with its ocean mapping capability provides observations across the world's largest tropical ocean fresh pool regions, and we discuss from intraseasonal to interannual precipitation impacts as well as large-scale river runoff from the Amazon-Orinoco and Congo rivers and its offshore advection. Synergistic multi-satellite analyses of these new surface salinity data sets combined with sea surface temperature, dynamical height and currents from altimetry, surface wind, ocean color, rainfall estimates, and in situ observations are shown to yield new freshwater budget insight. Finally, SSS observations from the SMOS and Aquarius/SAC-D sensors are combined to examine the response of the upper ocean to tropical cyclone passage including the potential role that a freshwater-induced upper ocean barrier layer may play in modulating surface cooling and enthalpy flux in tropical cyclone track regions.
\end{abstract}

Keywords: Sea surface salinity ; SMOS satellite ; Passive microwave remote sensing ; Oceanic freshwater cycle

\section{Introduction}

Salinity is known to play an important role in the dynamics of the ocean's thermohaline overturning circulation and in large-scale atmosphere-ocean climate signals such as the El Nino Southern Oscillation (ENSO), and is the key freshwater tracer within the oceanic component of the global hydrologic cycle, a branch that comprises most of the global precipitation and evaporation as well as the river runoff (Schmitt 2008). Multi-decadal sea surface salinity (SSS) trends have been documented in tropical and high latitudes and associated with signatures of evaporation or precipitation variation that are consistent with global warming scenarios (e.g., Dickson et al. 2002; Gordon and Guilivi 2008; Morrow et al. 2008; Cravatte et al. 2009; Yu 2011; Durack et al. 2012; Terray et al. 2011). These studies highlight the need for well-sampled SSS time series both for 
monitoring the change and to improve basic understanding of the respective roles of the atmosphere and ocean dynamics, thermodynamics, air-sea interaction, and land-ocean interaction in the global water cycle context.

Our basic knowledge of the global SSS distribution is derived from the compilations of all available oceanographic data collected over time (e.g. Boyer and Levitus, 2002). The SSS in situ observing system has expanded significantly during the last decade due mostly to the full deployment of the Argo profiling float array, and now provides a monthly SSS estimate on a grid of roughly $300-400 \mathrm{~km}^{2}$. Notwithstanding these recent gains, this sampling density is still too sparse to resolve climatologically important intraseasonal, seasonal, and interannual to decadal signals at the $300 \mathrm{~km}$ spatial scale within which SSS is known to vary significantly (Lagerloef et al, 2010). The recent launch of the ESA/SMOS (Soil Moisture and Ocean Salinity, see Kerr et al., 2010; Font et al., 2010) and NASA/Aquarius SAC-D (Lagerloef et al., 2008; Lagerloef et al., 2012) mission satellites represent contributions towards filling this gap using passive microwave remote sensing.

Salinity remote sensing is based on measurement of sea surface microwave emission at the lower end of the microwave spectrum and from a surface skin layer having a thickness of $O(1 \mathrm{~cm})$. This emission depends partly on the dielectric constant of sea water, which in turn can be related to salinity and temperature. Thus, given sea surface temperature (SST), theory predicts some ability to invert SSS information. In practice however, numerous additional external factors (extra-terrestrial sources, atmosphere, ionosphere and surface roughness) also contribute to the satellite-observed emission and these must be corrected to allow accurate ocean salinity estimates. The SMOS and Aquarius sensors are both ocean microwave radiometers operating at a frequency of $\sim 1.4$ $\mathrm{GHz}$ (L-band, wavelength of $21 \mathrm{~cm}$ ), a band chosen for the relatively strong sensitivity to change in salinity and because this is a transmission-free, or protected, frequency. An additional and important benefit for this choice is minimization of atmospheric signal contributions.

Based on observed SSS variability and need to better resolve it, the satellite missions aim to produce salinity estimates with an accuracy of $0.1-0.2$ over the so-called Global Ocean Data Assimilation Experiment (GODAE) scales of $100 \mathrm{~km}$, one month or $200 \mathrm{~km}$, and 10 days. This is a challenging objective for several reasons. First, the sensitivity of L-band brightness temperatures to variations in SSS is on average $0.5 \mathrm{degK}$ per salinity unit. This sensitivity is very weak given that spatial and temporal variability in open-ocean SSS does not exceed several units and that the instrument noise is typically $2-5 \operatorname{degK}$. Second, there 
are many geophysical sources of brightness at L-band that corrupt the salinity signal, and correction models for these factors have uncertain accuracy. Moreover, the technical approach developed in order to achieve adequate radiometric accuracy and spatio-temporal resolution for SMOS is polarimetric interferometric radiometry, the first such spaceborne system. The complex SMOS image reconstruction data processing includes contamination by different errors and induces residual inaccuracies in SSS estimates. Finally, there is

110 significant radio frequency interference emanating from sources along the many coastlines

111 that contaminate data collected over many ocean regions. Nevertheless, much work at

112 ESA SMOS Level 2 expert centers and the CNES/IFREMER Centre Aval de Traitement 113 des Données SMOS (CATDS) has addressed these issues, leading to the first global 114 satellite SSS estimates (Font et al. 2012, Reul et al. 2012, Boutin et al. 2012a).
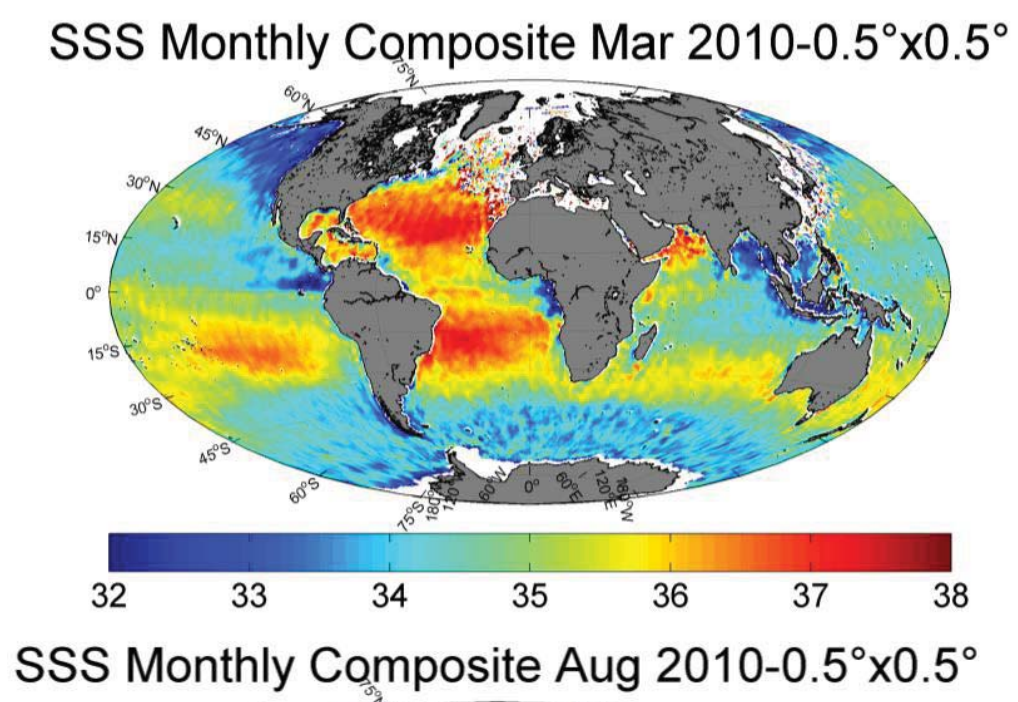

118 Figure. 1 Monthly composites of the sea surface salinity at a spatial resolution of $1190.5^{\circ} \times 0.5^{\circ}$ deduced from SMOS data (CATDS v2) for the months of March (top) and August (bottom) 2010. 
123 Two examples of monthly composite SMOS SSS maps are shown in Figure 1. They show

124 salient basin scale features, including the elevated salinity in the Atlantic relative to the 125 other basins, and the general correspondence of lower SSS with known river runoff and 126 tropical precipitation regions. SMOS data validation efforts using in situ observations 127 reveal an overall SSS accuracy on the order of 0.3 (Boutin et al., 2012a; Reul et al., 2012; 128 Bank et al., 2012; Font et al., 2013), but with degraded quality at high latitudes partly 129 because of reduced sensitivity in colder waters. While further improvements are in 130 progress, many interesting features of the global SSS could be already evidenced.

132 This paper reviews preliminary results addressing several key applications of these new satellite SSS data. Given the reduced SMOS sensitivity in colder waters, the focus in on

134 tropical ocean data where SMOS measurements have proven to be the most accurate. We 135 also attempt to highlight combined use of other satellite and in situ observations (altimetry, 136 SST, ocean color, river discharge, evaporation, precipitation). It is shown that these new 137 data are proving useful in the monitoring of intraseasonal to interannual variability across major Tropical freshwater pools of the world ocean. SMOS-detected SSS freshening events within intense precipitation zones (e.g., the Inter-Tropical Convergence Zone) are

140 also shown to provide promising new information related to the ocean surface response to 141 rainfall. Finally, SMOS SSS data are used to address interactions between wind-driven 142 phenomena, such as upwelling and Tropical cyclones, and some of the world largest Fresh

143 pools. The datasets used in these cases are described in Section 2. SMOS monitoring 144 capabilities for the major tropical river plumes are given in Section 3. In sections 4 and 5, 145 we illustrate rain impacts detected in SMOS SSS data then their application improved 146 understanding of freshwater pools interaction with the atmosphere. Conclusions and 147 perspectives are given in section 6.

\section{Data}

A range of satellite and in situ datasets are used in the present study with focus on the years 2010-2011 following the SMOS launch date. The data products are described below.

\subsection{SMOS SSS data}

155 SMOS (Soil Moisture and Ocean Salinity) is the European Space Agency (ESA)'s water 156 mission (Kerr et al. 2010; Mecklenburg et al. 2012), an Earth Explorer Opportunity 
157 Mission approved under the Living Planet Program. SMOS was launched in November

1582009 and the technical approach developed to achieve adequate radiometric accuracy, as

159 well as spatial and temporal resolution compromising between land and ocean science

160 requirements, is polarimetric interferometric radiometry (Ruf et al. 1988; Font et al. 2010)

161 at L-band (frequency of $\sim 1.4 \mathrm{GHz}$ ). ESA produces so-called Level 2 SSS, or L2 products

162 which correspond to instantaneous SSS retrievals under the satellite swath.

163 Table 1: Summary of characteristics of CATDS-CEC SSS level 3 products

\begin{tabular}{|c|c|c|}
\hline & CEC IFREMER & CEC LOCEAN \\
\hline SSS retrievalmethod & $\begin{array}{l}\text { SSS retrieved from first } \\
\text { Stokes parameter (Reul and } \\
\text { Tenerelli 2011) }\end{array}$ & $\begin{array}{l}\text { SSS retrieved from } \\
\text { polarized Tbs along dwell- } \\
\text { lines using an iterative } \\
\text { retrieval } \\
\text { (see ESA L2OS ATBD) }\end{array}$ \\
\hline $\begin{array}{llr}\text { Region } & \text { of } & \text { the } \\
\text { instrument } & \text { field of } \\
\text { View } & \text { (FOV) } \\
\text { considered for } & \text { SSS } \\
\text { retrieval } & & \end{array}$ & Alias Free Field of View only & $\begin{array}{l}\text { Alias Free Field of View } \\
\text { (AFFOV) and extended } \\
\text { AFFOV along dwell lines } \\
\text { with at least } 130 \mathrm{~Tb} \text { in } \\
\text { AFFOV ( }+/-300 \mathrm{~km} \text { from } \\
\text { the swath center) }\end{array}$ \\
\hline Tb sortings & $\begin{array}{lcr}\text { Determined } & \text { from } & \text { interorbit } \\
\text { consistency } & \text { in } & \text { incidence } \\
\text { angles } & \text { classes } & \text { and } \\
\text { thresholding } & & \end{array}$ & $\begin{array}{lr}\text { Determined } & \text { from } \\
\text { consistency along dwell } \\
\text { lines as reported in ESA } \\
\text { level } 2 \text { products }\end{array}$ \\
\hline Galactic model & Geometrical optics model & $\begin{array}{l}\text { Kirchoff Approx. scattering } \\
\text { at } 3 \mathrm{~m} / \mathrm{s}\end{array}$ \\
\hline Roughness/foammodels & $\begin{array}{l}\text { Empirical adjustment of } \mathrm{Tb} \\
\text { dependencies to wind speed }\end{array}$ & $\begin{array}{l}\text { Empirical adjustment of } \\
\text { parameters in roughness } \\
\text { model and foam coverage } \\
\text { models (Yin et al. 2012) }\end{array}$ \\
\hline Calibration & $\begin{array}{l}\text { Single Ocean Target } \\
\text { Transformation (OTT) + daily } \\
5^{\circ} \times 5^{\circ} \text { adjustment wrt World } \\
\text { Ocean } 2001 \text { SSS climatology }\end{array}$ & $\begin{array}{l}\text { Variable OTT (every } 2 \\
\text { weeks synchronised with } \\
\text { Noise Injection Radiometer } \\
\text { as defined in ESA } \\
\text { reprocessing) }\end{array}$ \\
\hline Average & Simple average & $\begin{array}{l}\text { Average weighted by } \\
\text { theoretical error on } \\
\text { retrieved SSS and spatial }\end{array}$ \\
\hline
\end{tabular}


165 In the present study, level 2 SMOS SSS are from the first SMOS/ESA annual reprocessing 166 campaign in which ESA level 1 v5.04 and level 2 v5.50 processors havebeen used. In these 167 versions, significant improvements with respect to the flaws discovered in the first 168 products (e.g. Reul et al., 2012) have been implemented (see a complete description in the 169 Algorithm TheoreticalBasis Document (ATBD) available at $170 \mathrm{http} / / / \mathrm{www}$. argans.co.uk/smos/docs/deliverables/). Nevertheless, accuracy of these 171 instantaneous SSS retrievals is rather low ( 0.6-1.7 unit) and space-time averaging of the 172 Level 2 products is needed (so-called Level 3 SSS) to decrease the noise level in the 173 retrievals.

174 Here we used two types of composite SSS level 3 products generated in 175 laboratories participating to the Expertise Center of the Centre Aval de Traitement des 176 Données SMOS (CATDS, http://www.catds.fr), which is the french ground segment for 177 the SMOS data. These products are built either from ESA level 1 products (Reul and 178 Tenerelli, 2011) or from ESA level 2 products (Boutin et al, 2012b).

179 These research products aim at assessing the quality of SMOS operational products 180 (ESA level 2 and CATDS-OP level 3) and at studying new processings to be implemented 181 in the future in operational chains. Main characteristics of these products are detailed in

182 Table 1. CEC-IFREMER products have been used in section $3 \& 5$, CEC-LOCEAN 183 products in section 4.

184 Overall accuracy of the 10-days composite products at $25 \mathrm{~km}$ resolution is on the order of 1850.3 practical salinity unit in the tropical oceans (Reul and Tenerelli, 2011). Note 186 thatsalinity computations are based on the Practical Salinity Scale PSS-78, and reported 187 with no units (United Nations Educational, Scientific and Cultural Organization, 1985).

\subsection{Ocean Surface Currents}

190 Here we used the $1 / 3^{\circ}$ resolution global surface current products from Ocean Surface 191 Current Analyses Realtime (OSCAR) (Bonjean and Lagerloef, 2002; 192 http://www.oscar.noaa.gov), directly calculated from satellite altimetry and ocean vector 193 winds.

194 The OSCAR data processing system calculates sea surface velocities from satellite 195 altimetry (AVISO), vector wind fields (QuikSCAT), as well as from sea surface 
196 temperature (Reynolds-Smith) using quasi-steady geostrophic, local wind-driven, and 197 thermal wind dynamics. Near real time velocities are calculated on both $\mathrm{a} 1^{\circ} \mathrm{x} 1^{\circ}$ and $1981 / 3^{\circ} \times 1 / 3^{\circ}$ grid on a $\sim 5$ day time base over the global ocean. Surface currents are provided 199 on the OSCAR website (http://www.oscar.noaa.gov) starting from 1992 along with 200 validations with drifters and moorings. The $1 / 3^{\circ}$ resolution is available for ftp download 201 through ftp://ftp.esr.org/pub/datasets/SfcCurrents/ThirdDegree.

\subsection{Rain, Evaporation and River Discharge data}

To estimate the rain-rate over the oceans, we used three different satellite products.

One is the monthly TRMM Composite Climatology (TCC) of surface precipitation based on 13 years of data from the Tropical Rainfall Measuring Mission (TRMM). The TCC takes advantage of the information from multiple estimates of precipitation from TRMM to construct mean value maps over the tropics $\left(36^{\circ} \mathrm{N}-36^{\circ} \mathrm{S}\right)$ for each month of the year at $0.5^{\circ}$ latitude-longitude resolution. The first-time use of both active and passive microwave instruments on board TRMM has made it the foremost satellite for the study of precipitation in the tropics and has led to a better understanding of the underlying physics and distribution of precipitation in this region. The products are available at NASA

213 Goddard Space Flight Center Global Change Master Directory (http://gcmd.nasa.gov).

214 The second type of satellite rain rate estimates that we used in the present study are the 215 so-called 'TRMM and Other Satellites' (3B42) products, obtained through the 216 NASA/Giovanni server (http://reason.gsfc.nasa.gov/OPS/Giovanni).The 3B42 estimates 217 are 3-hourly at a spatial resolution of $0.25^{\circ}$ with spatial extentcovering a global belt $218\left(-180^{\circ} \mathrm{W}\right.$ to $\left.180^{\circ} \mathrm{E}\right)$ extending from $50^{\circ} \mathrm{S}$ to $50^{\circ} \mathrm{N}$ latitude. The major inputs into the $3 \mathrm{~B} 42$ 219 algorithm are IR data from geostationary satellites and Passive Microwave data from the TRMM microwave imager (TMI), special sensor microwave imager (SSM/I), Advanced Microwave Sounding Unit (AMSU) and Advanced Microwave Sounding RadiometerEarth Observing System (AMSR-E).

The Special Sensor Microwave Imager (SSM/I) F16 and F17 orbits cross SMOS orbits within -20 min and +40 min. Hence, numerous SMOS level 2 are collocated with SSMI rain rates (RR) within this range of time. In addition to the TRMM 3B42 products, we therefore used SSM/Is datasets to perform co-locations between SMOS SSS and rain estimates. SSM/Is RR version 7 were used and downloaded from http://www.remss.com. Objectively Analyzed air-sea Fluxes (OAFlux) project (Yu and Weller, 2007). 
Finally the discharge data for the Amazon, Orinoco and Congo rivers were obtained

231 from the Environmental Research Observatory (ORE) HYBAM (Geodynamical,

232 hydrological and biogeochemical control of erosion/alteration and material transport in the

233 Amazon basin) website.

\subsection{Ocean Color products}

236 To study the spatio-temporal coherency between SSS signals from some major tropical 237 river plumes and ocean color properties, we used the level-3 daily, 4-km resolution estimates of the absorption coefficient of colored detrital matter (CDM) at $443 \mathrm{~nm}$. These products processed and distributed by ACRI-ST GlobColour service, are supported by the EU FP7 MyOcean2 and the ESA GlobColour Projects, using ESA ENVISAT MERIS data, NASA MODIS and SeaWiFS data. These products have been averaged at the SMOS L3 product $0.25^{\circ}$ resolution, with a 10 -days running mean.

\subsection{In situ data}

245 Salinity measurements from Argo floats are provided by the Coriolis data centre 246 (http://www.coriolis.eu.org/). The upper ocean salinity values recorded between $4 \mathrm{~m}$ and 247 10m depth will be referred to as Argo SSS following Boutin et al. (2012b).

248 Global SSS maps are derived from delayed time quality checked in situ measurements 249 (Argo and ship) by IFREMER/LPO, Laboratoire de physique des oceans, using the In Situ 250 Analysis System (ISAS) optimal interpolation (D7CA2S0 re-analysis product) (see a method description on http://wwz.ifremer.fr/lpo/SO-Argo-France/Products/Global-OceanT-S/Monthly-fields-2004-2010 and in (Gaillard et al., 2009)). The choice for the time and space scales used in that method results from a compromise between what is known of ocean time and space scales and what can actually be resolved with the Argo array $\left(3^{\circ}, 10\right.$ days); two length-scales are considered: the first one is isotropic and equal to $300 \mathrm{~km}$, the second one is set equal to 4 times the average Rossby radius of deformation of the area. As a result, we expect these maps being smoother, especially in tropical areas, than SMOS SSS maps averaged over $0.25^{\circ} \times 0.25^{\circ}$ or $1^{\circ} \times 1^{\circ}$.

\section{SMOS monitoring of the Major Tropical Atlantic River} Plumes

Rivers are important variables in oceanography as their fresh water affects SSS and the buoyancy of the surface layer, and they represent a source of materials exotic to the 
ocean and important to biological activity. Obviously, they are key hydrologic

265 components of the fresh water exchanges between land and ocean. Despite this importance, tracing major tropical river water (e.g. Amazon, Congo, Ganges) over large distances has not been straightforward previously principally because of a lack of SSS observations. Tracing those very large rivers over great distances now become an important endeavor, as sufficient data are available from surface salinity sensors placed aboard satellites. Occurrence of patches of low surface salinity $(<35$ practical salinity units) in the Tropical Atlantic Ocean is closely related to the presence of the mouths of the world's largest rivers in terms of fresh-water discharge (e.g. Amazon, Congo,Orinoco) and their subsequent spreading of fresh water by the upper ocean circulation. Another key fresh water source here is the Inter Tropical Convergence Zone (ITCZ), associated with relatively intense precipitation that migrates latitudinally over the tropical Atlantic throughout the year (Binet and Marchal 1993). One of these major low salinity pools is formed by the Amazon and Orinoco river plumes spreading offshore from the South America north-eastern coasts, and influencing a large fraction of the western tropical North Atlantic (Neumann, 1969; Lentz 1995; Muller-Karger et al. 1988; Dessier and Donguy, 1994). The Gulf of Guinea, situated in the North-Eastern Equatorial Atlantic (NEEA) is also an important location for the fresh water budget in the tropical Atlantic. It is a region of intense precipitation with as much as $30 \mathrm{~cm}$ of rain falling per month during the rainy season (Yoo and Carton [1988]). Furthermore, into this area flows the Congo River, the largest fresh water input to any eastern ocean boundary. These large-scale low salinity 'lenses' at the Tropical Atlantic surface can be traced over distances ranging from several hundreds up to thousands of kilometers in the upper ocean. They are characterized by very distinct and in general strong seasonally varying spatial extents.

\subsection{Amazon and Orinoco River Plume monitoring}

The Amazon is the world's largest river in terms of fresh water discharge (Milliman and Meade, 1983; Perry et al. 1996). It drains a large fraction of the South American continent, discharging on average $1.55 \pm 0.13 \times 10^{5} \mathrm{~m}^{3} \mathrm{~s}^{-1}$ of fresh water into the equatorial Atlantic Ocean (Perry et al.1996).This is about $15 \%$ of the estimated global river discharge on an annual basis. The Amazon River is by far the largest single source of terrestrial fresh water to the ocean and contributes about $30 \%$ of total river discharge to the Atlantic Ocean (Wisser et al., 2010). The structure of the Amazon plume is strongly influenced by a 
variety of physical processes which are present on the northern Brazilian shelf: the North

299 Brazil Current (Flagg et al., 1986; Richardson and McKee, 1984), trade winds (Hellerman 300 and Rosenstein, 1983) and strong currents associated to the tide (Nittrouer and Demaster, 301 1986). These physical processes play a very significant role in the dispersal and spreading 302 of Amazon discharge (fresh water and suspended sediment) on the northern continental 303 shelf of South America.

305 Previous studies have shown that Amazon Plume water can be traced offshore and northwestward along the north Brazilian coast, covering most of the continental shelf from $11^{\circ} \mathrm{S}$ to $5^{\circ} \mathrm{N}$ (Muller-Karger et al. 1988, 1995) into the Caribbean (e.g. Steven and Brooks 1972; Froelich et al.1978; Hellweger and Gordon, 2002; Cherubin and Richardson,2007), and over $1000 \mathrm{~km}$ eastward into the North Atlantic depending on the season. Beyond this region, the Amazon's water has been traced northwestward into the Caribbean Sea and eastward in the North Atlantic (Muller-Karger et al. 1988, 1995; Johns et al., 1990; Hellweger and Gordon, 2002). Hydrographic surveys by Lentz and Limeburner (1995) revealed that the Amazon Plume over the shelfis typically 3-10m thick and between 80 and $>200 \mathrm{~km}$ wide. Beyond the shelf, fresh water within the plume gradually attenuates with depth as it travels away from the source, with a penetration depth of $40 \mathrm{~m}$ to $45 \mathrm{~m}$ as far as 2600 km offshore (Hellweger and Gordon, 2002; Hu et al., 2004).

317 Both chlorophyll (Chl) concentration and primary productivity are greatest in the river 318 plume-ocean transition zone, where the bulk of heavy sediments are deposited (Smith and 319 Demaster, 1996). The combination of riverine nutrient input and increased irradiance 320 availability creates a highly productive transition zone, the location of which varies with 321 the discharge from the river. High phytoplankton biomass and productivity of over $25 \mathrm{mg}$ $322 \mathrm{Chl}-\mathrm{a} \mathrm{m} \mathrm{m}^{-3}$ and $8 \mathrm{~g} \mathrm{Cm}^{-2} \mathrm{~d}^{-1}$, respectively, are found in this transition region (Smith and 323 Demaster, 1996). Because ofthis, the North Brazil shelf acts as a significant sink for 324 atmospheric $\mathrm{CO}_{2}$ (Ternon et al., 2000).

The north western Tropical Atlantic is also an area where another major river in the world, the Orinoco, enters the ocean. The Orinoco River originates in the southern part of Venezuela, and discharges waters from about 31 major and 2000 minor tributaries into the western tropical Atlantic. These waters are most of the time transported into the southeastern Caribbean sea and during the rainy season a larger but unquantified fraction of the plume also flows east around Trinidad and Tobago into the Caribbean. The Orinoco 
332 is considered to be the third largest river in the world in terms of volumetric discharge 333 (after the Amazon and the Congo), discharging an average of $\sim 3.6 \times 10^{4} \mathrm{~m}^{3} \mathrm{~s}^{-1}$ (Meade et 334 al.,1983; Muller-Karger et al., 1989; Vörösmarty et al., 1998). Low discharge occurs 335 during the dry season (January-May) and high discharge during the rainy season (July336 October) as a result of the meridional migration of the ITCZ.

338 The fresh water discharges from the Amazon and Orinoco Rivers spread outward into the western equatorialAtlantic Ocean while continually mixing with surroundingsalty ocean surface water. The averaged geographicaldistribution of the low-salinity signatures of the Amazonand Orinoco River plumes can be revealed with historical in situ surface salinity data. However, only satellite remote sensing data is known to provide means to monitor the wide surface dispersal of these two fresh pools, with ocean color data being the first to illustrate Amazon plume reach to well beyond 1000 km (Muller Karger et al., 1988). Since these first observations, the application of ocean color, altimetry, and SST satellite mapping in this region has increased in its sophistication, showing the ability to track surface plume area (e.g. Hu et al., 2004; Molleri et al., 2010), fronts along the shelf to the North West (Baklouti et al., 2007), and northward propagating eddies or waves shed near the North Brazil Current (NBC) retroreflection region, the so-called NBC rings (Ffield, 2005; Goni and Johns, 2001; Garzoli et al., 2004). In each case, the satellite data are able to provide time-resolved information on advective processes up to certain limits that include cloud cover, minor SST and ocean color gradients, non-conservative dilution processes for the ocean color to salinity conversions (Salisbury et al., 2011), and baroclinicity and subgrid variability of the altimetry Seas Surface Height Anomaly (SSHA) tracking of the NBC rings. As first evidenced by Reul et al., 2009, passive remote sensing data at low microwave frequencies can be successively used to complement these more 'classical' satellite observations to better follow the temporal evolution and spatial distribution of surface salinity within and adjacent to the Amazon River Plume.

To illustrate this new capability, we first show in Figure 2 comparisons between collocated SMOS SSS and in situ Conductivity-Temperature Depth (CTD) measurements acquired during the Geotraces West Atlantic cruise leg 2 across the Amazon river plume in June 2010. This campaign was conducted on RV Pelagia in the frame of the GEOTRACES international program (see http://www.geotraces.org/). 
365

366
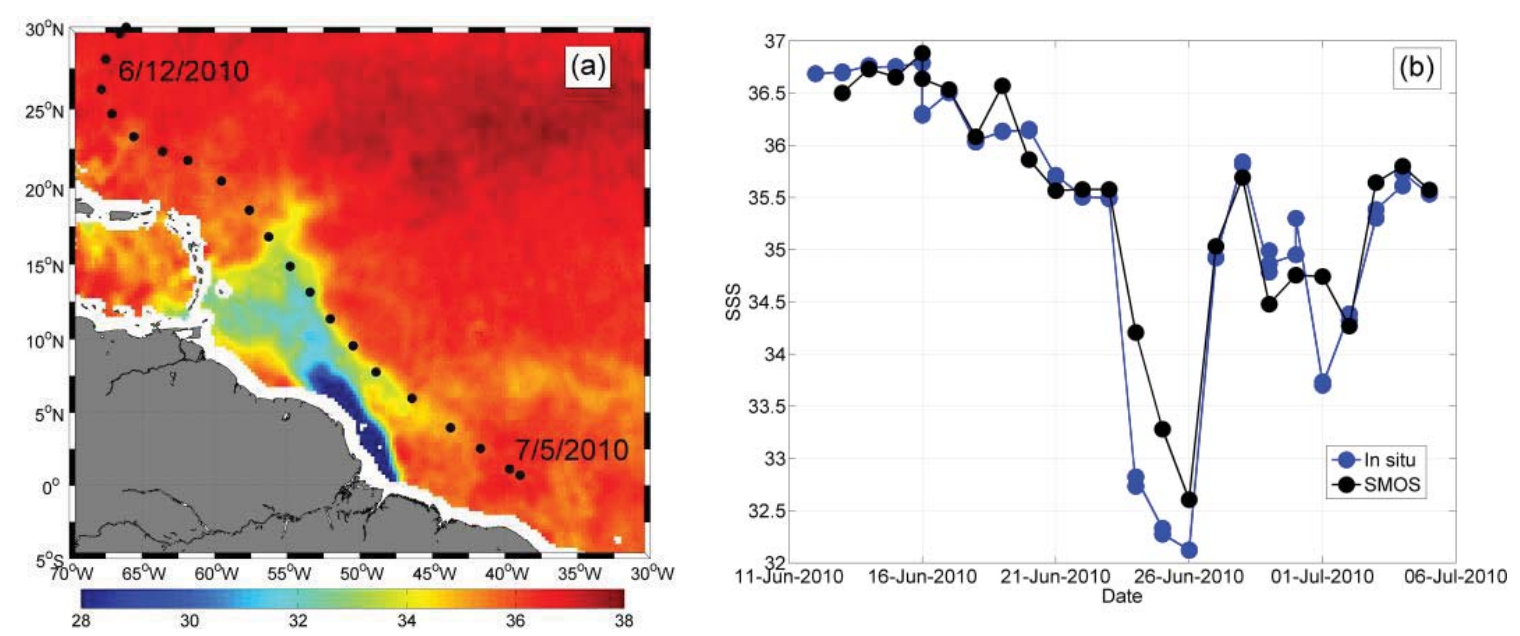

Figure 2: (a) Black dots: location of the CTD stations conducted during the Geotraces West Atlantic cruise leg 2 (RV Pelagia) from 11 June to 5 July superimposed on the SMOS averaged SSS from June 12th to July 5th 2010. (b) Co-located surface salinity between SMOS and in situ data along the leg. SMOS data have been averaged at $50 \mathrm{~km}$ resolution with a \pm 5 days running temporal window.

Comparison between satellite and 3-m depth in situ SSS data reveals an overall good agreement with a standard deviation of the difference $\operatorname{SSS}_{\mathrm{SMOS}}-\mathrm{SSS}_{\mathrm{CTD}}$ of $\sim 0.45$. In particular, the strong gradient and $\sim 3$ unit drop observed as the R/V Pelagia leg crossed the Amazon river plume is well detected by the satellite observations.

New sea surface salinity products from satellite plateforms such as SMOS allow in particular to gain insights into the advection pathways of the fresh water Amazon and Orinoco river plume along surface currents. For the first time, SMOS sampling capability thus enables imaging the plume structure almost every 3 days with a spatial resolution of about $40 \mathrm{~km}$. Combining SMOS SSS with altimeter-derived geostrophic currents and wind-driven (Ekman) estimated motions (Lagerloef et al., 1999), the advection of the spatial patterns of low salinity discharged from the major river mouths can now be analyzed systematically with an unprecedented resolution.

As illustrated by the Figure 3 and by the animation available at http://www.ifremer.fr/naiad/salinityremotesensing.ifremer.fr/altimetry_amazon_atl.gif, a very good visual consistency is found between the geostrophic and Ekman surface current pattern estimates and the SMOS SSS spatio-temporal distribution along the year. 


\section{SSS Averaged from Jun 04 through Jun 14}
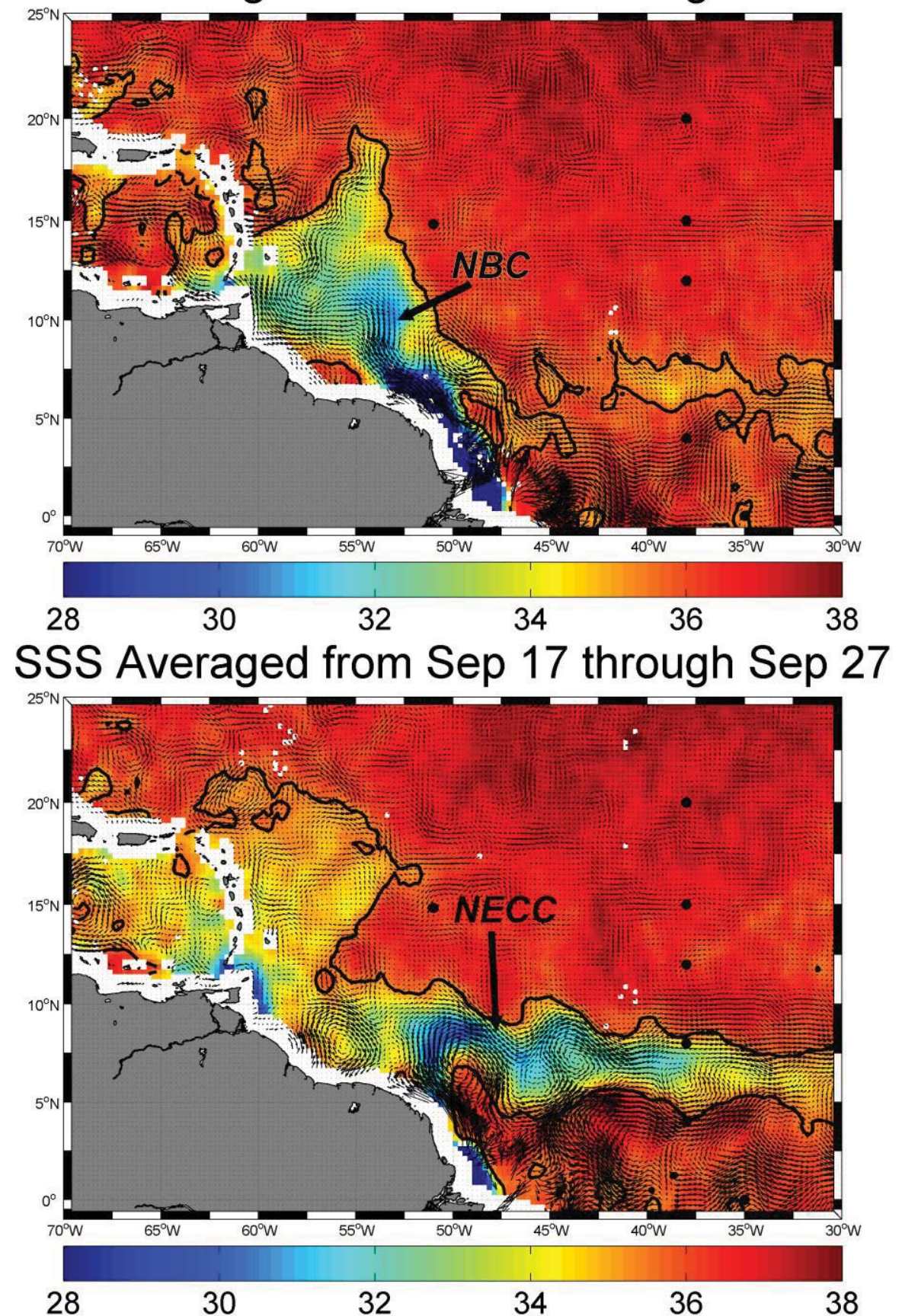

391 Figure.3 Major pathways for the freshwater Amazon-Orinoco river plume detected by SMOS in 2010. Surface salinity fields from SMOS are superimposed with coinciding surface OSCAR currents estimatedfrom altimetry and surface wind data. Top: the freshwater Amazon river plume is advected northwestward along the Brazilian Shelf by the North Brazilian Current (NBC) during boreal spring. Bottom: during boreal summer to fall period, the Amazon plume is carried eastward by the North Equatorial Counter Current (NECC). Note also the signal from the Orinoco river plume extending Northeastward along the southern lesser Antilles. In both plots the thick black curve is indicating the 35 SSS contour. 
403 entrainment into the North Equatorial Counter Current (NECC) - but they cannot clearly 404 confirm or track this laterally with time in a given year.

405 SMOS SSS data combined with altimetry and surface wind information now enable to 406 follow the spatio-temporal evolution of the plume along these twofresh water offshore 407 pathways.

408 As illustrated in Figure 3 (top), the surface fresh water dispersal patterns of the Amazon 409 river plume are closely connected to the surface current topology derived from the merged 410 altimeter and wind field product. As also evidenced earlier from several hydrographic 411 surveys (e.g., Hellweger and Gordon, 2002), it is clearly apparent in the satellite imagery 412 that the NBC rings are key factors in modulating the fresh water pathways of the Amazon 413 plume from the river mouth at the equator towards higher latitudes up to $20^{\circ}-22^{\circ} \mathrm{N}$.

414 Eastward entrainment of low salinity water from the mouth of the Amazon river into the 415 North Equatorial Counter Current (NECC) is also evident in the SMOS data for the 416 second half of the year 2010 (see Figure 3, bottom). During that period, fresh water 417 dispersal structure exhibits a zonal wavy pattern centered around $\sim 8^{\circ} \mathrm{N}$ induced by current 418 instability waves shed near the North Brazil Current (NBC) retroflection region $419\left(52^{\circ} \mathrm{W}, 8^{\circ} \mathrm{N}\right)$. To analyze the freshwater plume transport and the evolution of salinity along 420 Lagrangian paths following such wavy patterns, hypothetical drifters were dropped around 421 the mouth of the river at the beginning of June and temporally advected with the surface 422 currents deduced from merged altimeter and wind products. The evolution of sea surface 423 salinity from SMOS L-band and AMSR-E C-band sensors (see Reul et al., 2009 for details 424 on the AMSR-E SSS product), sea surface temperature analysis products and merged 425 MERIS-MODIS Colored Dissolved Organic Matter (CDOM) absorption coefficient was 426 estimated by interpolating the data in space and time along the path of such drifters. 


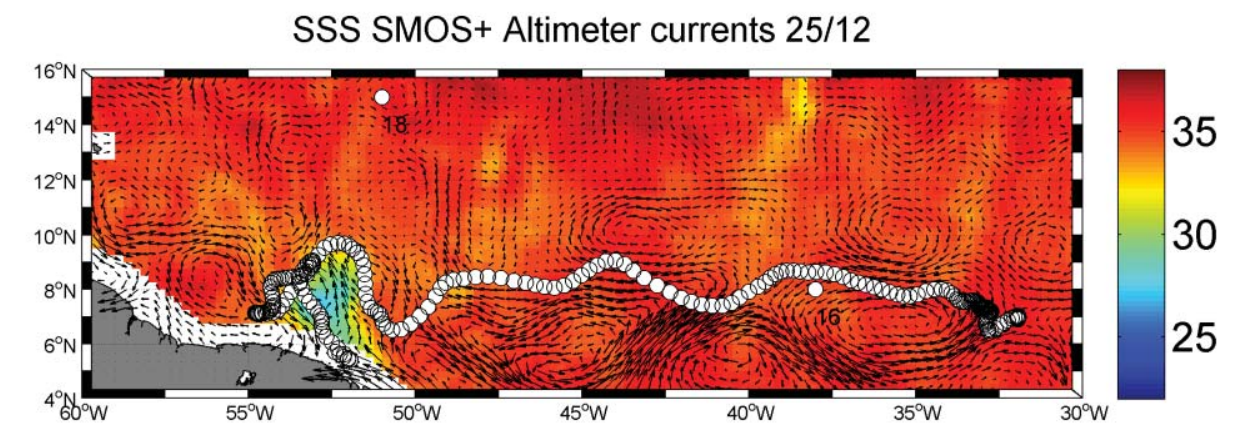

SSS: SMOS-AMSR-E 25/12

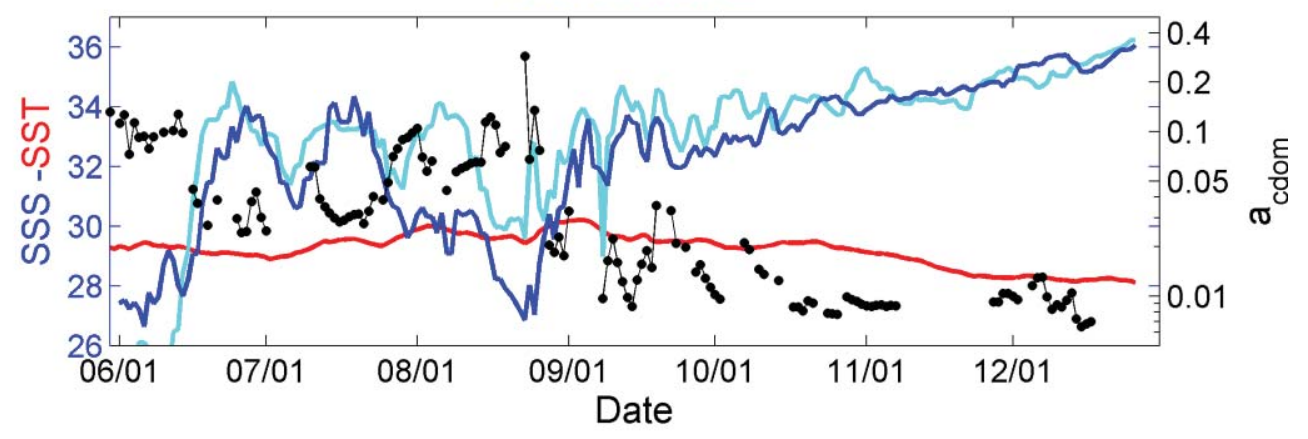

428 Figure 4: Top:spatio-temporal evolution of the location of an hypothetical drifter (white 429 dots) dropped at $52^{\circ} \mathrm{W}^{\circ} \mathrm{N}$ at the beginning of june 2010 and advected with surface 430 currents estimated from altimetry\& surface winds (arrows). Superimposed are the +/-5 431 days averaged daily SSS fields from SMOS and the surface currents (black arrows). 432 Bottom: time series of the co-localized SSS from SMOS (blue) and from AMSR-E (cyan), 433 the analyzed SST (red), and the merged daily CDOM (black) along the drifter path.

435 As further illustrated by the example shown in Figure 4, it takes approximately 6 months to 436 cover a distance of $3700 \mathrm{~km}$ for a fresh water particle (SSS 26-28) in the proximity of the 437 Amazon mouth to relax to an open ocean surface salinity of $\sim 36$. At the beginning of the 438 period, the low SSS of water particles is modulated by mixing processes with saltier 439 waters transported westward by the NBC rings shed at the NBC retroflection. The particle440 following SSS signal modulation observed here is clearly consistent with the ocean color 441 signal (anti-correlated to SSS), fresher water being systematically associated with colored 442 waters showing high CDOM values, typical of the brackish plume waters. The drifter is 443 then advected eastward along the NECC, remixed with 'younger' advected plume waters in 444 August and reached an eastern position slightly north of $8^{\circ} \mathrm{N}-38^{\circ} \mathrm{W}$ with an SSS of about 44532 at the beginning of October. The SSS change along the drifter pathway is progressively 446 and quasi-linearly relaxing to the open ocean values during the next 3 -month period.

448 The link between the SSS and ocean color properties moreover enables investigations of 449 the interactions between bio-optical and bio-chemical properties of the ocean and 
hydrological fluxes of terrestrial origin. Along with the fresh water, the Amazon provides 451 the largest riverine flux of suspended (1200 Mt $\left.\mathrm{y}^{-1}\right)$ and dissolved matter (287 $\mathrm{Mt}^{-1}$ ), 452 which includes a dissolved organic matter (DOM) flux of 139 Mt y $^{-1}$ (Meybeck and Ragu 453 1997). These fluxes can have a dramatic effect on regional ecology as they represent 454 potential subsidies of organic carbon, nutrients, and light attenuation into an otherwise 455 oligotrophic environment (Muller-Karger et al., 1995).

456 In the most proximal regions of the Amazon Plume, light attenuation by suspended 457 detritus acts as the main limitation to phytoplankton growth (Demaster and Smith, 1996). 458 Away from this region, as mineral detritus is removed by sinking, absorption attributable 459 to organic substances begins to dominate the attenuation of light in surface waters. 460 DelVeccio and Subramaniam (2004) studied such conditions in the Amazon Plume and 461 characterized the relative contributions of CDOM, particulate organic material and 462 phytoplankton to the total absorption field. In the coastal ocean adjacent to river sources, 463 CDOM tends to behave as a fresh water tracer, decreasing away from the river source with increasing salinity. Linear correlations between CDOM and salinity in river plume waters are well documented in ocean color literature with reported relationships robust enough to 466 allow salinity retrievals from CDOM and vice versa (e.g. Ferrari and Dowell, 1998; Palacios et al., 2009; D’Sa et al., 2002; Conmy et al., 2004).

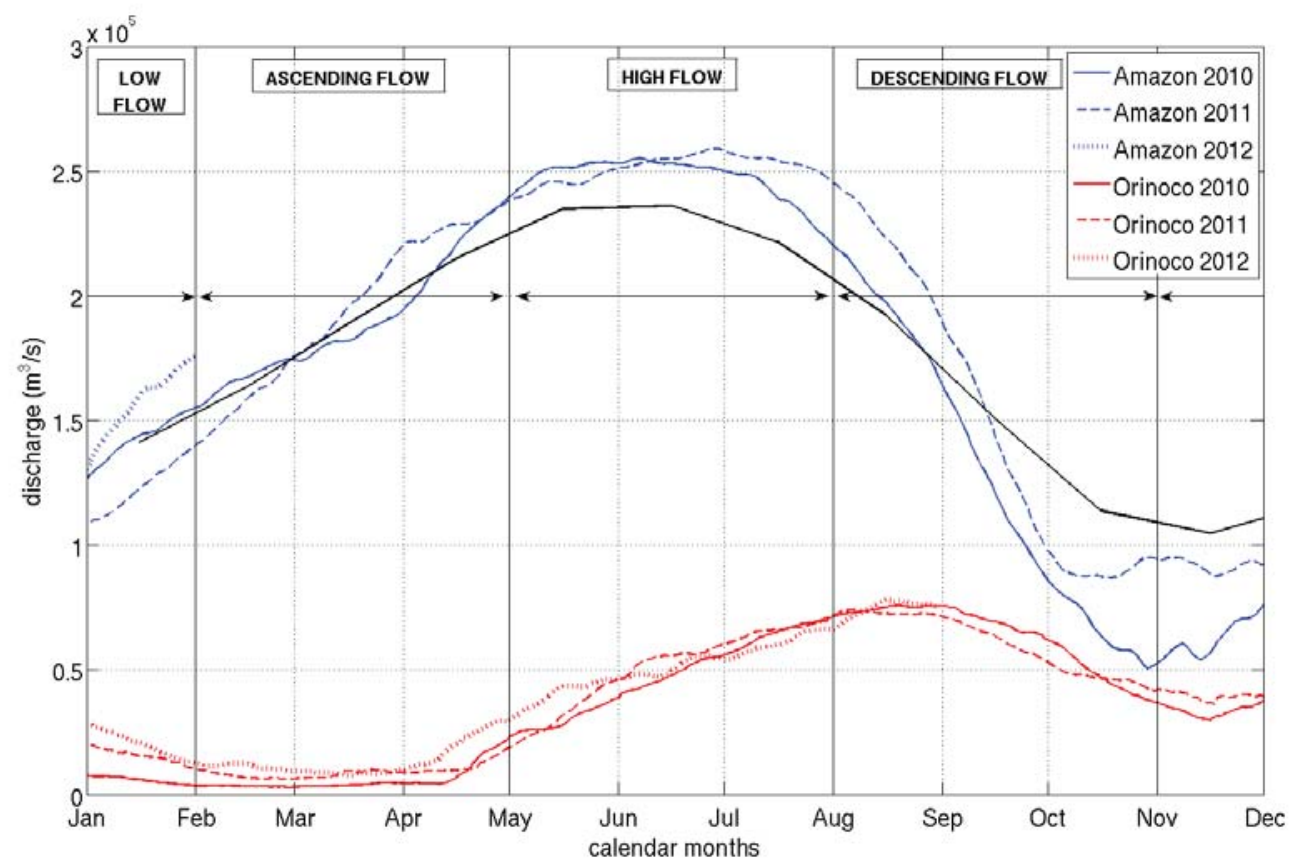

469 Figure 5:Amazon (blue) and Orinoco (red) River discharge cycles measured respectively 470 at Obidos and Bolivar gauges, during the period 2010-2012. The black curve is showing the Amazon river discharge climatology from 1968 to 2012. 
473 Linearity in the CDOM - salinity relationship implies conservative mixing dominated by 474 two distinct endmembers. Departures from linearity can occur when additional water 475 masses are present (Blough and Delveccio, 2002), or by in situ subsidies of CDOM 476 released via net phytoplankton growth (Yamashita and Tanoue, 2004; Twardoski and 477 Donaghay, 2001), microbial utilization (e.g. Moran et al., 1999; Obernostererand Herndl, 478 2000), or photochemical oxidation (e.g. Miller and Zepp, 1995).

479 Based upon preliminary satellite microwave SSS data from AMSR-E sensor and ocean 480 color products, Salisbury et al., (2011) recently demonstrated the spatial coherence 481 between surface salinity and the absorption coefficient of CDOM at $443 \mathrm{~nm}$ in the Amazon 482 and Orinoco river plume-influenced waters. Given the new SMOS data, the spatial and 483 temporal coherence between SSS and optical properties of the river plumes, e.g. CDOM, 484 can now be systematically analyzed. 


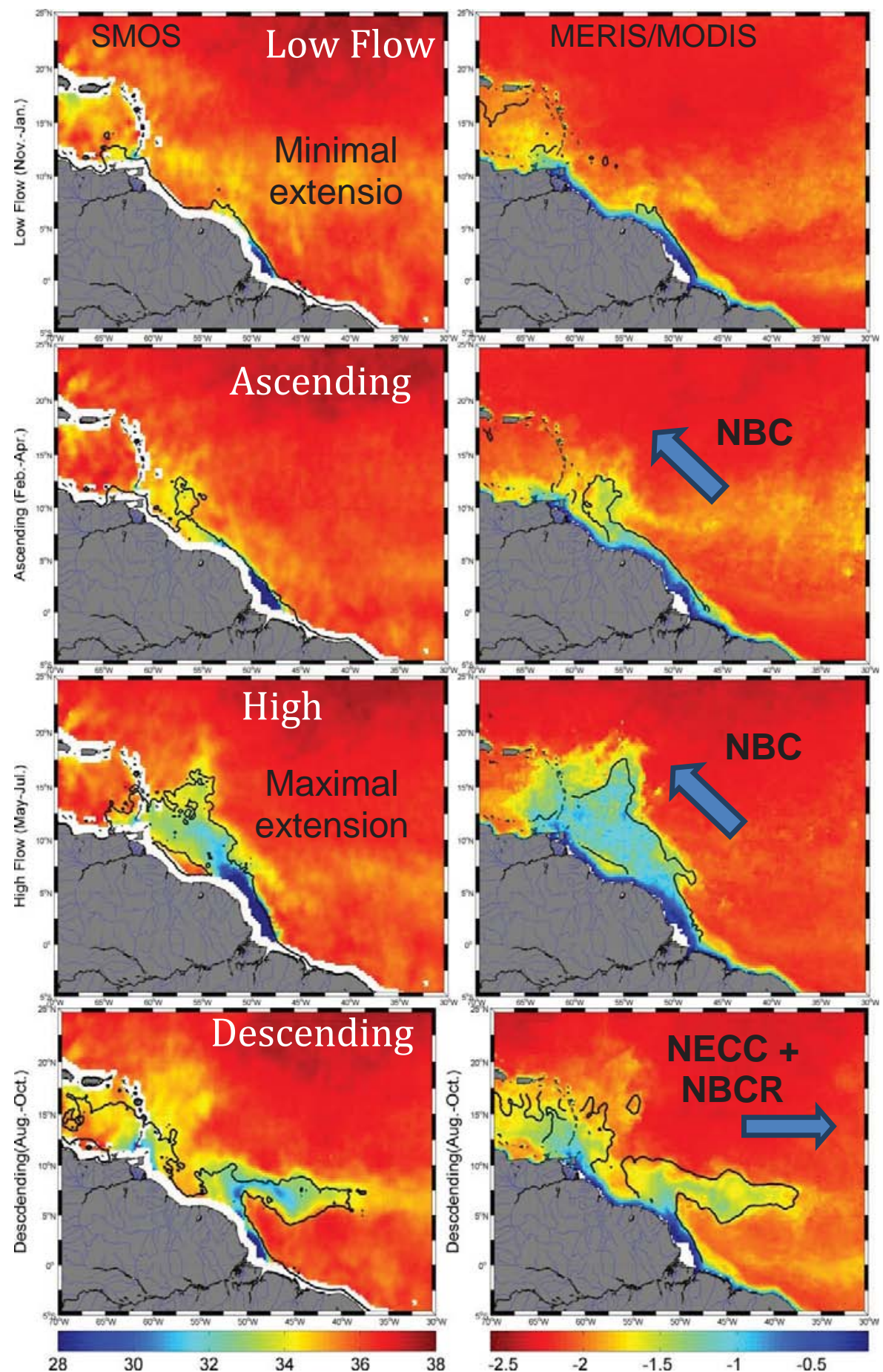

Figure 6: Seasonal cycle of the freshwater Amazon and Orinoco river Plume signals for year 2010. Left: SSS from SMOS averaged over the different periods of the discharge cycle. From Top to bottom: Low Flow (Nov-Jan); Ascending flow (Feb-Apr); High-flow (May-Jul);Descending flow (Aug-Oct). Right: corresponding CDOM absorption coefficient averaged from the merged MERIS/MODIS products. The colorbar is logarithmic in unit of $1 / m$.

As illustrated in Figure 5, the amplitude of the annual cycle of the Amazon river discharge peaks in June-July and was apparently more important in 2010 and 2011 compared to the averaged 'climatological' cycle since 1968. In comparison the discharge from Orinoco is much lower and peaks in September. Based upon the Amazon river discharge cycle, four 
497 main periods can be distinguished as shown in Figure 6. From November to April (low

498 flow and ascending periods), the plume is carried northwestward with the NBC while the 499 summer and fall display a plume mostly carried eastward as the seasonal NECC 500 retroflection strengthens. In comparison, the spatial pattern in the distributions of the 501 CDOM are in general very similar to SSS during the river discharge seasonal cycle. 502 However, the CDOM patterns can deviate from the SSS patterns at large distances from 503 the mouth of the river for some period of the seasonal cycle. This is particularly evident in 504 the region around the northern Antilles and the Caribbean during the High flow season of 5052010 (Figure 6, third panel from top) wherby high CDOM values are detected north of the 506 low salinity plume extent (contours at $\mathrm{SSS}=35.5$ on the right panels) suggesting presence 507 of dissolved organic matter concentrations that are non-correlated with the Amazon river 508 plume dilution. Altogether, this demonstrates the strength in combining satellite SSS 509 observations with complementary satellite observations in order to better characterize the 510 variability of the pathway of freshwater runoff along with the corresponding mixing 511 processes at seasonal to interannual time scales.

512 Quasi-linear relationships between SMOS SSS and the MERIS/MODIS CDM absorption 513 coefficient (acdm) estimated for year 2010 are illustrated in Figure 7. Acdm values were 514 averaged over SSS bins with 0.5 pss bin width. As evidenced, while CDOM mixing 515 processes seem to be conservative on average, clear departure from linearity are observed 516 below 30 pss during the Descending and Low-flow seasons. This fact potentially indicates 517 changes in the endmember values at the mouths of the rivers and tributaries and/or, 518 illustrate occurrence of non-conservative mixing processes as listed above. Thanks to the 519 new satellite observations, departure from conservative mixing and the inter-annual 520 sources of variability will be certainly more detailed in the next future. 

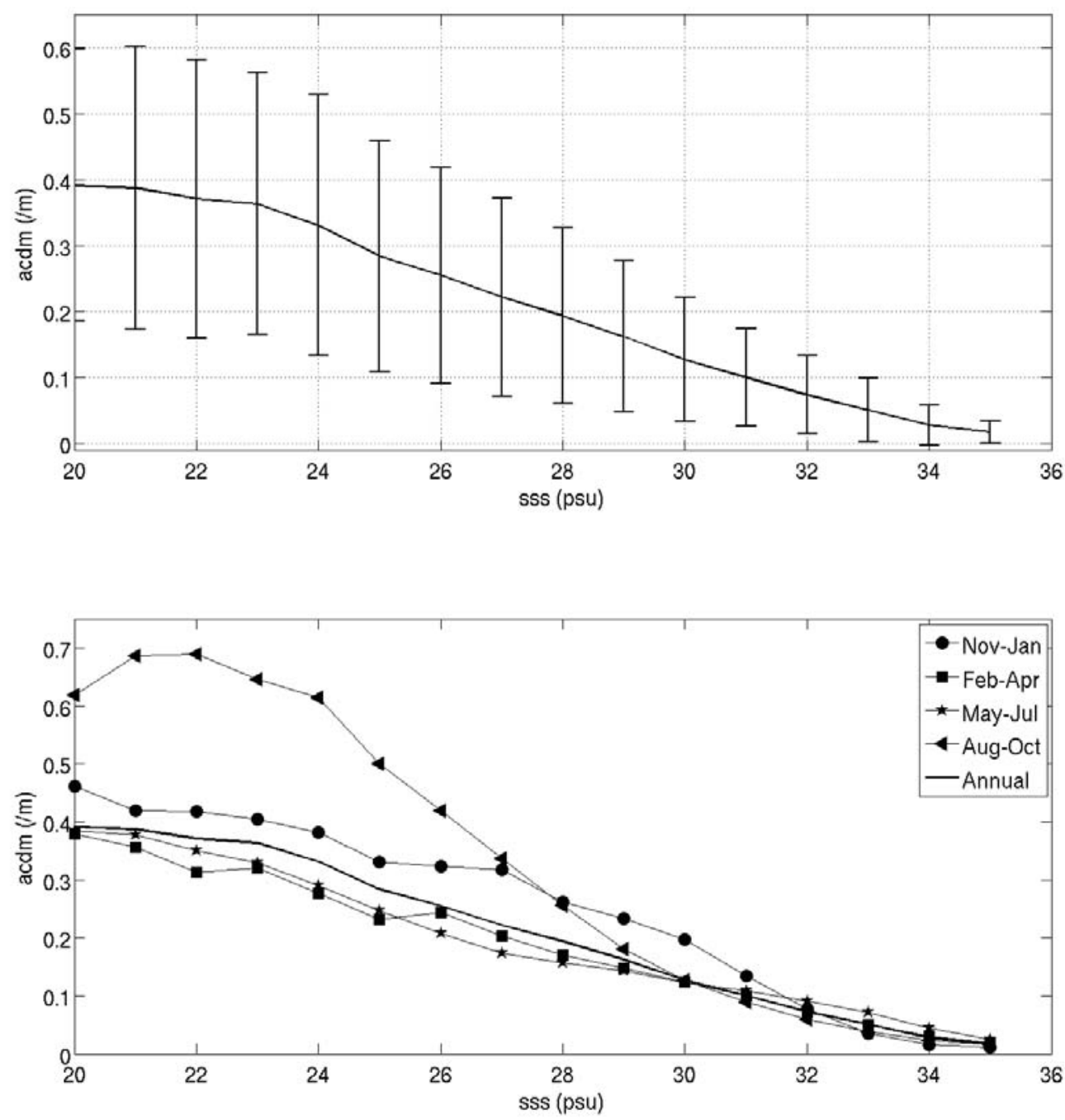

523 Figure 7: $a_{\text {СDОм}}(490)$ to SMOS SSS dependence in the Western Tropical North Atlantic 524 averaged over years 2010-2012 for all seasons of the Amazon River Discharge cycle (Top) 525 and for each season separately (bottom). In the upper panel, the mean $a_{C D O M}(490)$ per 0.5 pss bins is shown as a solid black line \pm 1 standard deviation (vertical bars).

\subsection{Eastern Tropical Atlantic Freshwater Pools Monitoring} intense upwelling and where the second largest river in the world, the Congo, enters the ocean together with the Niger, Volta and numerous other smaller rivers (Figure 8). In addition, intense precipitations also decrease SSS in the Guinea current and Northeastern Gulf of Guinea (Hisard, 1980; Merle, 1980). The ETA is therefore characterized with a 
highly complex hydrographic system, largely influenced by the Congo River, intense precipitation, and strong seasonal coastal and equatorial upwelling in the boreal summer.

540 discharge in March through April. The outflow is hardly detectable from SST or sea level

541 data. In chlorophyll, however, the mouth of the Congo River shows a strong signal all year round with large plumes extending offshore. While these ocean colour signals highlight real oceanographic features of the plume, frequent cloud cover found in this region during the rainy season strongly inhibits the spatio-temporal evolution of the Congo plume structure to be monitored.

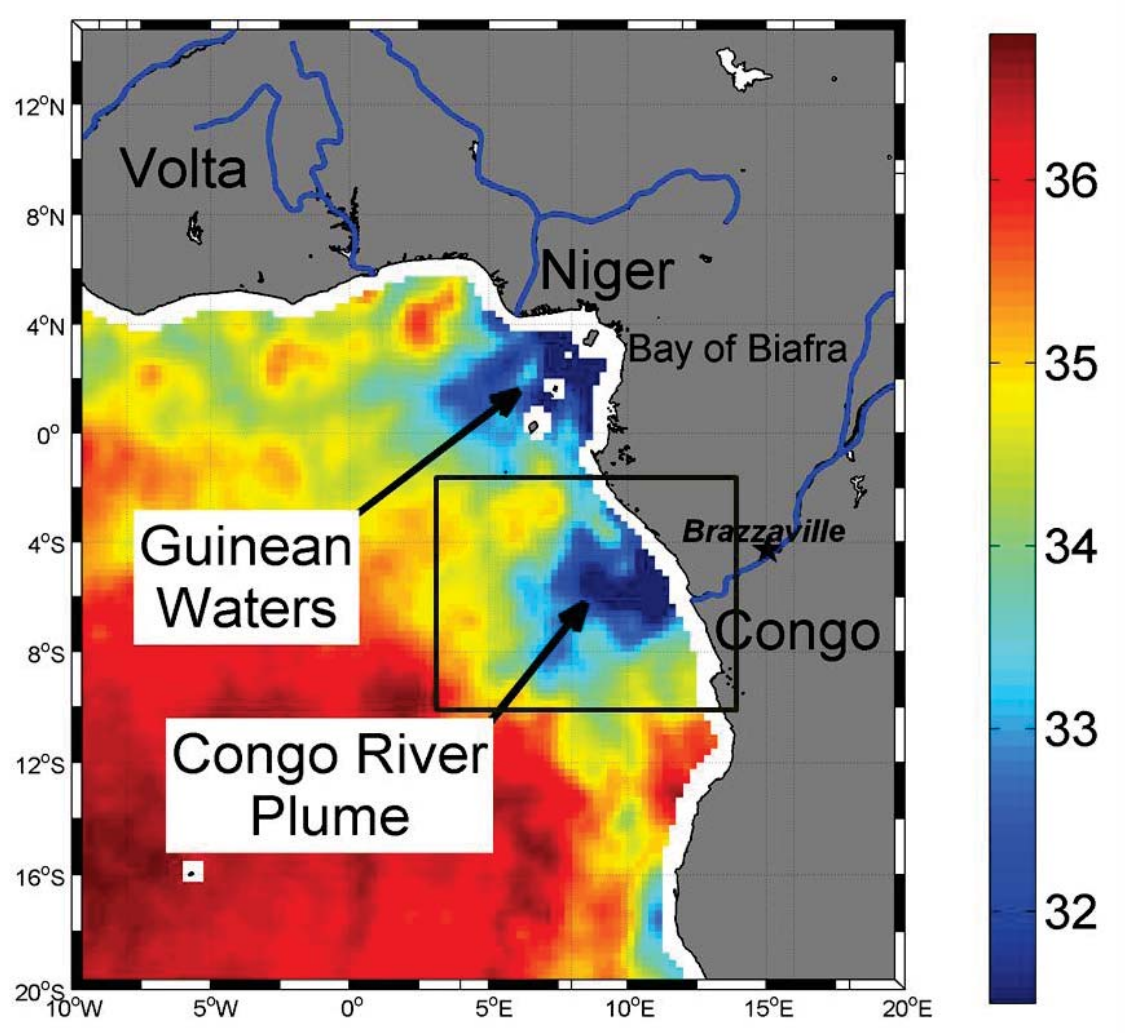

Figure 8: Map of SMOS SSS in the Gulf of Guinea and Southeast Atlantic Ocean indicating the two largest pools of low salinity waters in the eastern tropical Atlantic: the Bight of Biafra (Guinean waters) and the Congo River plume. The map was generated by averaging SMOS data over 2010-2012 considering only data acquired during months of April.

555 Hitherto the knowledge about the seasonal extension and spreading of the Congo river plume is therefore mainly relying on dedicated in situ surveys (e.g. see Meulenbergh 1968;

557 Koleshnikov, 1973 ;Bornhold, 1973; Wauthy, 1977; van Bennekom et al., 1978; Eisma and

558 Van Bennekom, 1978; van Bennekomand Berger, 1984; Piton andWacongne, 1985; Braga 
et al., 2004; Reverdin et al., 2007; Vangriesheim et al., 2009; Lefevre 2009). However, the ensemble of in situ SSS data collected during the period 1977-2002 in the ETA is sparse and only enabled retrievals of low-resolution $\left(1^{\circ} \times 1^{\circ}\right)$ monthly climatology of the SSS field

562 (Reverdin et al., 2007), as displayed in Figure 9. Since 2003 the in situ SSS sampling has 563 improved with the increasing deployments and operations of Argo floats.
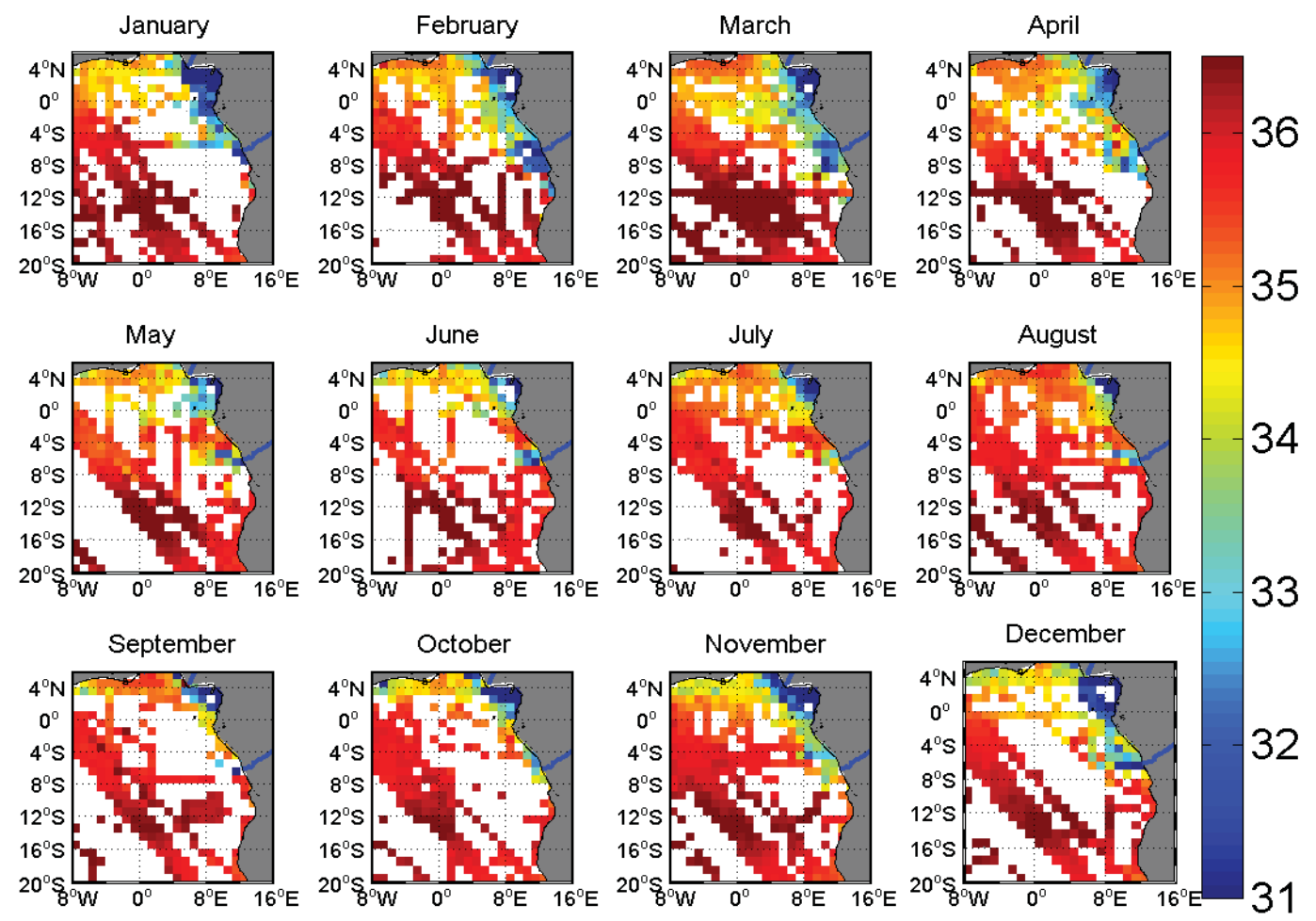

566 Figure 9: Maps of the monthly averaged SSS in the ETA derived from the ensemble of in

567 situ measurements collected during the period 1977-2002 and used to build up Reverdin et 568 al. , 2007 climatology.

569

570 The monthly averaged SMOS SSS maps shown in Figure 10 were generated by combining 571 SSS data over the SMOS 3 years life period. As evidenced in detail by these maps, 572 consistent with historical in situ observations, the Congo River plume is spreading north573 westward along the coast and mix with southwestward flowing freshwater from the bight 574 of Biafra during February and March (Koleshnikov, 1973 ; Wauthy, 1977). In May (Van 575 Bennekom et al., 1978), June-July (Bornhold, 1973; Wauthy, 1977) and August 576 (Koleshnikov, 1973) the two fresh pools are disconnected with the Congo plume directed 577 in westerly direction, extending up to $800-1000 \mathrm{~km}$ offshore, as far as $8^{\circ} \mathrm{E}$. In November, a 578 "jet stream" of low salinity water is ejected from the estuary with a large velocity and 579 protrudes in WNW direction (Wauthy, 1977). The plume extent can also show southward 
581 Bennekom and Berger, 1984, Dessier and Donguy, 1994).
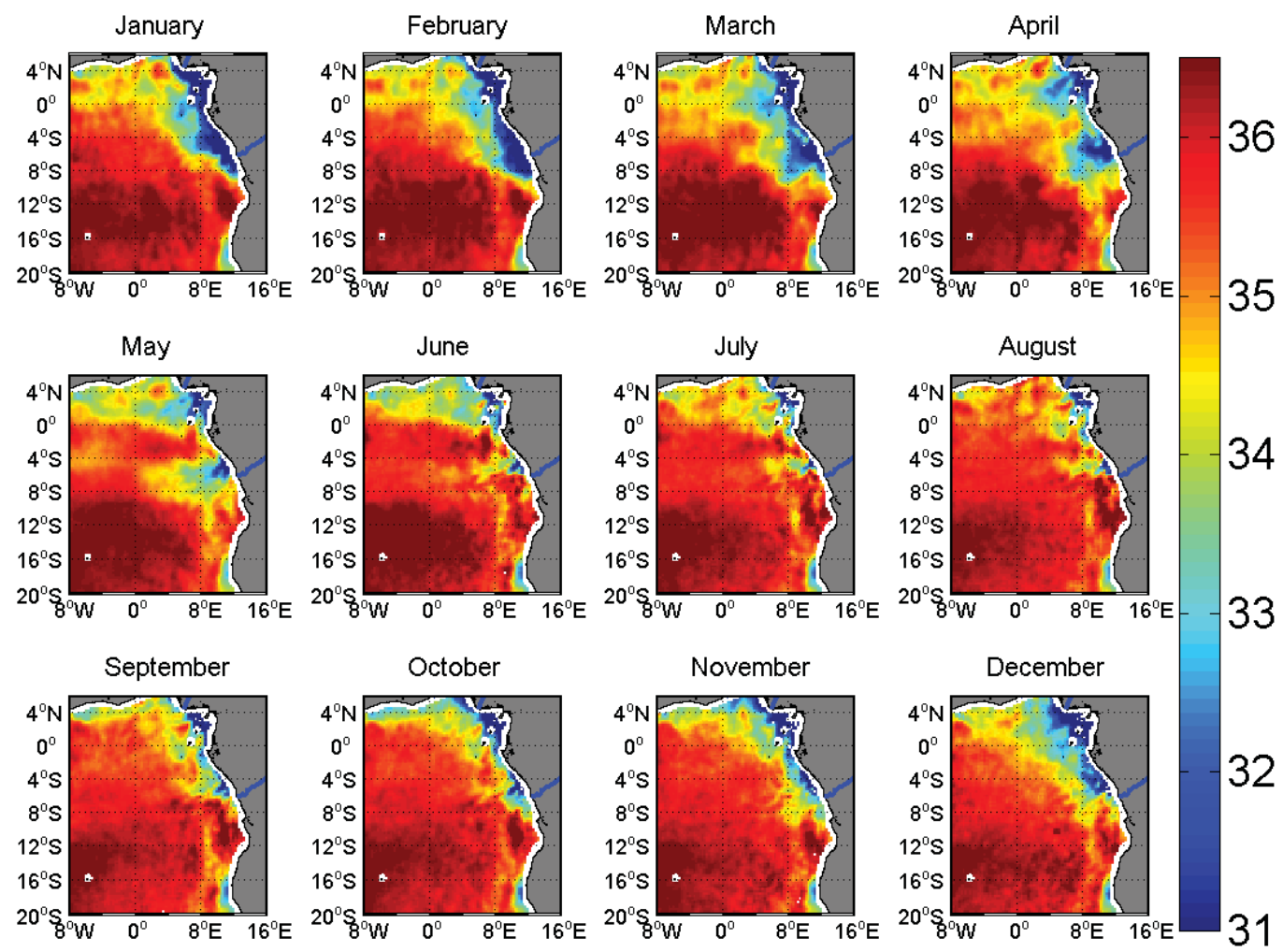

583 Figure 10: 2010-2012 monthly averaged seasonal cycle of surface salinity in the Eastern Tropical Atlantic derived from SMOS observations.

586 The dispersal patterns of the Congo River plume during all seasons can mostly be included inside the rectangle domain shown in Figure 8. The 10-day running mean time series of the SMOS SSS averaged over that spatial domain is shown in Figure 11 together with the time series of the river discharge measured at Brazaville gauge station during the period 20102012. Maxima in the averaged SSS within that region occur regurarly in August at the time of the Congo river minimum discharge. Minima in SSS (detected around April) however lag by approximately 4 months the maxima in the river discharge at Brazaville station (found around December-January). These lags probably indicate the time for the

594 freshwater masses to be transported from Brazaville to the river mouth and then to be further advected by surface currents far offshore. However, the inter-annual variability in

596 the amplitude of the seasonal cycle of SSS and river discharge are not correlated. While the

597 river discharge reached significantly different minimum values of $\sim 3.3 \times 10^{4} \mathrm{~m}^{3} / \mathrm{s}$ and $\sim 2.3$

$598 \times 10^{4} \mathrm{~m}^{3} / \mathrm{s}$ in 2010 and 2011, respectively, the maxima in the averaged SSS is constantly 599 found at $\sim 35.5$ pss. Similarly, the maximum discharge level of $\sim 5.8 \times 10^{4} \mathrm{~m}^{3} / \mathrm{s}$ measured 600 over the period is found in January 2012 while the minimum in the averaged SSS ( 31.9) occurred in April 2011. 


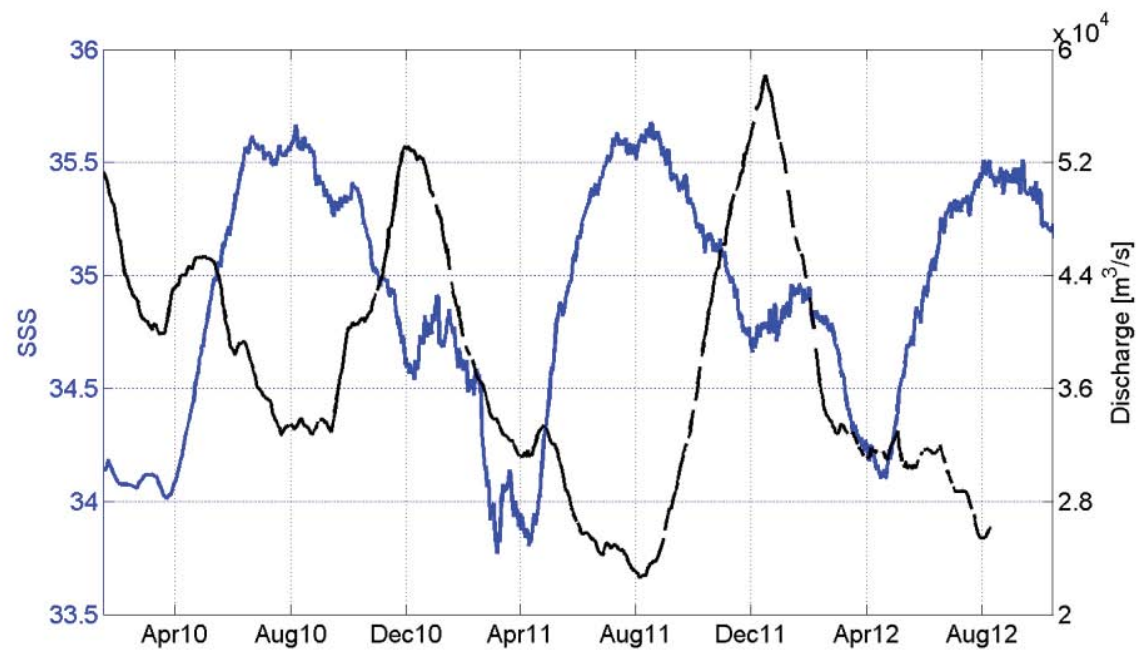

602

603 Figure 11: Times series of (i) the SMOS SSS averaged over the spatial domain $\left[3^{\circ} E\right.$ -

$\left.60414^{\circ} \mathrm{E} ; 10^{\circ} \mathrm{S}-2^{\circ} \mathrm{S}\right]$ illustrated by the black rectangle in Figure 8 (blue) and (ii) of the Congo

605 discharge level measured at Brazaville (black).

606

607 While understanding the observed satellite SSS trend in that region is still an undergoing

608 activity, combining satellite information on surface currents, SST, rain rates and SSS

609 together with River discharge levels will certainly help in the near future to better quantify

610 the sources of variability in the local hydrological cycle of the Gulf of Guinea. The

611 terrestrial and atmospheric hydrological fluxes in this region also act as a dominant

612 modulator of the local fishery. The regular SMOS SSS data can therefore help to better

613 understand the mechanisms involved in the biophysical interplay and its relevance for the

614 fishery with potentially significant socio-economic impact in that region.

615 In addition, similarly to the Amazon-Orinoco river plumes, conservative mixing

616 laws for bio-optical properties of the major river plume in the ETA region can now be

617 systematically studied using SMOS data as shown in Figure 12. Examples of the

618 conservative mixing linear laws for the CDOM coefficient deduced only from spaceborne

619 measurements are shown for year 2010 around the Congo and Niger river. 


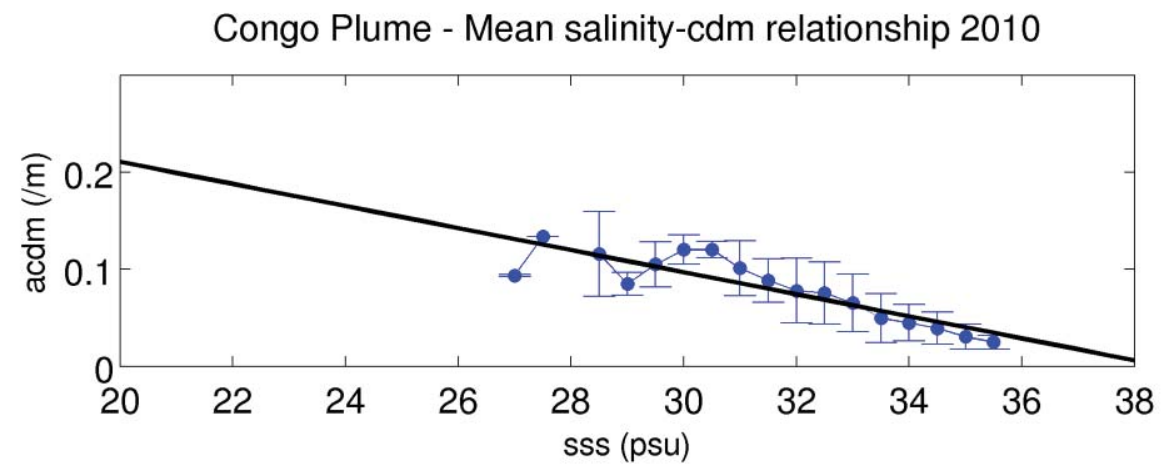

Niger Plume - Mean salinity-cdm relationship 2010

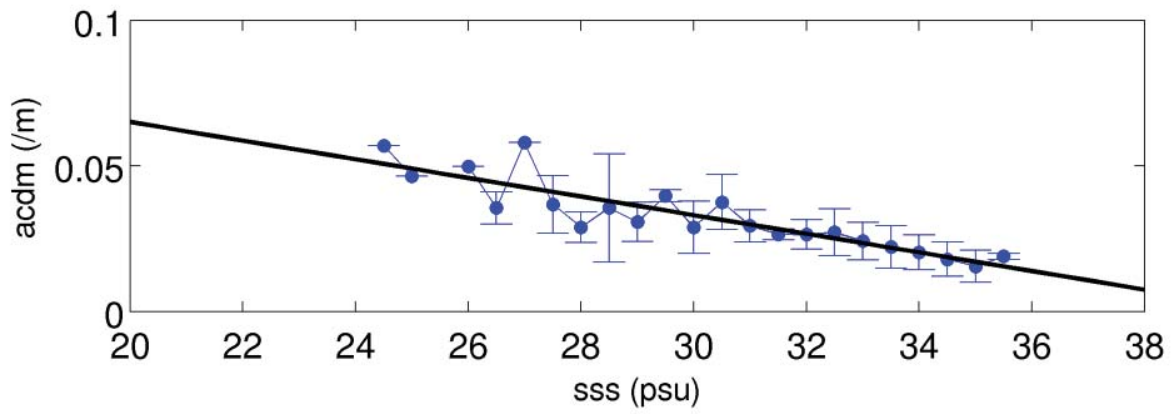

620

621

622

623

624

625

626

627

628

629

630

631

632

633

634

635

636

637

638

639

640

641

Figure 12: $a_{C D O M}(490)$ to SMOS SSS dependence in the Eastern Tropical Atlantic averaged over year 2010 for the Congo(Top) and Niger (Bottom) River Plumes. The mean $a_{\text {СDOM }}(490)$ per 0.5pss bins is shown as a solid black line \pm 1 standard deviation (vertical bars).

\section{Precipitation signatures in SSS data from Space}

Large vertical gradients can develop in the upper few meters of the ocean after a heavy rainfall, as first evidenced during the Tropical Oceans-Global Atmosphere Coupled OceanAtmosphere Response Experiment (TOGA COARE) (Soloviev and Lukas, 1996; Schlössel et al., 1997;Wijesekera et al. 1999). The downward fresh water flux at the sea surface establishes a haline diffusive molecular layer (or freshwater skin of the ocean) (Katsaros and Buettner, 1969) that is characterized by a salinity gradient, with salinity differences across this freshwater skin sometimes greater than 4 salinity unit. The residual effects of the rain-induced skin layers can even be stronger at the highest rain rates (Schlössel et al., 1997). This freshwater skin stabilizes the near-surface layer (Ostapoffetal., 1973) and tends to dampen free convection in the upper oceanic boundary layer.

These conditions motivate the development of autonomous sea surface salinity drifters able to monitor the salinity at less than $50 \mathrm{~cm}$ depth. Using such instruments, Reverdin et al., (2012) documented salinity freshening between $15 \mathrm{~cm}$ and $50 \mathrm{~cm}$ depth in the tropical 
642 oceans. Sudden salinity decreases are often associated with local rainfall and vertical 643 salinity gradients that last for a few hour, depending, among other factors, on wind speed 644 conditions. The haline molecular diffusion layer that is established in the upper ocean 645 during rainfall can thus be important for the radiometric observation of the sea-surface at 646 low microwave frequencies. At centimeter wavelengths the dielectric constant is modified 647 by the sea-surface salinity (e. g. Klein and Swift, 1977; Yueh et al., 2001) and any change 648 of the latter might cause interpretation problems when comparing remotely measured 649 surface salinity at these frequencies to deeper in situ measurements.

650 Hence, under rainy conditions (or just after a rainfall), satellite SSS shall better 651 characterize the salinity at the ocean-atmosphere interface rather than the 1-10 $\mathrm{m}$ deep in 652 situ samples. Whether accumulated precipitation can be estimated from changes in salinity 653 at the ocean surface as observed from Space remains however an open question, as 654 asumptions have to be made about the penetration depth of the fresh water. In addition, 655 assimilation of the new satellite SSS data into ocean circulation models having limited 656 vertical resolution also challenges our modeling perspectives concerning the dynamics of 657 the first centimeters to first meter of the ocean surface.

659 In the following section, we discuss signatures of precipitation detected in the new SMOS 660 SSS data. First, the strong SSS spatio-temporal variability associated with rain events as 661 seen both by spaceborne and in situ sensors in the Pacific Ocean Inter-Tropical 662 convergence zone is presented. Second, it is revealed that the SSS from space is 663 systematically showing lower values (negative bias) with respect to the deeper 5-10 m 664 depth of Argo upper salinity. These effects are shown to be statistically correlated with rain. Third, long-lived, large-area and large amplitude SMOS SSS anomaly patterns in the

666 Tropical Atlantic are shown to follow local anomaly patterns in the Evaporation667 Precipitation (E-P) budget. Finally, the preliminary results of the inter-annual variability 668 of the SMOS SSS signal in the Indian and in the Tropical Pacific oceans and connections 669 to key climate indexes will be presented and discussed.

\subsection{SSS temporal variability associated with rain events}

673 Although satellite observations provide a better sampling of the global ocean than the in 674 situ observing systems, such as the Argo float array, individual SSS measurements are 675 obtained in rainy regions with a strong temporal variability seen on both SMOS and Argo 
676 SSS. In Figure 13, we show such an example of co-located SMOS and Argo profiler 677 measurements in the InterTropical Convergence Zone of the Tropical Pacific indicating a 678 significant surface freshening associated with a rain event. On 11 August 2010, the Argo 679 float WMO id\#4900325 detected a freshening of 0.9 between $20 \mathrm{~m}$ and $5.5 \mathrm{~m}$ depth 680 (Figure. 13a). In contrast, the Argo profile derived on 22 August shows that the salinity 681 between $30 \mathrm{~m}$ and $5 \mathrm{~m}$ depth is much more homogeneous with more saline water at $5 \mathrm{~m}$ 682 depth compared to the one recorded on 11 August.

a) ARGO profile on $11 / 8$ at $20 \mathrm{~h}$

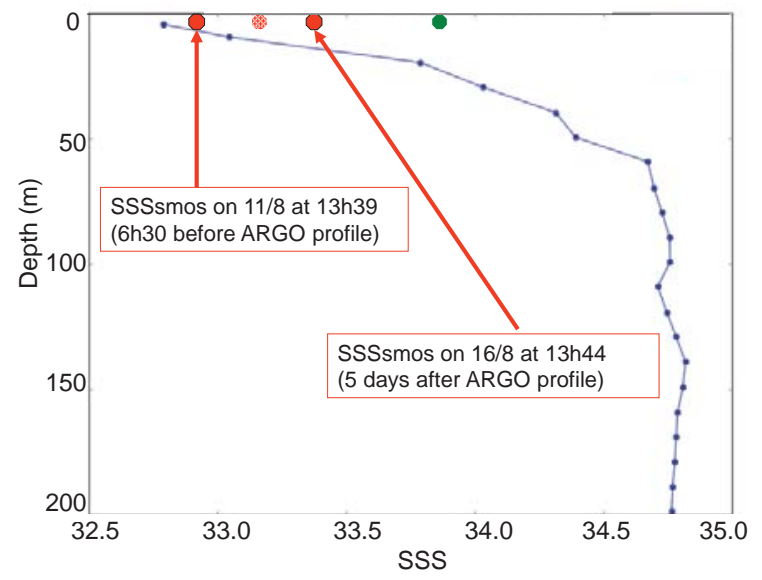

b) ARGO profile on 22/08 6:52 UTC

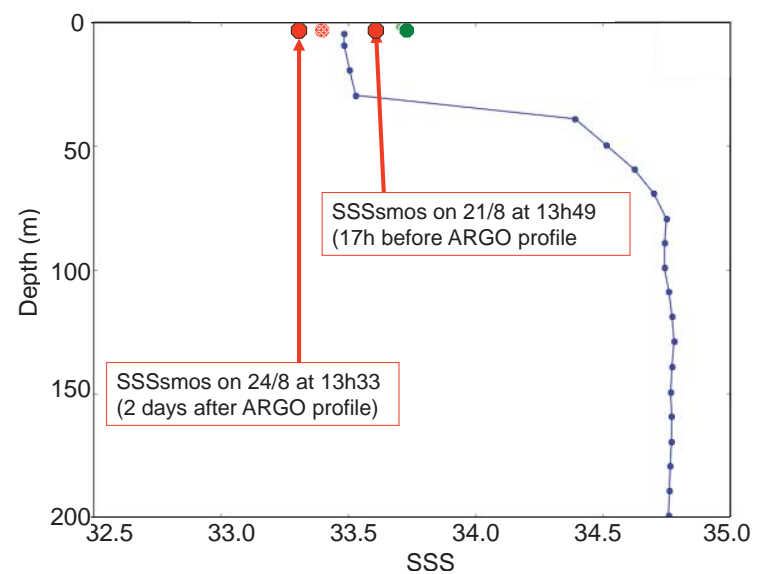

c)

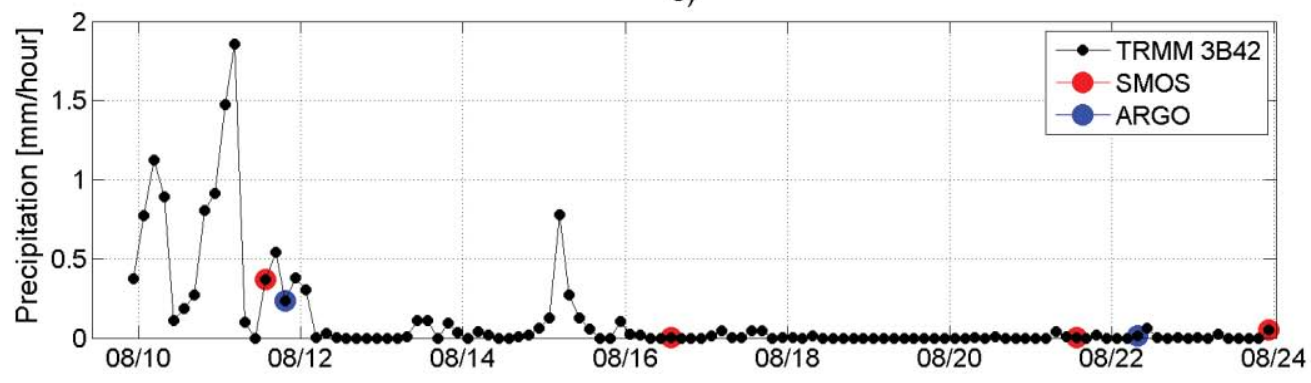

683

684

685

686

687

688

689

690

691

692

693

694

695

696

697

698

Figure 13:Two successive Argo profiles taken by float 4900325 (blue curve) in the Eastern Tropical Pacific on (a) 11 August20:00 UTC (latitude $=12.4^{\circ} \mathrm{N}$; longitude $=117.6^{\circ} \mathrm{W}$ ) and (b) 22 August 6:52UTC (latitude:12.2 ${ }^{\circ} \mathrm{N}$; longitude: 117.8 $\mathrm{W}$ ). Mean SMOS SSS collocated within a 5 days window and a radii of $50 \mathrm{~km}$ with these profiles are indicated by red dashed point. In each case, two SMOS passes have participatedto these collocations: mean SMOS SSS corresponding to each pass is indicated asred filled point. The corresponding ISAS SSS in August is indicated by the green point.The time series of the 3-hourly satellite rain rate from TRMM $3 B 42$ and averaged over $\left[11^{\circ} \mathrm{N}-13^{\circ} \mathrm{N} ; 116^{\circ} \mathrm{W}\right.$ $118^{\circ} \mathrm{WJ}$ is provided in c). The time at which SMOS and Argo acquired SSS data is indicated by red and blue dots, respectively.

The TRMM satellite Rain-Rate (RR) estimates averaged over a $2^{\circ} \times 2^{\circ}$ box centered on the Argo float location indicate a significant rain rate of $1-2 \mathrm{~mm} \mathrm{~h}^{-1}$ on 11 August that lasted for at least a day before the Argo profile raised to the surface (Figure 13c). Contrarily, 
negligible precipitation occurred on 22 August and during the preceding week. The first

700 SMOS pass collocated with the 11 August Argo profile (Figure 13a) was acquired also 701 during rainy conditions and is showing a low SSS of $~ 32.8$ (0.1saltier than the Argo SSS 702 taken 6:30 h later, Figure 13c). The second SMOS pass on the 16th August occurred under 703 non-rainy condition (Figure 13c) and is 0.5 saltier. Consistent with the 22 August Argo 704 profile (Figure 13b) observations, the collocated SMOS SSS during these rain-free 705 conditions (Figure13c) are also significantly saltier by 0.4-0.6. The large SSS variation 706 (0.7) measured by this Argo float at a 10 day interval and by the collocated SMOS 707 measurements over several SMOS passes clearly demonstrates the influence of the rain 708 timing on the SMOS-Argo SSS differences.

709

710

\subsection{Systematically fresher skin SSS in rainy regions}
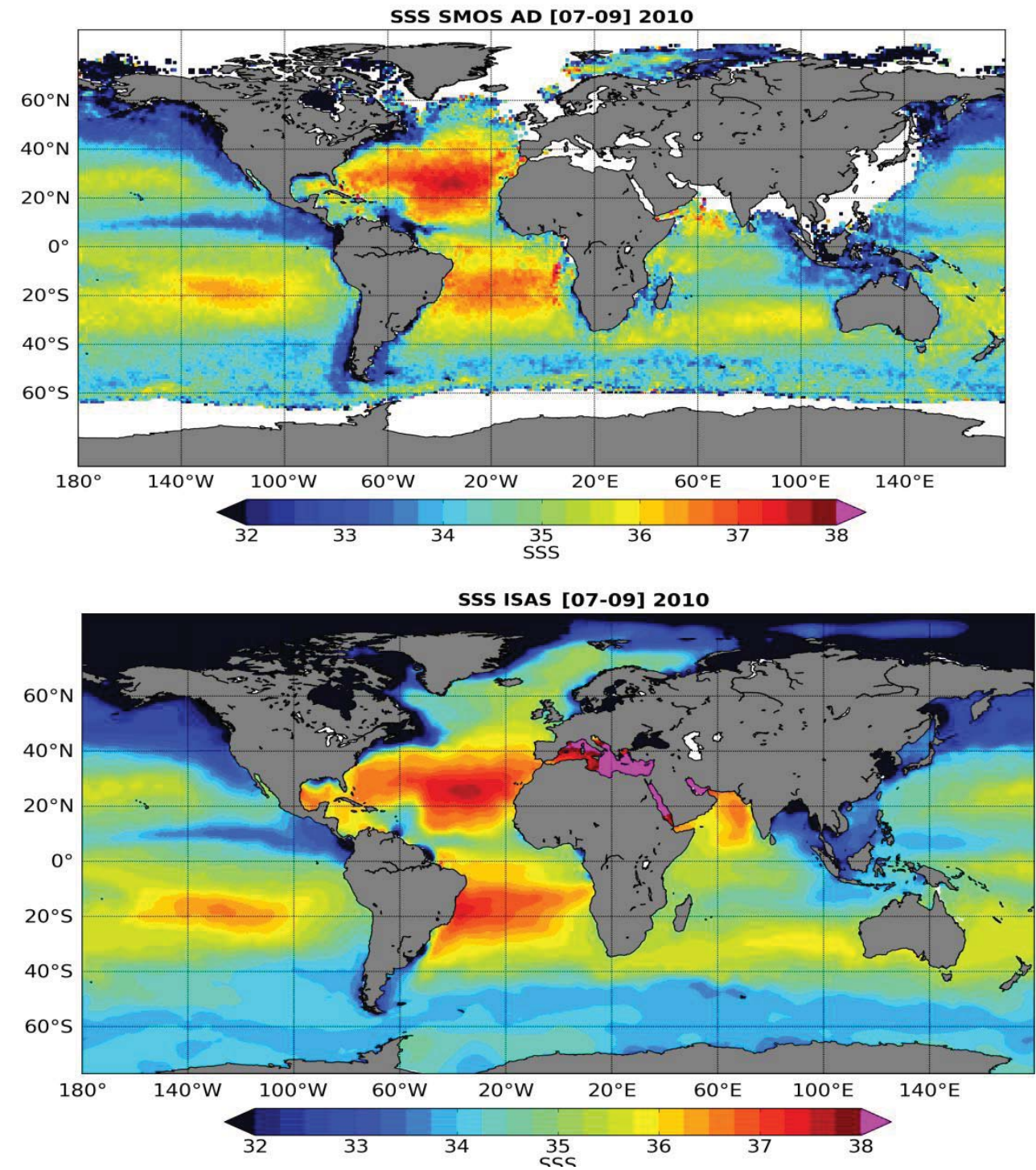
714 Figure 14: Maps of SSS averaged from July to September 2010, derived from (top) SMOS 715 ascending and descending orbits and ISAS (bottom).

The SMOS SSS map averaged over July-September 2010 is compared to Optimally 718 Interpolated in situ ISAS map averaged over the same period on Figure 14. At large scale, 719 SSS spatial variability sensed by SMOS is consistent with ISAS. A striking visual feature 720 of the SMOS SSS map compared to the ISAS map in the tropics is the freshest SSS in the 721 North Tropical Pacific, under the location of the ITCZ (particularly west of $120^{\circ} \mathrm{W}$ ).

\begin{tabular}{|l|l|l|l|}
\hline & Mean $(\Delta \mathrm{SSS})$ & Std $(\Delta \mathrm{SSS})$ & $N$ \\
\hline $\begin{array}{l}\text { Subtropical Atlantic Ocean } \\
\left(15^{\circ} \mathrm{N}-30^{\circ} \mathrm{N} ; 45^{\circ} \mathrm{W}-30^{\circ} \mathrm{W}\right)\end{array}$ & -0.13 & 0.28 & 206 \\
\hline $\begin{array}{l}\text { Tropical Pacific Ocean } \\
\left(5^{\circ} \mathrm{N}-15^{\circ} \mathrm{N} ; 180^{\circ} \mathrm{W}-110^{\circ} \mathrm{W}\right)\end{array}$ & -0.23 & 0.35 & 692 \\
\hline $\begin{array}{l}\text { Southern Indian Ocean } \\
\left(40^{\circ} \mathrm{S}-30^{\circ} \mathrm{S} ; 70^{\circ} \mathrm{E}-90^{\circ} \mathrm{E}\right)\end{array}$ & 0.04 & 0.39 & 114 \\
\hline $\begin{array}{l}\text { Southern } \mathrm{Pacific} \mathrm{Ocean} \\
\left(50^{\circ} \mathrm{S}-40^{\circ} \mathrm{S} ; 180^{\circ} \mathrm{W}-100^{\circ} \mathrm{W}\right)\end{array}$ & -0.08 & 0.51 & 467 \\
\hline
\end{tabular}

Table 2.Comparison of SMOS SSS (10day, $100 \times 100 \mathrm{~km} 2$ average) collocated with Argo upper depth measurements. $\triangle S S S=S S S_{\text {smos }}-S S S_{\text {argo }}$ Only SMOS ascending orbits are considered. Std (USSS) primarily reflects the decreasing signal to noise ratio with decreasing SST. Note that subtropical Atlantic Ocean and tropical Pacific Ocean have similar SST.

When SMOS SSS are precisely colocated around Argo SSS in various regions of the 730 global ocean (see Boutin et al. (2012)), a more negative bias ( - 0.1 than in other regions) and larger standard deviation are systematically observed between $5^{\circ} \mathrm{N}$ and $15^{\circ} \mathrm{N}$ in the Pacific Ocean with respect to other regions (Table 2).

To investigate if a systematic negative bias of $\sim 0.1$ between the satellite skin depth SSS and the $\sim 5 \mathrm{~m}$ depth Argo floats data could be related to rain-induced vertical stratification, a triple collocation between Argo, SMOS Level 2 products (at $\sim 40 \mathrm{~km}$ resolution, non averaged in time) and SSMI satellite rain rate (RR) data was conducted. SMOS and SSMI $\mathrm{RR}$ data were co-located within a temporal window of $-40 \mathrm{~min}$ and +80 min while a $+/$ 5days windows was considered to co-locate SMOS and Argo data. colocation exercise is $\sim 0.5$. Without any RR sorting, the statistical distribution of the 
741 differences $\triangle S S S$ is skewed towards negative values (Figure15 and Table 3); when only

742 SMOS non rainy events are considered, the negative skewness disappears, and statistics of 743 the SMOS-Argo differences in the Tropical Pacific Ocean become close to the ones in the 744 subtropical Atlantic Ocean (Tables 2 and 3). Largest skewness towards negatives 745 differences are obtained when only SMOS SSS close to rain events are considered. For 746 these rainy SMOS cases, we find a negative dependency of the SMOS-Argo SSS 747 differences with respect to SSMIs RR of $-0.17 \mathrm{pss} / \mathrm{mm}^{-1}$ h, i.e., a freshening of 1.7 for a 748 SSM/I RR of $10 \mathrm{mmh}^{-1}$ (Boutin et al., 2012).

\begin{tabular}{|l|l|l|l|l|}
\hline & Mean $(\triangle \mathrm{SSS})$ & Std( $\triangle \mathrm{SSS})$ & Skew $(\triangle \mathrm{SSS})$ & $\mathrm{N}$ \\
\hline \multicolumn{5}{|l|}{ Tropical Pacific $\left(\mathbf{5}^{\circ} \mathrm{N}-\mathbf{1 5}^{\circ} \mathrm{N} ; \mathbf{1 1 0}^{\circ} \mathrm{W} ; \mathbf{1 8 0 ^ { \circ } \mathrm { W } )}\right.$} \\
\hline All colocations & $-\mathbf{0 . 2 0}$ & 0.62 & -0.38 & 38543 \\
\hline No Rain $\left(\mathrm{RR}<0.1 \mathrm{~mm} \mathrm{hr}^{-1}\right)$ & -0.13 & 0.56 & 0.01 & 29084 \\
\hline Rainy $\left(\mathrm{RR}>=0.1 \mathrm{~mm} \mathrm{hr}^{-1}\right)$ & -0.40 & 0.73 & -0.58 & 9459 \\
\hline
\end{tabular}

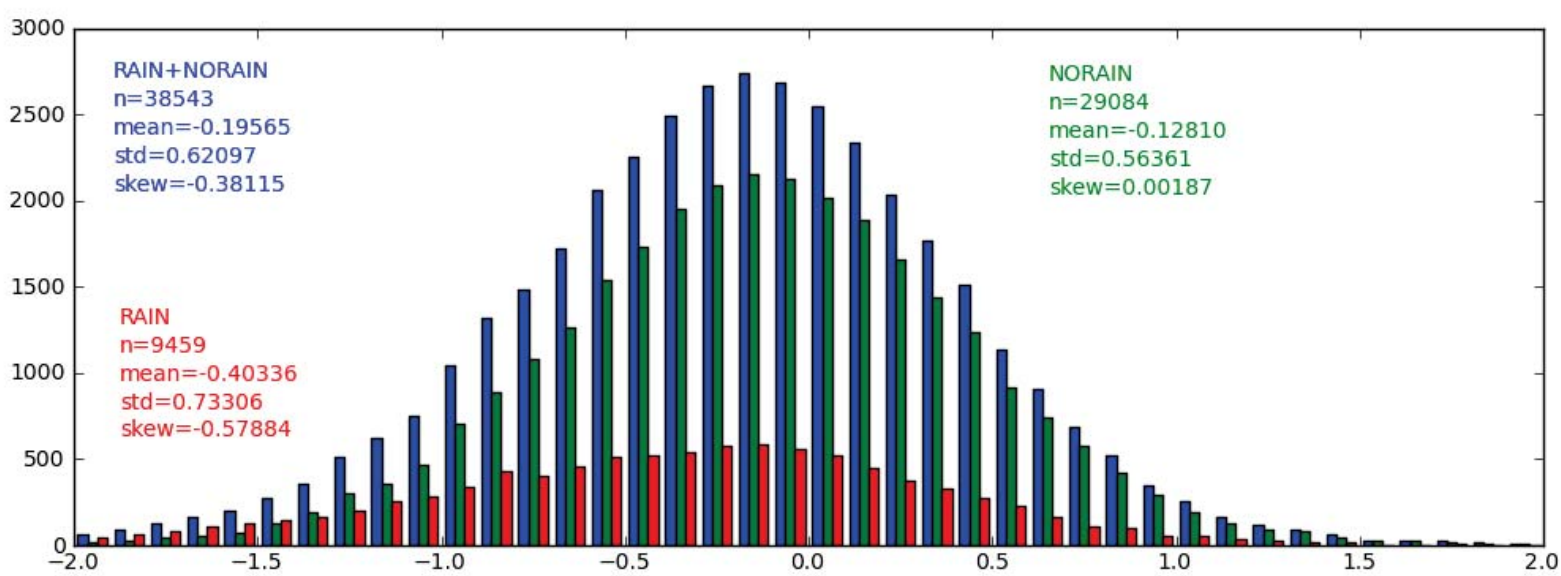
$\triangle S S S=S S S_{\text {smos }}-S S S_{\text {argo }}$

Figure 15: Statistical distribution of SSS differences $\triangle S S S=S S S_{\text {smos }}-S S S_{\text {argo }}$ in the Tropical Pacific Oceanfor various sorting on co-located SSSM/I rain rates.Blue:all collocations (without any rain sorting); green: for non rainy cases (SSM/I rain rates less than $0.1 \mathrm{mmh}^{-}$ $\left.{ }^{1}\right)$; red: rainy cases (SSM/I rain rates larger than $0.1 \mathrm{mmh}^{-1}$ ). Corresponding statistics are

763 The non sorting of SMOS measurements close in time with rain events in SMOS-Argo 764 collocated datasets (within 10 days and $100 \mathrm{~km}$ ) is responsible for (i) a mean -0.1 negative 
bias over 3 months between $5^{\circ} \mathrm{N}$ and $15^{\circ} \mathrm{N}$ in the Tropical Pacific region with respect to non rainy conditions and with respect to thesubtropical Atlantic region, and (ii) a negative skewness of the statistical distribution of SMOS minus Argo SSS difference (Figure 15). Given that the whole set of SMOS-Argo collocations also includes the situations with rainy Argo measurements collocated with non rainy SMOS measurements, these results indicate a systematic freshening of SMOS SSS in rainy conditions and is likely a signature of the vertical salinity stratificationbetween the first centimeter of the sea surface layer sampled by SMOS and the5m depth sampled by Argo. For more detail on the vertical SSS stratification induced by rain, the reader is also referred to Boutin et al. (2012b).

\subsection{SSS as a tracer of the Evaporation-Precipitation budget in the oceanic mixed layer}

The SMOS derived SSS can also be used to investigate the consistency between observed SSS variability and the Evaporation minus Precipitation budget in the ITCZ of the tropical Atlantic based upon the SSS and SST relationship in the ocean mixed layer (OML). The salt conservation budget in the OML with depth $h$ can be expressed as follows (Michel, 2007; Yu 2010, 2011):

782

$$
\frac{\partial S}{\partial t}=\frac{(E-P-R) S}{h}-\vec{u} \cdot \nabla S-\Gamma\left(w_{\theta}\right) \frac{w_{\varepsilon}\left(S-S_{h}\right)}{h}+\kappa \nabla^{2} S
$$

where $S$ is the surface salinity, $E$ and $P$, the evaporation and precipitation rates, respectively, $\mathrm{R}$ the fresh water input by river runoffs, $h$, the mixed layer depth, $\vec{u}$ the (vertically averaged) current vector within the OML and $w_{\varepsilon}$, the vertical entrainment rate. $S_{h}$ is the salinity just below the OML, $\kappa$ is the horizontal diffusivity coefficient $(\kappa \sim 2000$ $\left.m . s^{-2}\right)$. The total entrainment term must be treated differently in case of upward or downward entrainment, so it is multiplied by a step function $\Gamma$ in Eq (1). Indeed, when additional water is included into the mixed layer, its properties are affected by mixing with the deeper layer: $\Gamma\left(w_{\varepsilon}\right)=w e$ if $w e>0$. On the contrary, if water is removed from the mixed

793 layer, the properties of the remaining water are conserved and only its depth $h$ can change: $\Gamma\left(w_{e}\right)=0$ if $w e<0$. The vertical processes are conveniently represented by a single entrainment term, consisting of the vertical Ekman advection and the OML conditions. 
The first term in the right-hand side of Eq. (1) is the net fresh water flux. The impact of this flux on the surface water strongly depends on the salinity itself. Moreover, SSS has no direct feedback on the surface flux. These particularities have important consequences on the salt budget and on the duration of SSS anomalies. The second term is the horizontal advection of salinity by surface currents that can be separated into a wind induced component, the Ekman transport, and the geostrophic current. Ekman transport is due to wind friction on the sea surface, which is rotated by the Coriolis force as it penetrates in depth. The Ekman layer depth is systematically lower than the mixed layer depth, because both increases with the wind stress, although the depth of the mixed layer also deepens in response to other processes. Thus, the Ekman transport occurs entirely in the OML. In addition, the geostrophic current that arise from the balance between the horizontal pressure force and the Coriolis force can usually be considered constant the mixed layer resulting from the homogeneous density structure.

809 The value of the SMOS SSS at a fixed point, $\boldsymbol{S}(\boldsymbol{t}, \boldsymbol{r})$, is obtained by averaging individual

810 SMOS swath SSS measurements over a considerable time interval $(t-\tau / 2, t+\tau / 2)$, say 10 811 days, which is enough to filter out noise in the SSS. Suppose that the climate mean, or 812 norm, of this SSS (provided by climatology) is $\overline{S(t, r)}=S_{o}(t, r)$. In the following, we

813 define the SSS anomaly as the departure of the SSS from the norm:

$$
\Delta S(t, r)=S(t, r)-S_{o}(t, r)
$$

815 Following approaches traditionally used for studying large-area SST anomalies (Piterbarg, 816 and Ostrovskii, 1997), a formal definition can be introduced for the large-area SSS 817 anomalies. For example, large area and large amplitude SSS anomaly comprises the 818 connected components of the set: $\left\{(x, y):|\Delta S(t, r)|>S_{T}\right\}$

820 where $\mathrm{r}=(\mathrm{x}, \mathrm{y})$ and $\mathrm{S}_{\mathrm{T}}$ is a threshold that can be taken either as a fixed salinity value, for example, $0.2 \mathrm{pss}$, or as a function of the standard deviation of SSS anomalies, $\sigma_{\mathrm{S}}$, for

822 example $0.5 \sigma_{\mathrm{S}}$. This choice for the threshold depends on the magnitude of the anomaly of 823 interest.

824 In the tropical Atlantic, Michel et al. (2007) and Yu (2011) have shown that the dominant 825 terms of the mixed-layer salinity balance are horizontal advection by Ekman and 826 geostrophic currents and the atmospheric forcing fluxes (E-P-R). In that context, the salinity balance equation in the OML can be simplified as follows: 


$$
\frac{\partial S}{\partial t} \cong \frac{(E-P-R) S}{h}-\vec{u} \cdot \nabla S
$$

829 Using OSCAR surface current products (which comprise contributions of both Ekman and

830 geostrophic currents), the horizontal salt advection term $\vec{u} \cdot \nabla S$ can be deduced from

831 SMOS observations. The following residual SSS anomaly can then be estimated from

832 SMOS temporal observations of salinity $S(t, r)$ at point $\mathrm{r}$ following:

$$
\Delta S(t, r)=S(t, r)-S_{o}(t, r)-\vec{u}(t, r) \cdot \nabla S(t, r)
$$

834 According to the simplified salinity balance (Eq. 2), a priori valid for the tropical Atlantic,

835 the resulting SSS anomaly given by Eq.3 shall be strongly correlated with the net fresh836 water flux forcing term. Examples for such SSS anomaly analysis is shown in Figure 16 837 for a selected point in the middle of the North Tropical Atlantic $\left(16^{\circ} \mathrm{N}-35^{\circ} \mathrm{W}\right)$. From 838 TRMM precipitation and OAFLUX daily evaporation fluxes, large-area $\mathrm{P}$ and $\mathrm{E}$ anomalies 839 were also evaluated:

840 $\Delta P(t, r)=P(t, r)-P_{o}(t, r)$

841

$$
\Delta E(t, r)=E(t, r)-E_{o}(t, r)
$$

842 where $P_{o}$ and $E_{o}$ are the local climate mean for the precipitation and evaporation.

843

844
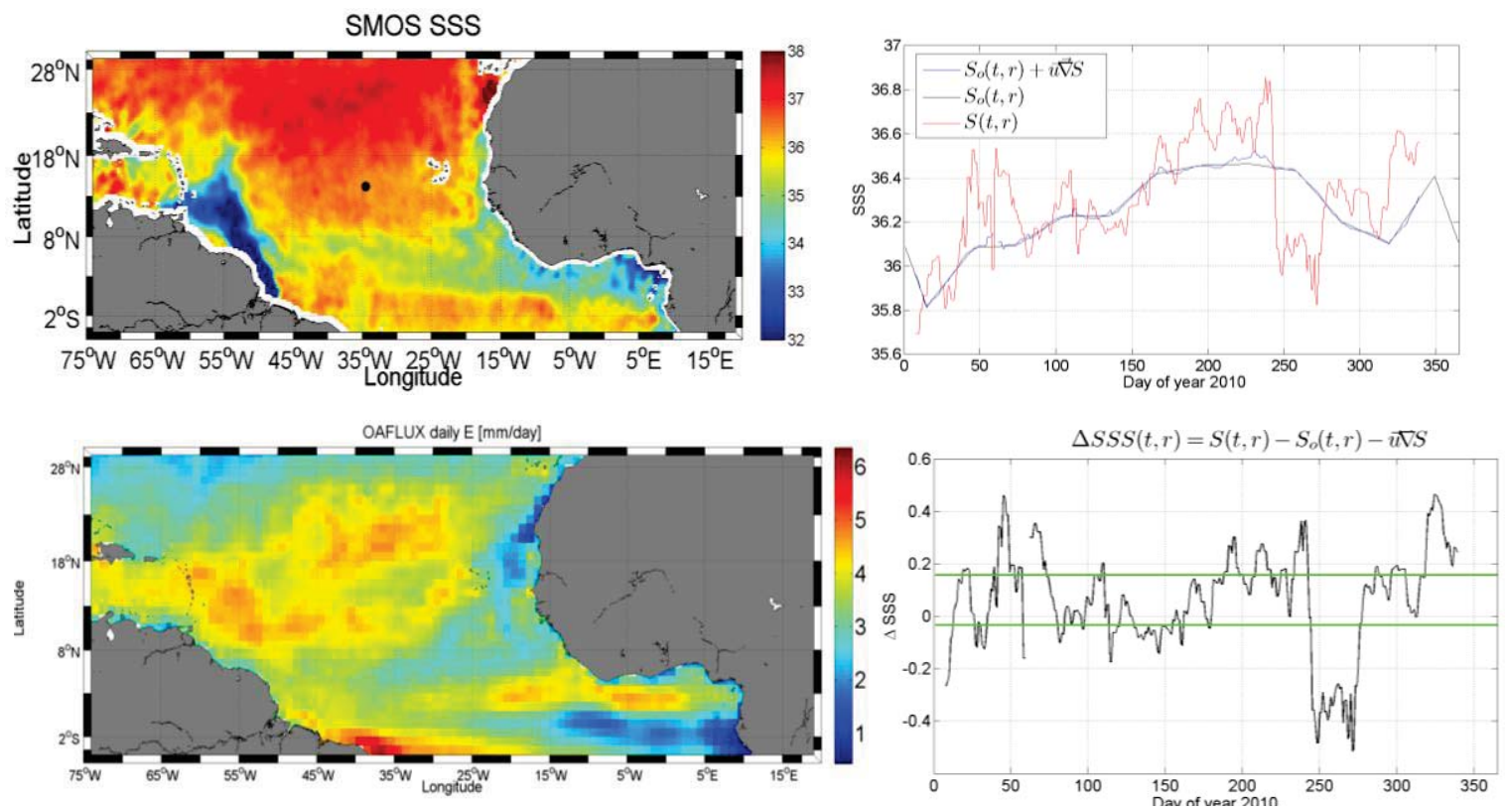

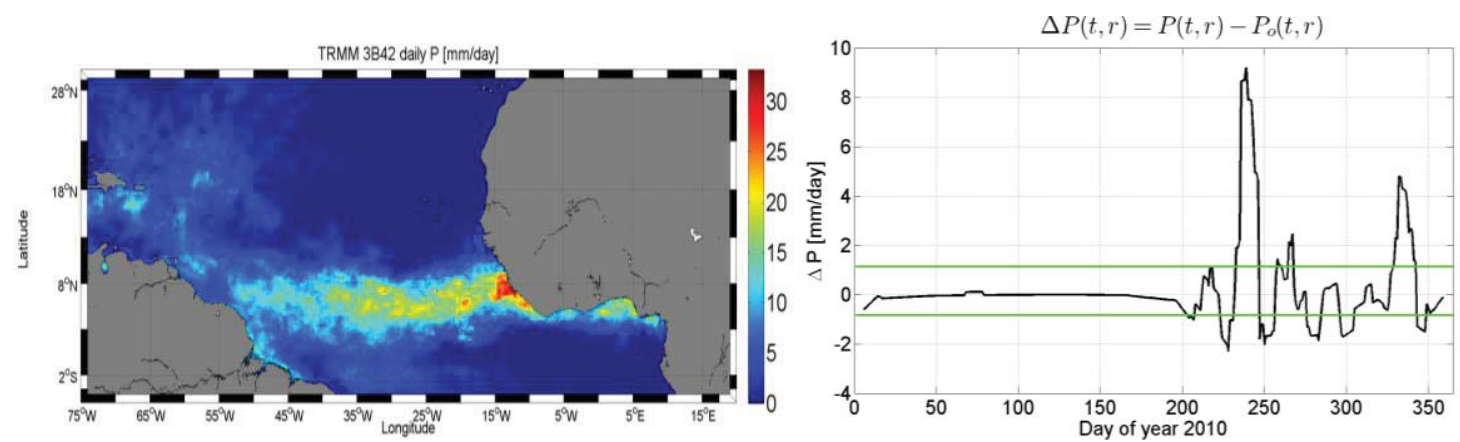

847

848 Figure 16:Top left: SMOS 10-days SSS field in June 2010. Top right: time series of the 849 surface salinity $S(t)$ at the black point shown in the top left figure $\left(35^{\circ} \mathrm{W} ; 16^{\circ} \mathrm{N}\right)$. Red: 850 SMOS SSS, blue curve: local mean climatological annual cycle at that point $S_{o}(t)$. The 851 resulting time series for the SMOS anomaly $\triangle S S S$ at that point is shown in the middle 852 panel, right plot. The green horizontal lines are indicating \pm one standard deviation of the 853 local SSS anomalies, $\sigma_{S}$. In the middle and bottom left panels, we show the corresponding 854 OAFlux Evaporation and TRMM $3 B 42$ precipitation field $(\mathrm{mm} /$ day). The time series of the

857 As illustrated in Figure 16 (middle right pannel), very significant long-lived negative $858 \Delta \mathrm{S}(\mathrm{t}, \mathrm{r})$ values are detected in SMOS anomalies at the selected point in the North Tropical 859 Atlantic during September/October months (days 250-300) of 2010. Apparently, this 860 happened just after a strong positive anomaly in the precipitation rate as detected from 861 TRMM during the passage of the ITCZ in August (bottom right panel).

862

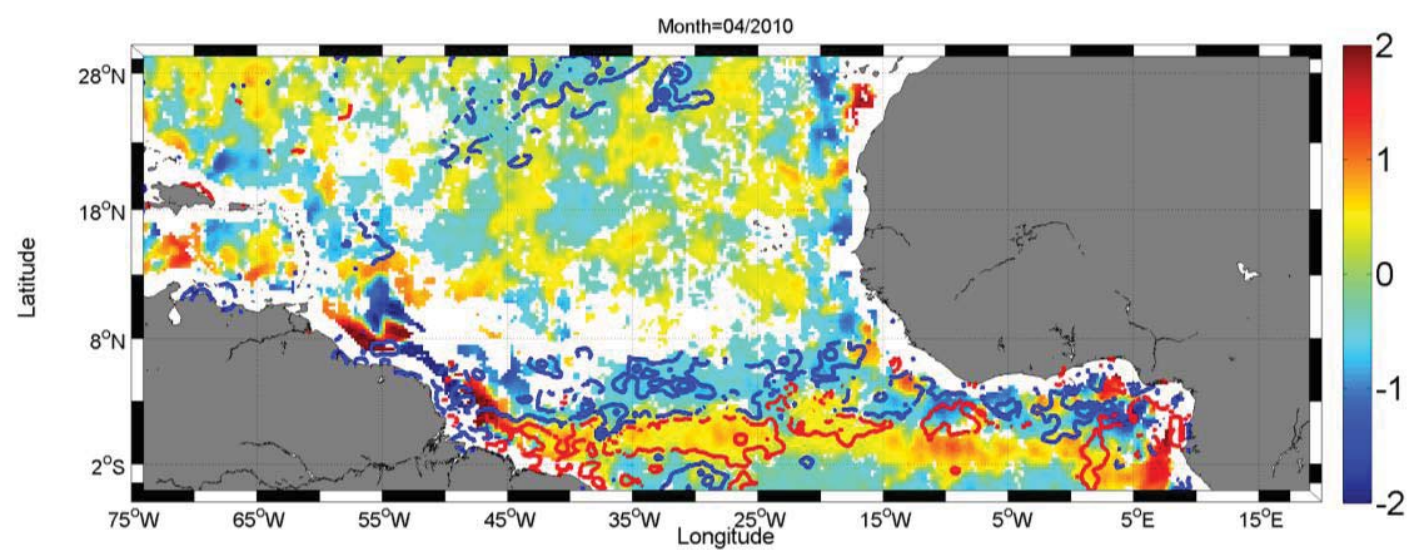




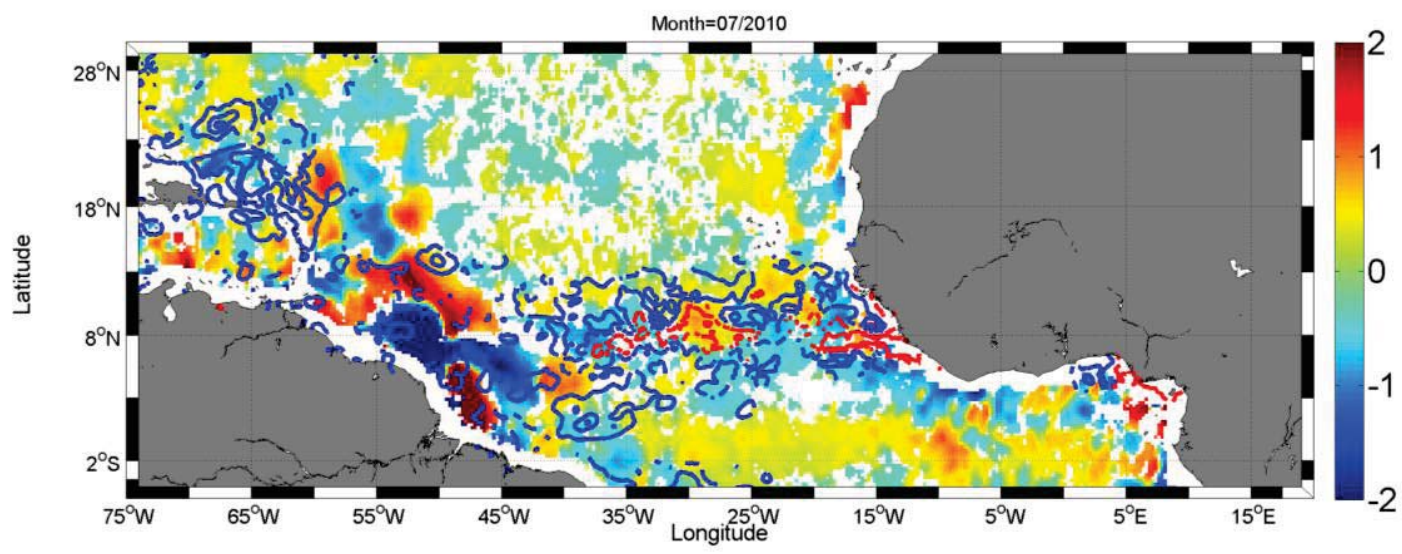

865 Figure 17: Maps of the monthly averaged large amplitude SSS anomalies deduced from 866 SMOS data for two selected months of 2010 (Top: month of march 2010;. Bottom: month 867 of July 2010). The threshold value $S_{T}$ used to derive the anomaly is defined by $1 \sigma_{S}$, the

868 local standard deviation of SMOS anomaly. Superimposed are the contours of the large 869 positive amplitude Precipitation anomalies (blue) and positive Evaporation anomalies 870 (red).

871

872 The spatio-temporal consistency between the large area and large amplitude S, P and E 873 anomalies can be further analyzed over all the Tropical Atlantic. This is illustrated in 874 Figure 17 for two selected months of 2010. The spatial distribution of the large-area and 875 long-lived (monthly averaged) SSS anomalies generally matches well the spatial patterns 876 for the large E-P anomalies. In particular, North-South oscillation in $\Delta \mathrm{S}(\mathrm{t}, \mathrm{r})$ around the 877 ITCZ (centered around $5^{\circ} \mathrm{N}$ in March and $8^{\circ} \mathrm{N}$ in July) follows the $\Delta \mathrm{E}-\Delta \mathrm{P}(\mathrm{t}, \mathrm{r})$ far from the 878 Amazon plume area, with negative $\Delta \mathrm{S}(\mathrm{r}, \mathrm{t})$ corresponding to positive $\Delta \mathrm{P}(\mathrm{t}, \mathrm{r})$ and positive $879 \Delta \mathrm{S}(\mathrm{r}, \mathrm{t})$ found in region of positive $\Delta \mathrm{E}(\mathrm{t}, \mathrm{r})$. The average relationship between SMOS SSS 880 anomalies and the corresponding anomalies in the net atmospheric fresh water flux in the 881 tropical Atlantic (defined here by $5^{\circ} \mathrm{S}-20^{\circ} \mathrm{N} ; 75^{\circ} \mathrm{W}-15^{\circ} \mathrm{E}$ ) was further evaluated over year 8822010 by binning $\Delta \mathrm{S}(\mathrm{t}, \mathrm{r})$ values as function of $\Delta \mathrm{E}-\Delta \mathrm{P}(\mathrm{t}, \mathrm{r})$ as shown in Figure 18. 


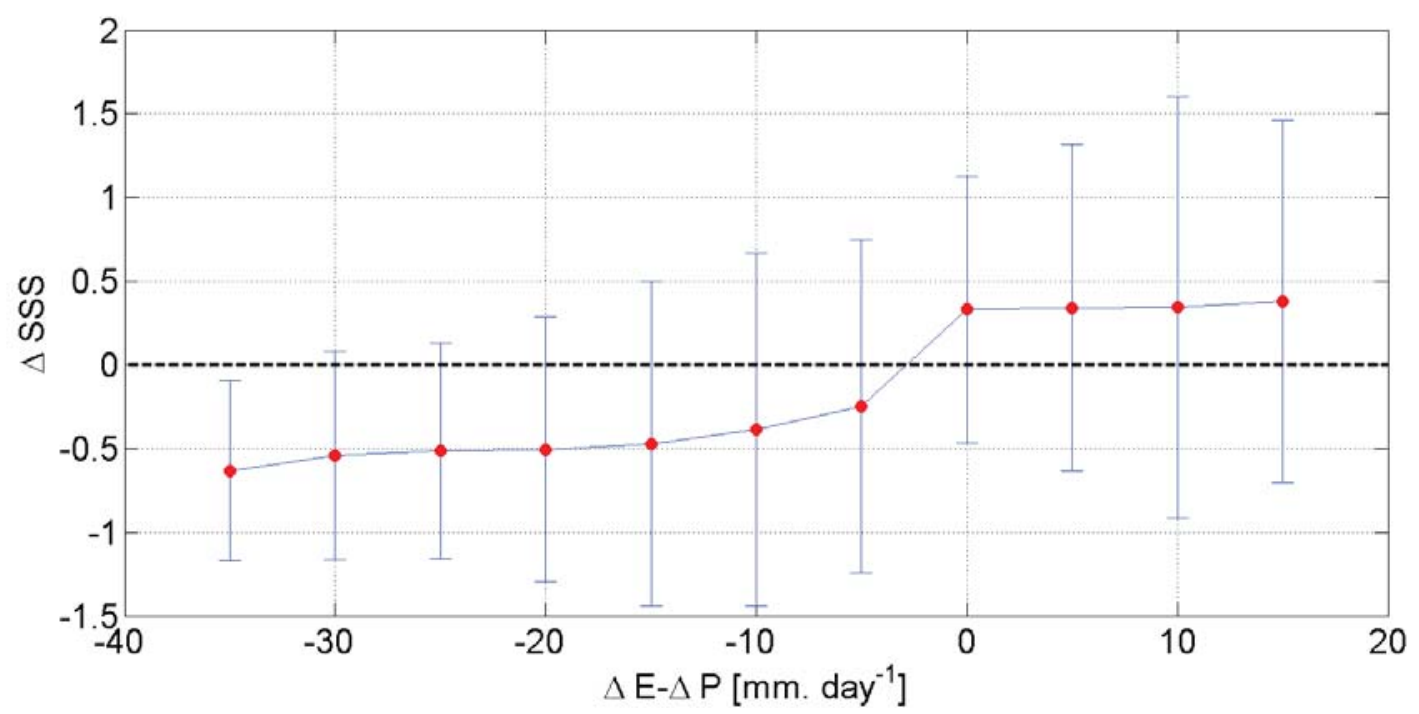

884

$\Delta \mathrm{E}-\Delta \mathrm{P}\left[\mathrm{mm} \cdot\right.$ day $\left.^{-1}\right]$

885 Figure 18: Average relationship between SMOS SSS anomalies and the net atmospheric 886 fresh water flux anomalies $\triangle E-\triangle P$ in the tropical Atlantic (defined here by $5^{\circ} S$ $88720^{\circ} \mathrm{N} ; 75^{\circ} \mathrm{W}-15^{\circ} \mathrm{E}$ ) over year 2010 .

889 Despite a significant scatter in the data, the results clearly indicate the strong coherency 890 between SMOS SSS anomalies and the Evaporation minus Precipitation flux signal in the 891 tropical Atlantic. On average, SMOS SSS are thus systematically fresher than the SSS 892 climatology when Precipitation rate exceed Evaporation rate with respect climatological 893 means, and vice-versa. As expected by the skin layer effects (Zhang et al. 2012), satellite 894 SSS anomalies are weakly sensitive to excess evaporation showing an almost constant 895 value whatever positive values for $\Delta \mathrm{E}-\Delta \mathrm{P}$. Nevertheless, and as discussed in section 4 , the average 0.3 salinity unit excess amplitude found for $\Delta \mathrm{S}$ in evaporative zones is 897 significantly larger than the expected evaporation-induced effect on the satellite SSS 898 ( 0.01). The source for such observed signal amplitude is not yet understood. Other 899 physical processes, not yet well accounted for in the SSS retrieval algorithm may 900 systematically affect the L-band brightness temperature in strongly evaporative zone (e.g. 901 skin effects in SST, badly accounted for roughness effects at low winds).

902 Nevertheless, Figure 18 clearly evidences that SSS anomalies become increasingly 903 negative as the precipitation anomalies progressively exceed the Evaporation anomalies.

904 This shows that it is important to monitor SSS from Space in the rainy regions as it makes 905 a good oceanic rain gauge for the changing water cycle [Cravatte et al., 2009; Yu, 2011, 906 Terray et al., 2011], and therefore help tomaintain a continuous observation network in 907 these key regions of the marine branch of the global hydrological cycle. In that context, 908 SMOS SSS may therefore be an interesting dataset for assimilation into ocean models in 909 the perspective of better constraining oceanic precipitation forcing terms. 


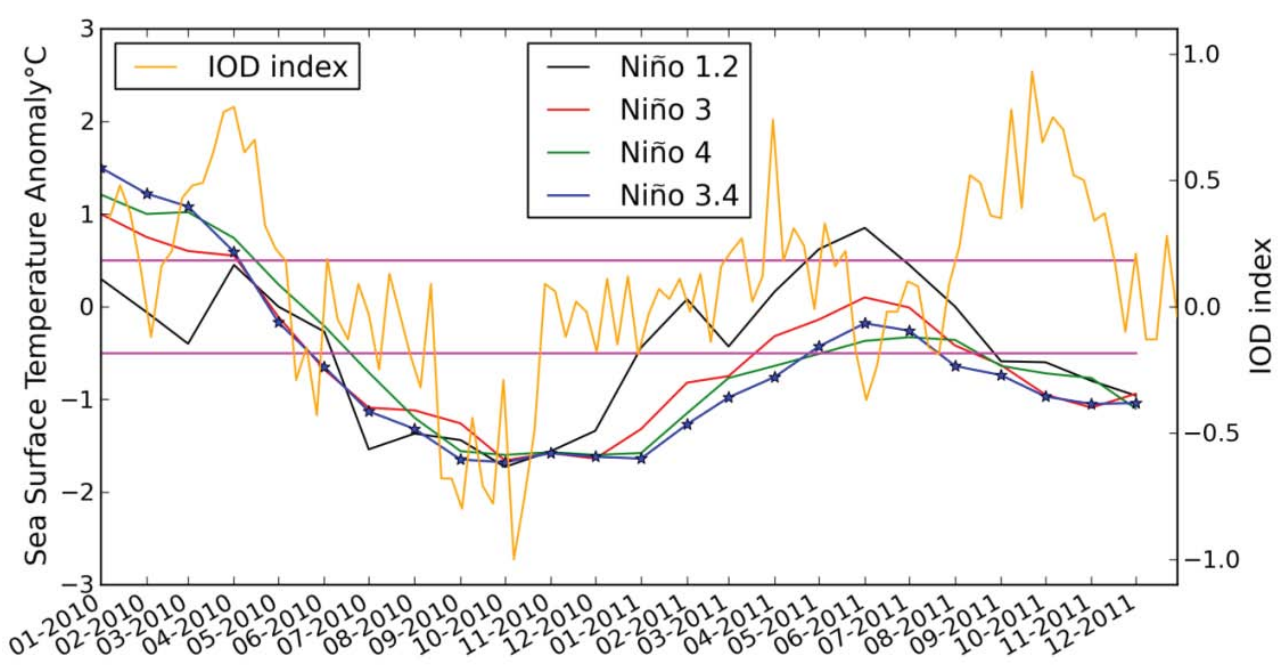

913

914 19:Time series of SST anomalies in the four Niño regions from 915 http://www.cpc.ncep.noaa.gov/data/indices/sstoi.indices in 2010-2011 and corresponding

916 Indian Ocean Dipole (IOD) Index (SST difference between eastern and western equatorial

917 Indian Ocean) from the Australian bureau of Meteorology (BOM).

918

919 In the Indian and Pacific Oceans the precipitation impact on the large scale SSS variability

920 can also be observedfrom SMOS and ISAS monthly maps.

921 The 2010-2011 period was characterized by a strong La Niña event lasting from July 2010 922 to March 2011 and by an Indian Ocean Dipole (IOD) index in negative phase in

923 September-November 2010 and in positive phase during about the same months in 2011 924 (see Figure 19). Such events are known to generate large scale SSS signatures in the 925 tropics (e.g., Gouriou et al., 2002; Singh et al. 2011, Grunseich et al. 2011) and are clearly 926 depicted in the SSS signals in both theISAS and the SMOS monthly difference maps 927 between 2010 and 2011 for both July and November (Figure 20). 

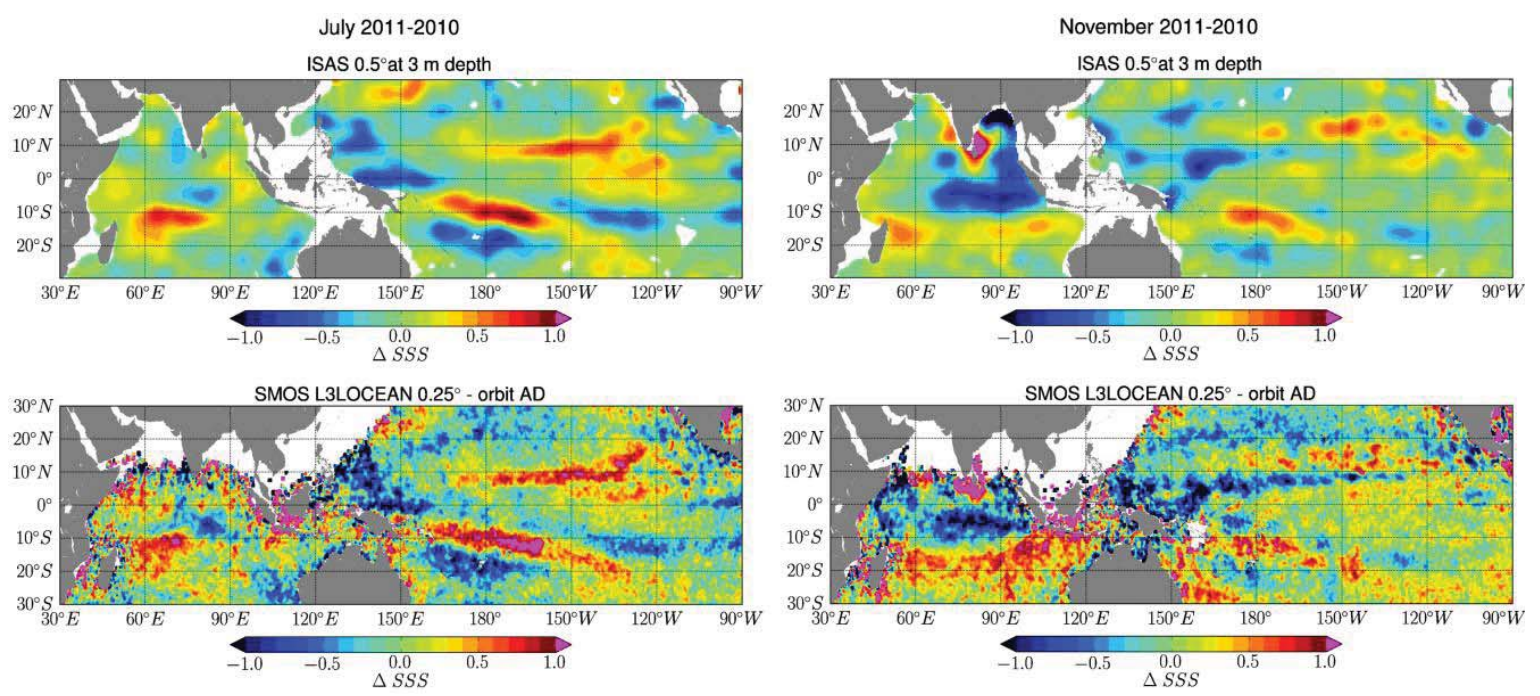

930 Figure 20 :Differences in the monthly averagedSSS between year 2011 and 2010 for 931 months of July (left) and November (right). Top panels show the $\triangle S S S=S S S_{2011}-S S S_{2010}$ 932 results obtained from in situ OI analysis products ISAS and bottomones from SMOS data.

933

934
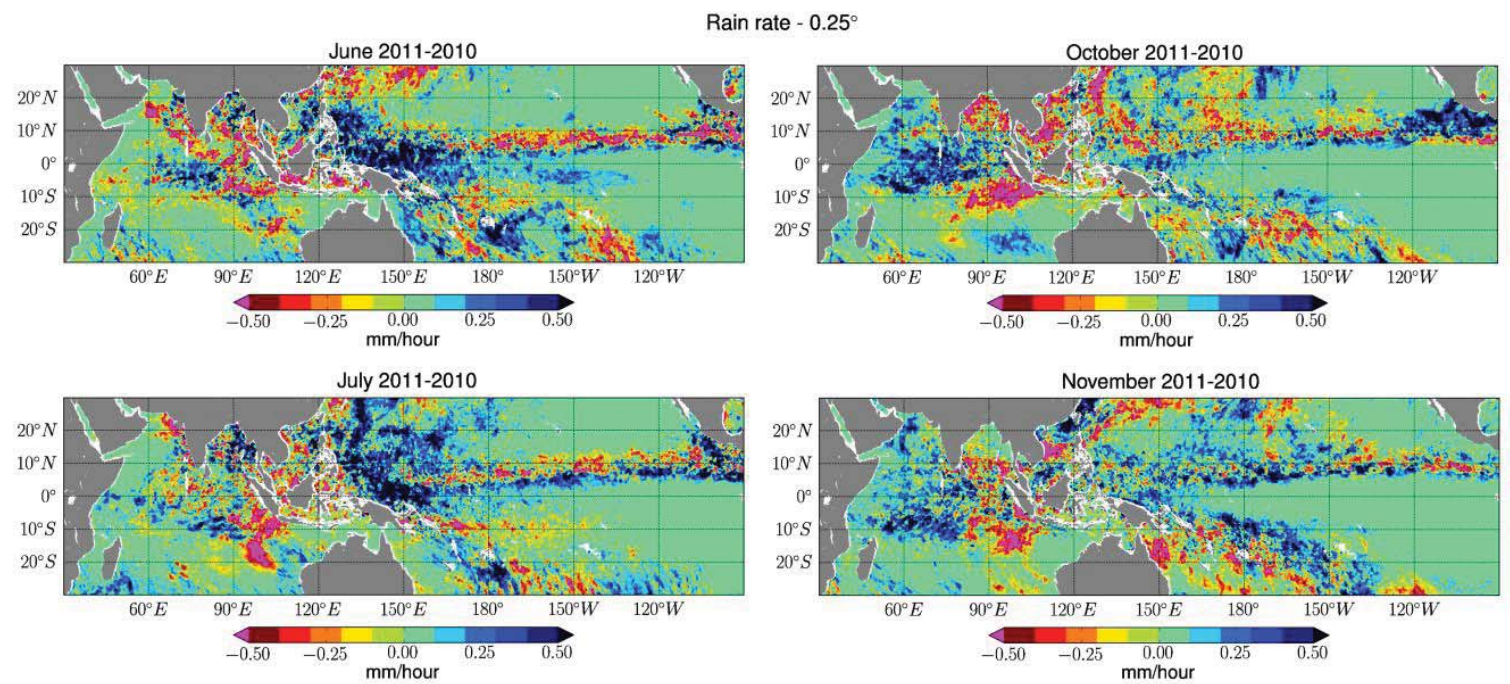

936 Figure 21:Rain Rate differences $\triangle R R=R R_{2011}-R R_{2010}$ derived from SSM/I F17 between 9372011 and 2010 for months of June (Top left);July (Bottom Left); October (Top right) and

938 November (Bottom right).

939

940 The differences in rain rate as derived from SSM/I F17 sensor between 2011 and 2010 for

941 several selected months as shown in Figure 21 further demonstrate that part of the

942 observed SSS interannual variability for July and November are associated with large

943 precipitations anomalies during previous months, associated with displacements of the

944 ITCZ and of the South Pacific Convergence Zone (SPCZ). In the Indian Ocean, SSS

945 differences $\Delta \mathrm{SSS}=\mathrm{SSS}_{2011}-\mathrm{SSS}_{2010}$ observed in November indicate saltier SSS in 2010 than

946 in 2011 in the eastern equatorial Indian Ocean within the band $\left[10^{\circ} \mathrm{S}-0^{\circ} ; 70^{\circ} \mathrm{E}-95^{\circ} \mathrm{E}\right]$

947 associated with a smaller rain rate $\left(R_{2010}<R_{2011}\right)$ in the surrounding region during 
948 preceding months, as evidenced by the rain rate difference on the October and November 949 maps shown in Figure 21. Between $\sim 10^{\circ} \mathrm{S}$ and $20^{\circ} \mathrm{S}, \mathrm{SSS}$ are fresher in 2010 than in 2011; 950 this is associated with higher precipitation in 2010 than in $2011\left(R_{2011}<R R_{2010}\right)$ in the 951 eastern basin but not over the whole basin. Patterns of positive SSS anomalies in the 952 eastern equatorial Indian Ocean, and negative anomalies in the eastern part of the region 953 south of $\sim 10^{\circ} \mathrm{S}$ are quite consistent with SSS anomalies already reported during negative

954 IOD coupled with a strong La Niña event (see Figure 8 of Grunseich et al. 2011).

956 Although patterns of 2011-2010 SSS differences are similar on SMOS and ISAS monthly 957 maps, the differences are often more contrasted in the SMOS data (e.g., Figure 20, left part 958 and Figure 22).
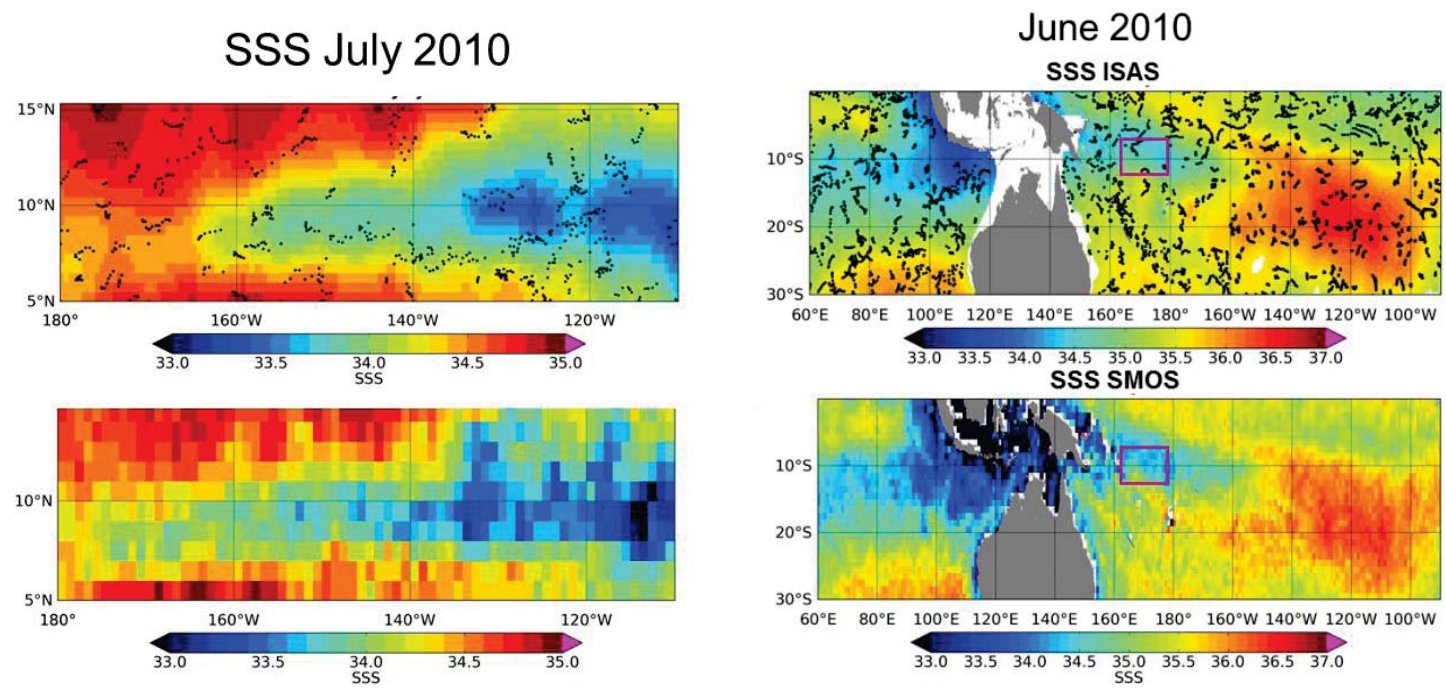

959

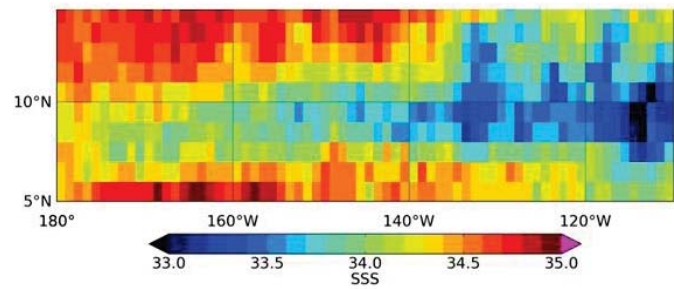

960 Figure 22: Left: July 2010 SSS maps in the Northern Tropical Pacific Ocean from ISAS 961 (top) and SMOS (bottom). Right: June 2010 SSS maps in south Pacific-Indian tropics from 962 ISAS (top) and SMOS (bottom). In both top panels, the small black dots represent the 963 locations of the in situ data samples used in the objective analysis. The purple square on 964 the right figure indicates the region where the drifter discusses in Figure 23 evolved.

965

966 This originates from fresher SSS seen in the SMOS SSS maps than in the ISAS SSS maps 967 (Figure 22). In addition the spatial extent of the low SSS region appears wider in the 968 SMOS map, as illustrated in Figure 22 left around $8^{\circ} \mathrm{N}$. This is possibly due to the in situ 969 measurements undersampling and/or smoothing by the OI applied to the ISAS. In addition, 970 the SMOS freshening could be linked to the different depth of the measurements (SMOS at $9711 \mathrm{~cm}$, and in situ SSS measured at several meters depths) as described in sections 4.1 and 972 4.2 . 

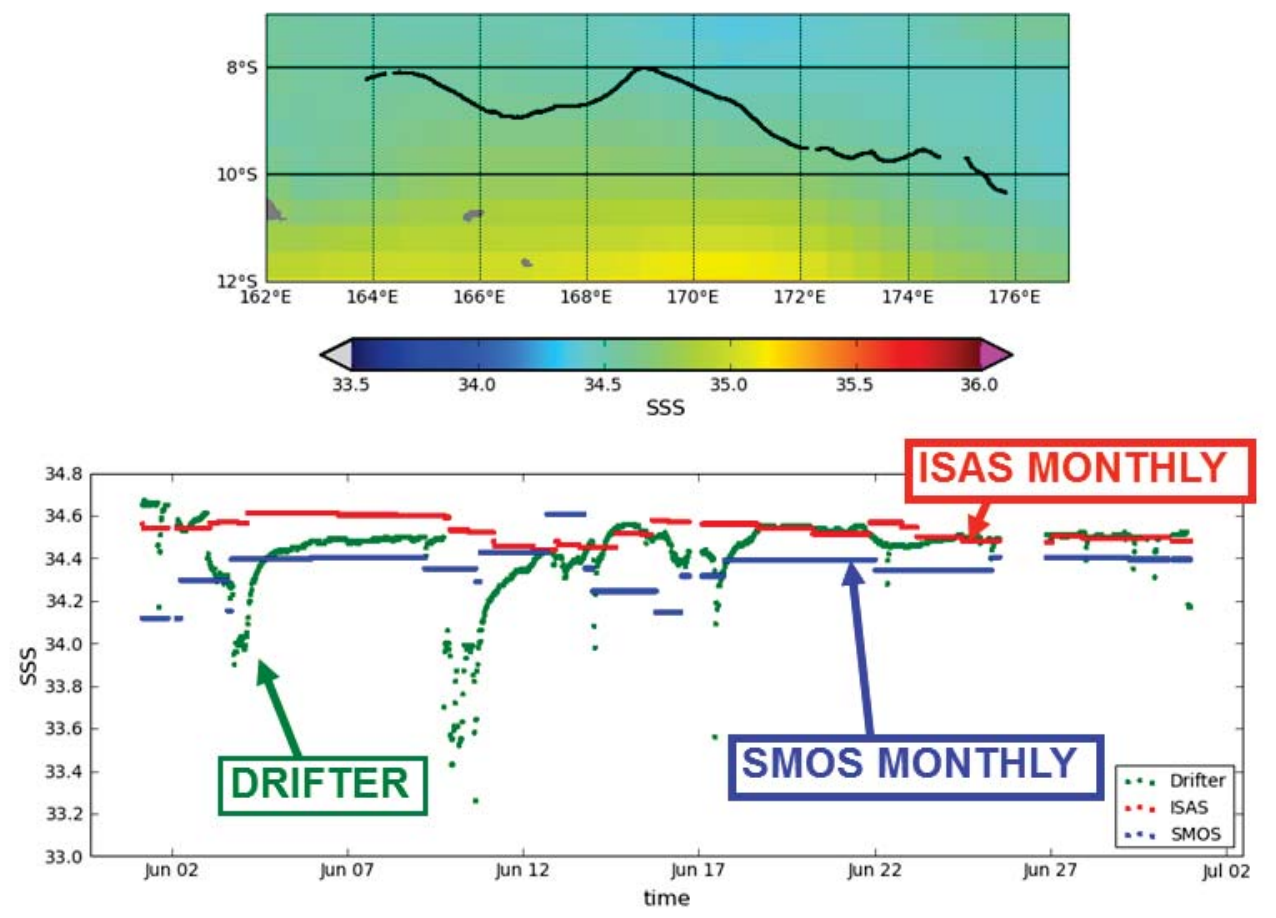

973

974 Figure 23:Top: trajectory of a Surface Velocity Program (SVP) float in the western 975 Pacific region measuring conductivity and temperature at $45 \mathrm{~cm}$ depth. Bottom: SSS along 976 the drifter trajectory measured by the drifter (green), derived from SMOS monthly map 977 (blue), from ISAS monthly map (red).

978

979 Finally, to illustrate the potential impact of thevertical stratification effect on the $\Delta$ SSS 980 differences between satellite and in situ, we compare along the drifter trajectory the salinity 981 measured at $45 \mathrm{~cm}$ depth by a surface float (Reverdin et al. 2012) in the 2010 rainy western 982 Pacific with monthly SSS maps (Figure 23). The drifter SSS data clearly indicates a large 983 signature of rainy events, with typical freshening events larger than -1 and lasting for more 984 than one day. The ISAS SSS is on the upper range of the drifter SSSwhile monthly SMOS 985 SSS is systematically on the lower range in this rainy region. While more work is certainly 986 needed to determine the physical sources for these observed differences, the vertical SSS 987 stratification associated with rain events, as illustrated by this case, is a likely contributor to 988 the different signatures in the inter-annual SSS variability as detected by the SMOS 989 satellite SSS data and the Argo data.

990 These preliminary results confirms the capability of L-band radiometry in detecting large 991 SSS signals and their low-frequency variability (here over a two-years period), in spite of 992 much noisier satellite than in situ measurements. In general this results from much better 993 satellite based spatio-temporal coverage and with a better spatial resolution, thus, offering 994 complementary information to existing in situ measurements. 


\section{5. Fresh Pools interactions with wind-driven processes}

997 In this section, two specific SMOS observation cases study cases of wind-driven

998 phenomena are presented. The first example illustrates the erosion of the Far Eastern

999 Pacific Fresh Pool by the gap-wind driven Panama Upwelling processes whereas the 1000 second focuses on the salty wake left behind hurricanes after their passing over the 1001 Amazon-Orinoco river plumes.

1002

$1003 \quad 5.1$ An example of Fresh Pool Erosion by wind-driven upwelling

1004 The eastern tropical Pacific Ocean between about $120^{\circ} \mathrm{W}$ and South America is unique in 1005 many respects. Lying in an environment predominantly influenced by the South and North1006 Eastern trades and the doldrums, and seasonally affected by the winds from the Caribbean, 1007 this region is characterized by complicated and large seasonal variations in the wind field, 1008 current pattern, and temperature and salinity structure.

1009
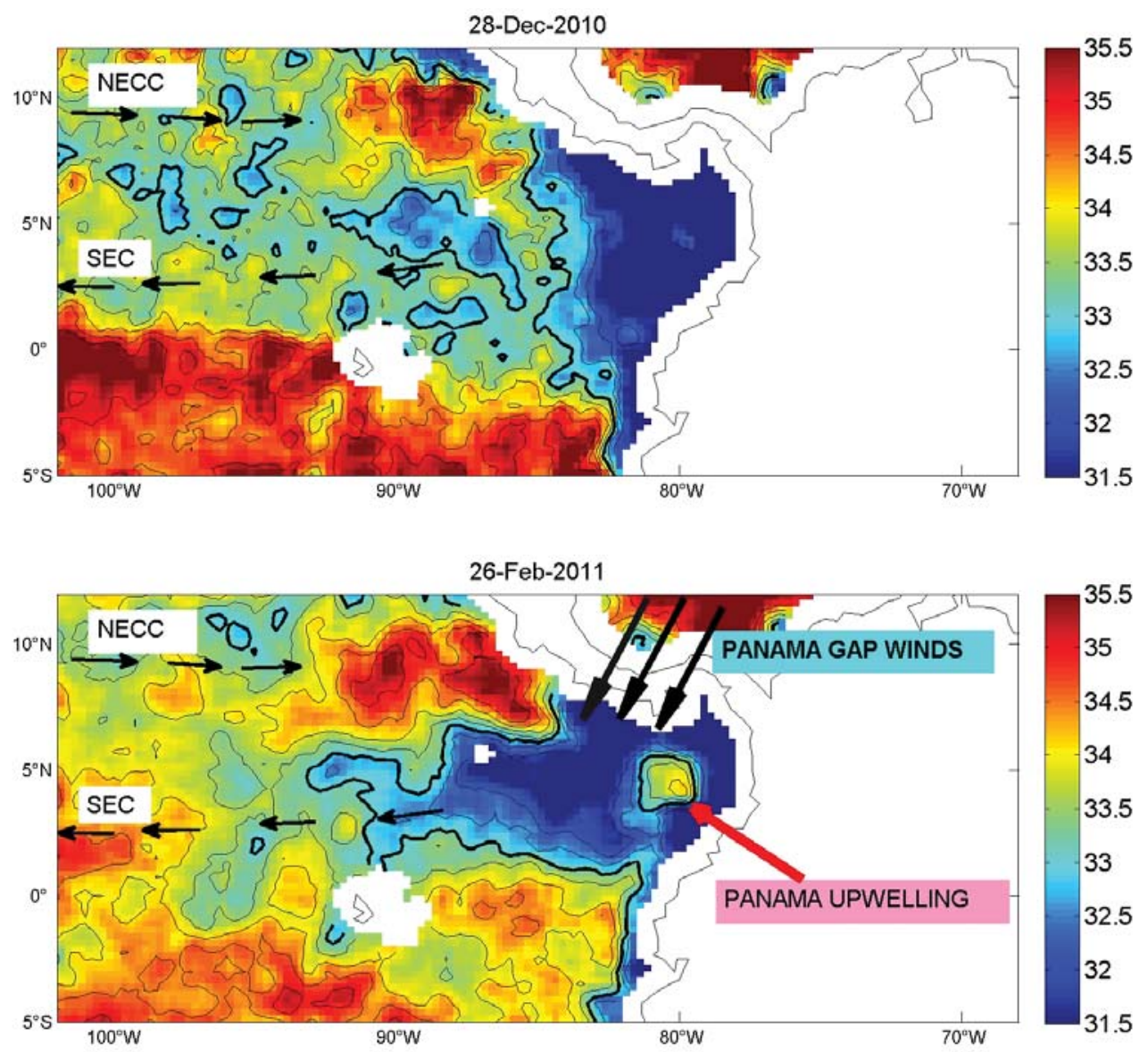


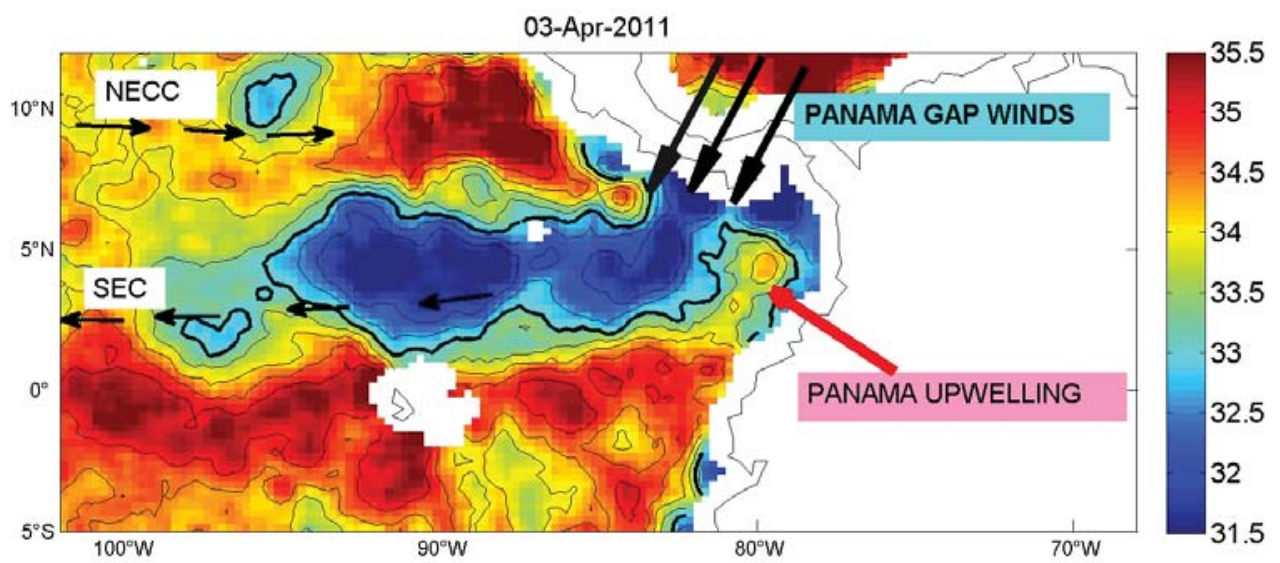

1012 Figure 24: 10-days averaged SMOS SSS fields centered on the 28 Dec 2010 (Top), 16 Feb 10132011 (middle) and 3 Apr 2011 (bottom). Small black arrows indicate the major surface 1014 currents, namely the South Equatorial Current (SEC) and North Equatorial Counter 1015 Current (NECC). Thick black contour is indicating the 32 isohaline.

1016

1017 The lowest sea surface salinity (SSS) of the tropical Pacific Ocean, the Easter Pacific Fresh

1018 Pool (EPFP), is found between the warm pool characterized by a mean sea surface 1019 temperature (SST) greater than $28^{\circ} \mathrm{C}$ centered around $15^{\circ} \mathrm{N}$ along the coast of Central 1020 America and the cold and fresh equatorial region, with SSS values lower than 33 off the 1021 Panama isthmus and lower than 34 extending as far as $130^{\circ} \mathrm{W}$ from the equator to $15^{\circ} \mathrm{N}$ 1022 (Figure 24).

1023 The EPFP reflects both the conditions of excessprecipitation over evaporation beneath the 1024 ITCZ and inputsof fresh water from the Andes and Caribbean region (Benwayand Mix, 1025 2004). Analysis of a recent gridded in situ SSS product (Delcroix et al., 2011) points out 1026 that interannual variations are relatively weak in the EPFP but that seasonal variations are 1027 the strongest within the tropical Pacific. Large-scale analysis suggests that the SSS 1028 seasonal balance is mostly driven by precipitation in the part of the EPFP covered by the 1029 ITCZ, but more complex in the far east as advection and entrainment become important 1030 processes (Bingham et al., 2010; Alory et al., 2012).

1031 By focusing on seasonal SSS variations along a well-sampled Voluntary Observing Ship 1032 (VOS) line from Panama to Tahiti, Alory et al.(2012) recently showed that this fresh pool 1033 dynamically responds to strong regional ocean-atmosphere-land interactions. First, 1034 monsoon rains (and associated river runoff) give birth to the fresh pool inthe Panama Bight 1035 during summer and fall. Second, strong currents driven by topography-induced winds 1036 extend the poolwestward in winter while it eventually disappear by mixing with upwelled 1037 saltier waters to the east. These dynamic features also generate steep SSS fronts at the 1038 edges of the fresh pool (sometimes larger than $\sim 4 \mathrm{psu} /{ }^{\circ}$ of longitude at the eastern edges). 
1039 These SSS fronts and the amplitude of their seasonal cycle are large enough to be detected

1040 by the new SMOS satellite mission. Compared to in situ data, SMOS satellite data provide 1041 a more homogeneous coverage with finer spatial resolution. Examples of SMOS SSS maps 1042 averaged over 10 days and centered at selected dates in December 2010, February and 1043 April 2011 are presented in Figure 24. Remarkably, all the major features observed with in 1044 situ VOS data as detailed in Alory et al. (2012) are well reproduced in the SMOS analysis, 1045 notably: the westward expansion of the fresh pool (SSS < 33) from $85^{\circ} \mathrm{Win}$ December to $104695^{\circ} \mathrm{W}$ in April, the steep SSS front east of the 32 isohaline and SSS minimum of 28 in the 1047 Panama Bight in December, and the strong SSS increase to around 35 in the Panama Bight 1048 in April. Moreover, SSS changes occurring between December and April are qualitatively 1049 consistent with the expected effects of winter climatological currents, including the 1050 Panama Bight upwelling.

1051 The freshwater pool disruption as observed by SMOS in the Panama bight (Figure 24, 1052 middle and bottom panels) are associated with the following processes: during the boreal 1053 winter, as the ITCZ moves southward, the north-easterly Panama gap wind creates a south1054 westward jet-like current in its path with a dipole of Ekman pumping/eddies on its flanks. 1055 As a result, upwelling in the Panama Bight brings cold and salty waters to the surface that erode the fresh pool on its eastern side while surface currents stretch the pool westward.

1057 Interestingly, SMOS data are also able to detect other meso-scale features in the 1058 region around the fresh pool such as the near-equatorial SSS front or the local SSS 1059 maximum in the Costa Rica dome.

1060 Therefore, SMOS SSS data will help in exploring qualitatively the seasonal 1061 dynamics of the fresh pools from their birth to their final erosion by wind-driven and 1062 turbulent processes (surface current stirring and wind-driven upwelling). Quantifying the 1063 relative contribution of the different mechanisms on SSS variations would require a 1064 model-based synergetic data analysis scheme to establish the mixed layer salt budget. Also, 1065 the regional occurrence of SSS fronts and barrier layers (de Boyer Montégut et al, 2007) 1066 suggests, by analogy with the western tropical Pacific, a link between surface and 1067 subsurface salinity which could give additional value to the satellite SSS data (Maes, 2008; 1068 Bosc et al., 2009). As barrier layers can play an active role on the tropical climate 1069 (e.g.,Maes et al., 2002, 2005), studying their impacts in the region seems worthwhile. This 1070 could be done through regional modeling combined with analysis of subsurface/surface in 1071 situ and satellite data. Also, interannual variations of the fresh pool, even if quantitatively 1072 smaller than its seasonal variations, need further investigation as ENSO is a strong climate 
1073 driver in the eastern Pacific. Now that 3 years of SMOS data are available, such type of 1074 analysis can be initiated.

\subsection{Fresh Pools interactions with Tropical Cyclones}

1077

1078 Because of the buoyant plume of fresh water that forms in the Atlantic due to discharge 1079 from the Amazon and Orinoco rivers, the North Western Tropical Atlantic (NWTA) 1080 region where the salt-driven upper ocean stratification may significantly impact oceanatmosphere interactions under Tropical Cyclones. The spreading of the Amazon-Orinoco River plume exhibits a seasonal cycle coinciding with the Atlantic hurricane season (1 June through 30 November) with river influenced minimum salinities observed farthest eastward and north westward during the height of the hurricane season (mid-August to mid-October). As shown by Ffield, (2007), for the 1960 to 2000 time period, $60 \%$ and $68 \%$ of all category 4 and 5 hurricanes, respectively, passed directly over the likely plume region, revealing that the most destructive hurricanes may be influenced by plumeatmosphere interaction just prior to reaching the Caribbean. Historical in situ data reveal that average ocean surface temperatures first encountered by tropical cyclones moving westward between $12^{\circ}$ and $20^{\circ} \mathrm{N}$ is only $26^{\circ} \mathrm{C}$, but upon reaching the northern reaches of

1091 the Amazon-Orinoco River plume (e.g. see Figure 25), the average sea surface 1092 temperatures (SST) encountered by tropical cyclones are $2^{\circ} \mathrm{C}$ warmer. These warm ocean 1093 surface temperatures may play a role in hurricane maintenance and intensification since 1094 hurricanes can only form in extensive ocean areas with a surface temperature greater than $109525.5 \mathrm{deg}$ C (Dare and McBride, 2011). In addition, as shown by Ffield (2007), the buoyant, and therefore stable, 10- to 60-m-thick layer of the plume can mask the presence and influence of other ocean processes and features just below the plume, in particular cool

1098 (during hurricane season) surface temperatures carried by NBC rings. After shedding from 1099 the NBC retroflection, the 300-500-km-diameter anticyclonic (clockwise) NBC rings pass 1100 northwestward through the Amazon-Orinoco River plume toward the Caribbean. The 1101 limited observations reveal that at times the cool upper-layer temperatures of the NBC 1102 rings are exposed to the atmosphere while at other times they are hidden just underneath 1103 warm plume water. Strong winds from the 300-1000-km-diameter cyclonic 1104 (counterclockwise) hurricanes might quickly erode a thin plume, exposing several degrees1105 cooler NBC ring water to the surface, and potentially contributing to limit further 1106 development of hurricanes. As shown by Ffields (2007), the warm temperatures associated 
1107 with the low-salinity Amazon-Orinoco River plume and the relatively cool temperatures 1108 associated with NBC rings are in close proximity to the passing hurricanes. As such they 1109 are expected to actively influence on the hurricane maintenance and intensification 1110 although the interaction is challenging to accurately quantify.

1111 Vizzy and Cook (2010) more recently studied the atmospheric response of the 1112 summertime large scale climate to the Amazon/Orinoco plume sea surface temperature 1113 anomaly forcing using a regional climate model. They performed simulations in the 1114 presence or absence of the Amazon/Orinoco plume SST anomalies. Results from their 1115 simulations indicate that the plume does significantly influence the frequency and intensity 1116 of summertime storm systems over the Atlantic, consistent with Ffield (2007). The 1117 presence of the plume increases the average number of Atlantic basin storms per summer 1118 by $60 \%$. An increase in storm intensity also occurs, with a $61 \%$ increase of the number of 1119 storms that reach tropical storm and hurricane strength. Results from their simulations 1120 suggests that Atlantic storms also tend to curve northward further west in the Atlantic basin 1121 in presence of the plume SST anomaly. These results support the premise that the warm 1122 and low salinity combined Amazon-Orinoco River plume play an important role in 1123 modulating the air-sea interaction during hurricane passages in a manner similar to 1124 persistent fresh water barriers layers.

1125 For instance, when there is a fresh water barrier layer, such as in the North Western 1126 tropical Atlantic, mixing is restricted within shallower mixed layer and entrainment of cool 1127 thermocline water into the mixed layer is reduced (e.g., Anderson et al., 1996; Vialard and 1128 Delecluse,1998a,b; Foltz and McPhaden, 2009). As discussed in Price (2009), if the net 1129 salinity anomaly (fresh water layer thickness times salinity anomaly in the initial state) is 1130 as large as about $20 \mathrm{~m}$, then the fresh layer will potentially inhibit vertical mixing 1131 significantly. As the fresh water surface layer (halocline) of the Amazon and Orinoco river 1132 plumes is warmer than the water below (Ffield, 2007), salinity stratification acts to reduce 1133 the depth of vertical mixing and thus sea surface cooling. The reduced cooling amplitude 1134 in the wake of hurricanes passing over the Amazon and Orinoco river plume, associated 1135 with thick BL effects, might be an important mechanism in favor of hurricane 1136 intensification in that region. Similar impact of barrier-layers on TC-induced sea surface 1137 cooling have been recently evidenced for several case studies such as in the Tropical 1138 Atlantic (Balaguru et al. 2012), in theBay of Bengal (Yu and McPhaden, 2011; Neethu et 1139 al., 2012) and in the tropical Northwest Pacific (Wang et al., 2011). 
1141 New insight into the interactions between such extreme atmospheric events and large-scale

1142 fresh pools at the ocean surface has been gained from the satellite based SSS observations 1143 as recently reported by Grodsky et al; (2012). They used data from the Aquarius/SAC-D

1144 and SMOS satellites to help elucidate the ocean response to hurricane Katia, which crossed

1145 the Amazon plume in early fall, 2011. As illustrated in their paper, the Katia passage left a

$11461.5 \mathrm{psu}$ high haline wake covering $>10^{5} \mathrm{~km}^{2}$ (in its impact on density, the equivalent of a $11473.5^{\circ} \mathrm{C}$ cooling) due to mixing of the shallow BL.

1148
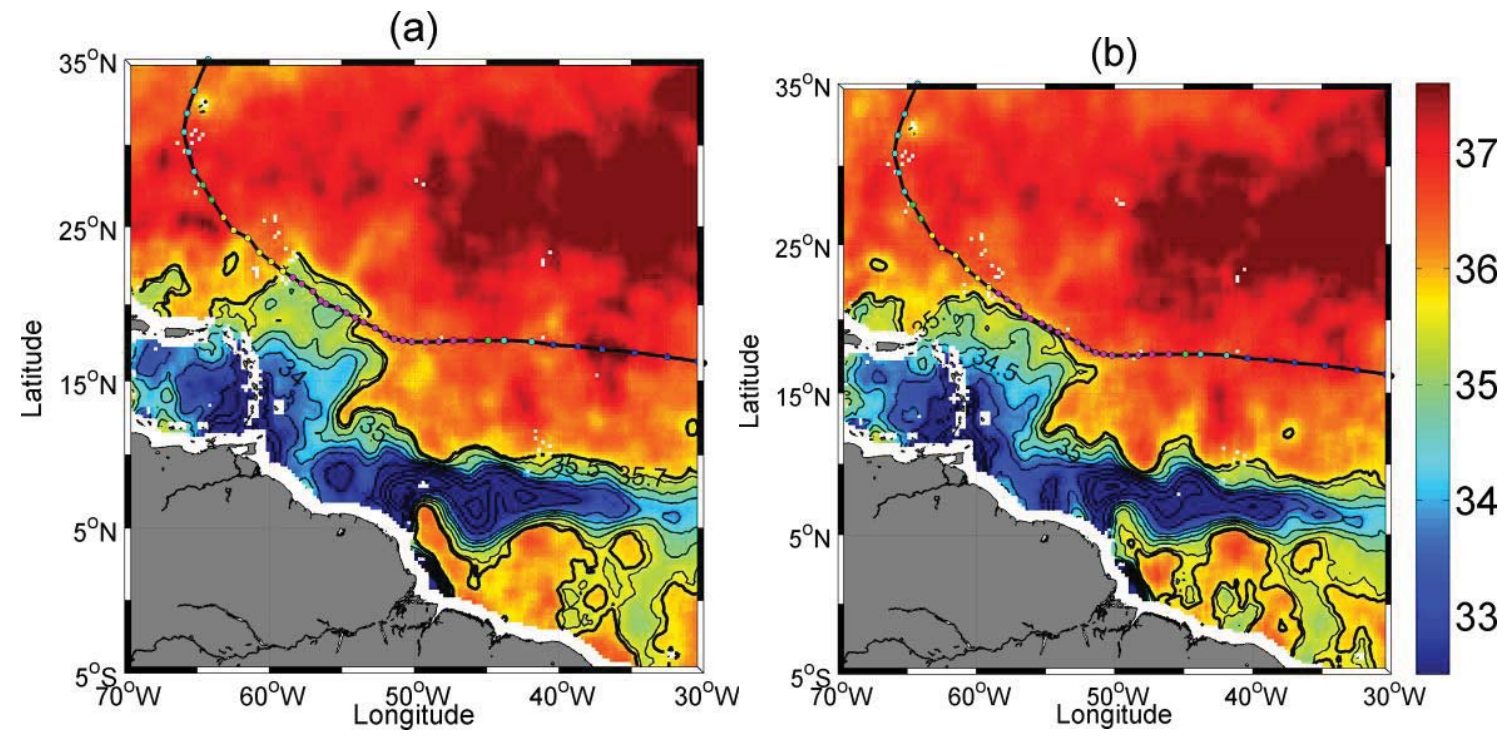

1150 Figure 25: Two SMOS microwave satellite-derived SSS composite images of the Amazon plume region revealing the SSS conditions (a) before and (b) after the passing of Hurricane Igor, a category 4 hurricane that attained wind speeds of 136 knots in September 2010 during its passage over the plume. Color-coded circles mark the successive hurricane eye positions. Seven days of data centered on (a) 10 Sep 2010 and (b) 22 Sep 2010 have been averaged to construct the SSS images, which are smoothed by a

1158 As illustrated in Figure 25, very similar observations were also detected from SMOS data 1159 alone during the passage of the Category 4 hurricane Igor over the river plume in 2010.

1160 The data evidence an erosion of the thin northern reach of the plume fresh surface layer by 1161 Igor hurricane-induced mixing, covering an area of $\sim 89000 \mathrm{~km}^{2}$ located on the storm right1162 hand side, where SSS increases by $\sim 1$ practical salinity unit whilst SST cools by $2-3^{\circ} \mathrm{C}$.

1163 On the left side of the storm, much smaller SSS and SST changes are detected after the 1164 storm passage.The strong SSS increase in the hurricane wake within the plume is explained 1165 by the erosion of the BL. This is supported by Argo profiles collected within the plume 1166 (see Grodsky et al., 2012). Mixed layer salinity is lower by 2 to 4 psu than the water 1167 beneath. The shallow haline stratification is destroyed by hurricane-forced entrainment 
1168 which is stronger on the right side of hurricane eye (Price, 2009). It results in a strong SSS 1169 signal. Although the hurricane strengthened further along the trajectory, the SSS change is 1170 much weaker there corresponding to weak vertical salinity stratification outside the plume.

1171 As further discussed in Grodsky et al., 2012, the fresh (more buoyant) BL limits the 1172 turbulent mixing and then the SST cooling in the plume, and thus preserved higher SST

1173 and fresh water evaporation than outside. Combined with SST, the new satellite SSS data 1174 thus provide a new and better tool to monitor the plume extent and quantify the upper 1175 ocean responses to tropical cyclones with important implications for hurricane forecasting.

\section{6. Conclusions\& Perspectives}

1179 The ocean is the primary return conduit for water transported by the atmosphere. It is the 1180 dominant element of the global water cycle, and clearly one of the most important 1181 components of the climate system, with more than 1100 times the heat capacity of the 1182 atmosphere. Two new satellite sensors, the ESA Soil Moisture and Ocean Salinity Mission 1183 (SMOS) and the NASA Aquarius SAC-D missions are now providing the first space borne 1184 measurements of the sea surface salinity (SSS). Synergetic analyses of the new surface salinity data sets together with sea surface temperature, dynamic height and surface geostrophic currents from altimetry, near surface wind, ocean color, in situ observations, and rainfall estimates will certainly help clarifying the fresh water budget in key oceanic tropical areas.

In this paper, we selected illustrative examples to review how the first SSS products derived from the SMOS sensor can readily help to better characterize some of the key processes of the marine branch of the global hydrological cycle. First, we illustrated the new monitoring capabilities for some of the world largest oceanic fresh water pools

1193 generated by the discharge of very large tropical rivers. In particular, we show how SMOS

1194 SSS traces the fresh water signals from the Amazon-Orinoco and Congo river 1195 plumes.River runoff is an important variable in oceanography as their fresh water affects 1196 SSS and the buoyancy of the surface layer, and they represent a source of materials exotic 1197 to the ocean and highly important to biological activity. Obviously, they are key 1198 hydrologic components of the fresh water exchanges between the atmosphere, land and 1199 ocean. Despite this importance, tracing river fresh watertransport over large distances has 1200 not been straightforward previously principally because of a lack of SSS data. Tracing 1201 those very large rivers over great distances now become an important endeavor, as 
1202 sufficient data are available from the SMOS and Aquarius sensors that can be further 1203 combined with satellite derived surface geostrophic current data.

1204 Second, we evidenced key oceanic precipitation signatures in the SMOS SSS signal. 1205 Satellite radiometry at L-band provides for the first time a global measure of the salinity at 1206 the ocean-atmosphere interface (within the upper centimeters). Rain events induce 1207 freshening of the ocean surface and are responsible for a high temporal variability in the 1208 SSS, consistently detected by both in situ and spaceborne sensors. Because of the vertical 1209 haline gradient generated by the rain-induced freshening in the upper ocean, fresher 1210 surface waters are however systematically found from space in rainy area compared with 1211 the 1-10 $\mathrm{m}$ depth in situ data. These differences challenge calibration/validation activities 1212 of the satellite SSS in high precipitation regions. Nevertheless, satellite SSS data certainly 1213 provide new information about ocean-atmosphere interfacial fresh water fluxes in these 1214 conditions. This was evidenced by comparing spatial patterns and amplitudes of the large 1215 scale SSS anomalies estimated from the SMOS data and the net Evaporation minus 1216 Precipitation fluxes in the Tropical Atlantic. Under the InterTropical Convergence Zone 1217 and sufficiently far away from the river runoff signals, residual SSS anomalies were shown 1218 to be highly correlated to the E-P anomalies. In particular, SSS anomalies become 1219 increasingly negative as the Precipitation anomalies progressively exceed the Evaporation 1220 anomalies. This demonstrate the importance of monitoring SSS from space in rainy 1221 regions, suggesting that the interfacial SSS values might be a good large-scale oceanic rain 1222 gauge of the global hydrological water cycle.

1223 The interfacial character of the spaceborne measurements also offer new information of interest for ocean circulation models in the perspective of better constraining oceanic precipitation forcing terms.

Finally, the SSS observations from SMOS satellite were used to reveal new aspect

1227 of the main tropical fresh pool evolution and interaction with wind-driven atmospheric 1228 processes. SMOS imagery thus captures how the large Eastern Pacific Fresh Pool is 1229 systematically eroded at the end of the boreal summer on its eastern side by the wind1230 driven Panama Upwelling which brings cold and salty waters to the surface. Prior to 1231 SMOS data availability, the few existing studies of the eastern Pacific describing seasonal 1232 variations of SSS did not investigate their cause beyond rainfall (e.g., Fiedler and Talley, 1233 2006). Thanks to the new SMOS data, SSS variability associated with wind-driven 1234 processes in that region, such as the Panama upwelling signal recently evidenced by Alory 1235 et al. (2012), can now be characterized more deeply. 
Because of the buoyant character of the fresh water that forms at the ocean surface

1237 due to large river discharges or intense local precipitation, the upper ocean stratification in 1238 several key tropical oceans regions (e.g., North Western Tropical Atlantic, Eastern and 1239 Western Pacific Fresh Pools, Bay of Bengal) is mostly controlled by salinity. In such 1240 freshwater pool regions, a uniform density mixed layer is found to form the so-called 1241 Barrier Layers at shallower depth than the uniform temperature layer. Because of stable 1242 halocline, the BL are acting to inhibit surface cooling and vertical mixing under the action 1243 of surface wind stresses. Therefore, there can be some feedback mechanisms between 1244 atmospheric, or terrestrial, fresh water fluxes to the ocean and intense atmospheric processes. About $68 \%$ of hurricanes that finally reached category 4 and 5 have thus crossed 1246 the Amazon/Orinoco plume [Ffield, 2007] where the presence of Barrier Layers can 1247 enhance their growth rate by 50\% [Balaguru et al., 2012]. Under an intense hurricane, the 1248 halocline, which is above the thermocline, is first mixed. This produces a SSS wake that is 1249 by a few psu saltier than initial SSS in the plume. By analysing SMOS SSS data before 1250 and after the passage of several intense hurricanes over the Amazon river plume in 2010 and 2011, SSS changes $>1$ psu over areas exceeding $10^{5} \mathrm{~km}^{2}$ were detected. These abrupt changes have implications for SSS climate, since SSS is more long-lived and not damped

1253 like SST. In addition, destruction of the BL is apparently associated with a decreased SST 1254 cooling in the plume that, in turn, preserves higher SST and evaporation than outside the 1255 BL. This difference in SST cooling is explained by additional work required to mix the 1256 BL. Thus BL leads to a reduction in hurricane-induced surface cooling that favors 1257 hurricane intensification, as the resulting elevated SST and high evaporation enhance the 1258 hurricane's maximum potential intensity. The geographic location and seasonality of the 1259 Amazon/Orinoco plume make hurricane overpasses a frequent occurrence. Indeed, the 1260 expansion of the plume in August-September coincides with the peak of the production of 1261 Cape Verde hurricanes, which includes many of the most intense (Category 4-5) 1262 hurricanes. Thus the results presented here strongly suggest that the role of the salinity 1263 stratification in mixed layer dynamics should be taken into account when forecasting 1264 tropical cyclone growth over freshwater pools that are generating thick BL (Amazon 1265 plume, Bay of Bengal, Eastern and Western Pacific Fresh Pools). The availability of satellite SSS from Aquarius and SMOS along with in situ Argo measurements is critical to making such model improvements practical. 
1271 Work presented in this paper was partly done under ESA support in the context of the 1272 development of the SMOS Level 2/Expert Support Laboratory, ESA Support to Science 1273 Element SMOS+SOS and SMOS+STORM projects. CNES also partly funded these 1274 activities in the frame of the Centre Aval de Traitement des Données SMOS (CATDS) 1275 and of the SMOS/ESA GLOSCAL Cal/Val projects. We are indebted to Micha Rijkenberg 1276 (Koninklijk Nederlands Instituut voor Onderzoek der Zee · Department of Biological 1277 Oceanography (BIO)) for giving us access to the Geotraces Leg 2 CTD data, to F. Gaillard 1278 (LPO/IFREMER) for providing ISAS maps version 6 (see http://wwz.ifremer.fr/lpo/SO1279 Argo/Products/Global-Ocean-T-S). Gilles Reverdin (LOCEAN/CNRS) is responsible for 1280 french salinity drifter deployment program, he supervised the quality control of these 1281 drifter data set and is warmly acknowledged. These data are available on www.locean1282 ipsl.upmc.fr/smos/drifters. We thank Nicolas Martin for data processing. We are also 1283 indebted to JéromeVialard, MatthieuLengaigneand Emmanuel Vincent for their very 1284 helpful comments about SSS variability in the tropical Indian Ocean and about Tropical 1285 Cyclones interactions with the Amazon plume, Thierry Delcroix about SSS variability in 1286 the tropical Pacific Ocean. SSM/I data have been processed by Remote Sensing System 1287 (www.ssmi.com). The global ocean heat flux and evaporation products were provided by 1288 the WHOI OAFlux project (http://oaflux.whoi.edu) funded by the NOAA Climate 1289 Observations and Monitoring (COM) program.

\section{References}

Alory G, Maes C, Delcroix T, Reul N, Illig S (2012), Seasonal dynamics of sea surface salinity off Panama: the far eastern Pacific fresh pool, J. Geophys. Res. 117: C04028

Anderson SP, Weller RA, Lukas R (1996) Surface Buoyancy Forcing and the Mixed Layer of the Western Pacific Warm Pool: Observations and 1D Model Results. J. Climate, 9, 3056-3085

Baklouti M, Devenon JL, Bourret A, Froidefond JM, Ternon JF, Fuda JL (2007) New insights in the French Guiana continental shelf circulation and its relation to the North Brazil Current retroflection, J. Geophys. Res. 112: C02023

Balaguru KP, Saravanan SR, Leung LR, Xu Z, Li M, Hsieh JS, (2012) Ocean barrier layers' effect on tropical cyclone intensification, PNAS, doi:10.1073/pnas.1201364109 surface salinity in the atlantic with Argo and operational ocean model data, IEEE Transactions on Geoscience and Remote Sensing 50: 1688-1702 
Benway HM, Mix AC (2004) Oxygen isotopes, upper-ocean salinity, and precipitation sources in the eastern tropical Pacific, Earth Planet. Sci. Lett., 224: 493-507

Binet D, Marchal E (1993) The Large Marine Ecosystem of Shelf Areas in the Gulf of Guinea:Long-Term Variability Induced by Climatic Changes. In Kenneth Sherman, et al. (eds.), Large Marine Ecosystems: Stress, Mitigation, and Sustainability (Washington, D.C.: American Association for the Advancement of Science, 1993) : 104-118.

Bingham FM, Foltz GR, McPhaden MJ (2010), Seasonal cycles of surface layer salinity in

Blough NV, Del Vecchio R (2002), Chromophoric DOM in the coastal environment, in Biogeochemistry of Marine Dissolved Organic Matter, edited by D. A. Hansell, and C. A. Carlson, pp. 509-546, Academic, San Diego, Calif

Bonjean F, Lagerloef GSE (2002): Diagnostic Model and Analysis of the Surface Currents in the Tropical Pacific Ocean. J. Phys. Oceanogr. (32): 2938-2954

Bornhold BD (1973) Late Quaternary sedimentation in the eastern Angola Basin. Massachusetts Institute of Technology: 1-213 (thesis).

Bosc C, Delcroix T, Maes C (2009) Barrier layer variability in the western Pacific warm pool from 2000 to 2007, J. Geophys. Res., 114, C06023

Boutin J, Martin N, Yin X, Reul N, Spurgeon P (2012a) First Assessment of SMOS Data Over Open Ocean: Part II-Sea Surface Salinity. IEEE Transactions on Geoscience and Remote Sensing 50 (5) Part 1: 1662 - 1675

BoutinJ, Martin N, Reverdin G, Yin X, Gaillard F (2012b), Sea surface freshening inferred from SMOS and Argo salinity: Impact of rain, Ocean Sci. Discuss., 9, $3331-3357$

Boyer TP, Levitus S (2002) Harmonic analysis of climatological sea surface salinity, J. Geophys. Res., 107(C12): 8006

Braga ES, Andrie C, Bourles B, Vangriesheim A, Baurand F, Chuchla R (2004) Congo River signature and deep circulation in the eastern Guinea Basin. Deep Sea Research Part I:Oceanographic Research Papers 51 (8): 1057-1073.

Carval T, Keeley B, Takatsuki Y, Yoshida T, Loch S, Schmid, C, Goldsmith R, Wong A, McCreadie R, Thresher A, Tran A (2012) Argo User's Manual v2.4, 85, IFREMER referencecor-do/dti-mut/02-084

Cherubin LM, Richardson PL (2007) Caribbean Current Variability And The Influence Of The Amazon And Orinoco Freshwater Plumes, Deep-Sea Research Part IOceanographic Research Papers, 54(9): 1451-1473

Conmy RN, Coble PG, Cannizzaro JP, Heil CA (2009) Influence of extreme storm events on West Florida Shelf CDOM distributions, J. Geophys. Res., 114, G00F04

Cravatte S, Delcroix T, Zhang D, McPhaden MJ, Leloup J (2009). Observed freshening and warming of the western Pacific warm pool.Clim. Dyn. 33, 565-589 
Dare RA., McBride JL(2011) The Threshold Sea Surface Temperature Condition for Tropical Cyclogenesis. J. Climate, 24: 4570-4576.

Del Vecchio R, Subramaniam A (2004) Influence of the Amazon River on the surface optical properties of the Western Tropical North Atlantic Ocean, J. Geophys. Res., 109, C11001

De Boyer Montégut C,MignotJ, Lazar A, CravatteS (2007), Control of salinity on the mixed layer depth in the world ocean: 1. General description, J. Geophys. Res., 112, C06011

Delcroix T, Alory G, Cravatte S, Corrège T, McPhaden MJ (2011) A gridded sea surface salinity data set for the tropical Pacific with sample applications (1950-2008), Deep Sea Res., Part I 58(1): 38-48

DeMaster D J, Smith W, Nelson DM, Aller JY (1996), Biogeochemical processes in Amazon shelf waters: Chemical distributions and uptake rates of silicon, carbon and nitrogen, Cont. Shelf Res., 16: 617-643

Dessier A, Donguy J (1994) The Sea-Surface Salinity In The Tropical Atlantic Between 10-Degrees-S And 30-Degrees-N - Seasonal And Interannual Variations (19771989), Deep-Sea Research Part I-Oceanographic Research Papers, 41(1): 81-100

Dickson RR, Yashayaev I, Meincke J, Turrell W, Dye S, Holfort J (2002) Rapid freshening of the deep North Atlantic Ocean over the past four decades. Nature 416: 832-837

Donguy JR, Hénin C (1980) Surface conditions in the eastern equatorial Pacific related to the intertropical convergence zone of the winds, Deep Sea Res., Part A, 27: 693714

D'Sa EJ, Hu C, Muller-Karger FE, Carder KL (2002) Estimation of colored dissolved organicmatter and salinity fields in case 2 waters using SeaWiFS: Examples from Florida Bay and Florida Shelf, J. Earth Syst. Sci., 111: 197-207

Eisma D, Van Bennekom A.J. (1978) The Zaire river and estuary and the Zaire outflow in

Durack PJ, Wijffels SE, Matear RJ (2012) Ocean salinities reveal strong global water cycle intensification during 1950 to 2000, Science 336: 455-458

Ferrari GM, Dowell MD (1998) CDOM absorption characteristics with relation to fluorescence and salinity in coastal areas of the southern Baltic Sea, Estuarine Coastal Shelf Sci., 47, 91-105

FfieldA (2005) North Brazil Current rings viewed by TRMM Microwave Imager SST and the influence of the Amazon Plume. Deep-Sea Res. I, 52: 137-160

1380 Ffield A, (2007) Amazon and Orinoco River plumes and NBC Rings: bystanders or participants in hurricane events? J. Clim. 20: 316-333

1382 Fiedler PC, Talley LD (2006), Hydrography of the eastern tropical Pacific: A review, Prog. Oceanogr., 69(2-4): 143-180 
Flagg CN, Gordon RL, McDowell S (1986) Hydrographic and current observations on the continental slope and shelf of the western equatorial atlantic, Journal of Physical Oceanography 16(8): 1412-1429

Foltz GR, McPhaden JM (2009) Impact of barrier layer thickness on SST in the central tropical North Atlantic. J. Climate 22: 285-299

Font J, Camps A, Borges A, Martín-Neira M, Boutin J, Reul N, Kerr YH, Hahne A, Mecklenburg S (2010) SMOS: The Challenging Sea Surface Salinity Measurement from Space, Proceedings of the IEEE 98(5):649-665

Font J, Boutin J, Reul N, Spurgeon P, Ballabrera-Poy J, Chuprin A, Gabarró C, Gourrion J, Guimbard S, Hénocq C, Lavender S, Martin N, Martínez J, McCulloch M, Meirold-Mautner I, Mugerin C, Petitcolin F, Portabella M, Sabia R, Talone M, Tenerelli J, Turiel A, Vergely JL, Waldteufel P, Yin X, Zine X, Delwart S (2013) SMOS first data analysis for sea surface salinity determination, International Journal of Remote Sensing, DOI:10.1080/01431161.2012.716541

Froelich PN, Atwood DK, Giese GS (1978) Influence of amazon river discharge on surface salinity and dissolved silicate concentration in the caribbean sea, Deep Sea Research,25(8):735-744

Gaillard F, Autret E, Thierry V, Galaup P, Coatanoan C, Loubrieu T (2009) Quality control oflarge Argo datasets, J. Atmos. Ocean. Tech., 26, 337-351

Garzoli SL, Ffield A, Johns WE, Yao Q (2004) North Brazil Current retroflection and transports, J. Geophys. Res., 109, C01013

Goni GJ, Johns W (2001) A Census of North Brazil Current Rings Observed from T/P Altimetry: 1992-1998, Geophys. Res. Let., 1-4

Gordon A, Guilivi CF (2008) Sea surface salinity trends over 50 years within the subtropicalNorth Atlantic. Oceanography 20 (1): 20-29

Gouriou Y, Delcroix T (2002) Seasonal and ENSO variations of sea surface salinity and temperature in the South Pacific Convergence Zone during 1976-2000. Journal of Geophysical Research 107: 3185

Grodsky SA, Reul N, Lagerloef G, Reverdin G, Carton JA, Chapron B, Quilfen Y, Kudryavtsev VN, Kao HY (2012) Haline hurricane wake in the Amazon/Orinoco plume: AQUARIUS/SACD and SMOS observations, Geophys. Res. Lett., 39, L20603

Grunseich G, Subrahmanyam B, Murty VSN, Giese BS (2011) Sea surface salinity variability during the Indian Ocean Dipole and ENSO events in the tropical Indian Ocean, J. Geophys. Res., 116: C11013

Hellerman S, Rosenstein M (1983), Normal monthly wind stress over the world ocean with error-estimates, Journal Of Physical Oceanography, 13(7): 1093-1104

Hellweger F, Gordon A (2002), Tracing Amazon River water into the Caribbean Sea, Journalof Marine Research, 60 : 537-549 
Hisard P, (1980) Observation de réponses de type "El Niño" dans l'Atlantique tropical oriental, Golfe de Guinée. Oceanol.Acta 3: 69-78

Hu C, Montgomery ET, Schmitt RW, Muller-Karger FE (2004) The dispersal of the Amazonand Orinoco River water in the tropical Atlantic and Caribbean Sea: Observation from space and S-PALACE floats, Deep Sea Res. Part II, 51: 11511171.

Johns, WE, Lee TN, Schott FA, Zantopp RJ, Evans RH (1990) The north brazil current retroflection: Seasonal structure and eddy variability, J. Geophys. Res. 95: 2210322120

Katsaros KB, Buettner K JK (1969) Influence of Rainfall on Temperature and Salinity at the Ocean Surface, J. Appl. Meteorol. 8: 15-18.

Kerr Y, Waldteufel P, Wigneron JP, Delwart S, Cabot F, Boutin J, Escorihuela MJ, Font J, Reul N, Gruhier C (2010) The SMOS Mission: New Tool for Monitoring Key Elements of the Global Water Cycle. Proceedings of the IEEE 98(5): 666-687

Klein LA, Swift CT (1977) Improved model for dielectric constant of seawater at microwavefrequencies.IEEE Transactions on Antennas andPropagation 25: 104111.

Koleshnikov AG (1973) Equalant I and Equalant II, Physical oceanography. UNESCO, Paris 1: 1-289

Lagerloef GSE, Mitchum G, Lukas R, Niiler P (1999) Tropical Pacific near surface currentsestimated from altimeter, wind and drifter data. J. Geophys. Res., 104: $23,313-23,326$

Lagerloef GSE, Colomb FR, Le Vine D, Wentz F, Yueh S, Ruf C, Lilly J, Gunn J, Chao Y, deCharon A, Feldman G, Swift C (2008) The Aquarius/SAC-D Mission: Designed to meet the salinity remote-sensing challenge. Oceanography 21(1):68-81

Lagerloef GSE, Boutin J, Chao Y, Delcroix T, Font J, Niiler P, Reul N, Riser S, Schmitt R, Stammer D, Wentz F (2010) Resolving the Global Surface Salinity Field and Variations by Blending Satellite and In Situ Observations, Oceanobs'09: Sustained Ocean Observations and Information for Society, Venise, Italy, 21-25 September 2009, ESA Publication WPP-306

Lagerloef GSE (2012) Satellite mission monitors ocean surface salinity, Eos Trans. AGU 93(25), 233, doi:10.1029/2012EO250001.

Lefèvre N (2009) Low C02 concentrations in the gulf of guinea during the upwelling season in 2006, Marine Chemistry, 113(1-2), 93

Lentz SJ (1995) Seasonal-Variations In The Horizontal Structure Of The Amazon Plume Inferred From Historical Hydrographic Data, J. Geophys. Res., 100(C2): 2391-2400

Lentz SJ, Limeburner R (1995) The Amazon River Plume during AMASSEDS: Spatial characteristics and salinity variability, J. Geophys. Res., 100: 2355-2375 
Maes C (2008) On the ocean salinity stratification observed at the eastern edge of the equatorial Pacific warm pool, J. Geophys. Res., 113, C03027

Maes C, Picaut J, Belamari S (2002) Salinity barrier layer and onset of El Niño in a Pacific coupled model, Geophys. Res. Lett., 29(24), 2206

Maes C, Picaut J, Belamari S (2005), Importance of salinity barrier layer for the buildup of El Niño, J. Clim., 18, 104-118

Meade RH, Nordin CF, Hernandez DP, Mejia A, Godoy JMP (1983) Sediment and water discharge in Rio Orinoco, Venezuela and Colombia. In: Proceedings of the Second International Symposium on River Sedimentation. Water resourcesand Electric Poers Press, Beijing, China, pp. 1134-1144.

Mecklenburg S, Drusch M, Kerr YH, Font J, Martin-Neira M, Delwart S, Buenadicha G, Reul N, Daganzo-Eusebio E, Oliva R, Crapolicchio R (2012) ESA's Soil Moisture and Ocean Salinity Mission: Mission Performance and Operations, IEEE Transactions on Geoscience and Remote Sensing 50 (5) Part 1: 1354 - 1366

Merle J, (1980) Variabilité thermique annuelle et interannuelle de l'océan Atlantique équatorial est. L'hypothèse d'un " El Niño " Atlantique. Oceanol. Acta 3, 209-220

Meulenbergh J (1968) Diffusion des eaux du fleuve Congo dans les eaux de l'Atlantique Sud.Acad. roy. SC. Outre-Mer, SC. Te\&., N.S. SVI (6) Bruxelles, 148 p.

Meybeck M, Ragu A (1997) River discharges to the oceans: An assessment of suspended solids, major ions, and nutrients, IAHS Publ., 243: 1-245

Michel S, Chapron B, Tournadre J, Reul N (2007) Sea surface salinity variability from a simplified mixed layer model of the global ocean, Ocean Sci. Discuss., 4: 41-106

Mignot J, de Boyer Montégut C, Lazar A, Cravatte S (2007) Control of salinity on the mixed layer depth in the world ocean: 2. Tropical areas. J. Geophys. Res., 112, C10010

Miller R, Zepp RG (1995) Photochemical production of dissolved inorganic carbon from terrestrial organic matter: Significance to the oceanic organic carbon cycle, Geophys.Res. Lett., 22, 417-420

Milliman JD, Meade RH (1983) World-wide delivery of river sediment to the oceans, The Journal of Geology, 91(1): 1-21

Molleri GSF, de M. Novo EML, Kampel M (2010), Space-time variability of the Amazon River plume based on satellite ocean color, Continental Shelf Research 30(3-4):, 342-352

Moran M A, Sheldon WM, Sheldon JE (1999), Biodegradation of riverine dissolved organiccarbon in five estuaries of the southeastern United States, Estuaries, 22: 5564

Morrow R, Valladeau G, Sallee J-B (2008) Observed subsurface signature of Southern Ocean sea level rise. Prog.Oceanogr. 77(4): 351-366 
Muller-Karger FE, McClain CR, Richardson PL (1988) The dispersal of the Amazon's water, Nature, $333: 56-59$

Muller-Karger FE, McClain CR, Fisher TR, Esaias WE, Varela R(1989) Pigment distribution in the Caribbean Sea: Observations from space, Prog. Oceanogr., 23: 23-64

Muller-Karger FE, Richardson PL, McGillicuddy D (1995), On the offshore dispersal of the Amazon's Plume in the North Atlantic, Deep Sea Res. Part I, 42: 2127-2137

Neetu S, Lengaigne M, Vincent EM, Vialard J, Madec G, Samson G,Ramesh Kumar MR, Durand F (2012) Influence of upper-ocean stratification on tropical cyclonesinduced surface cooling in the Bay of Bengal. Journal of Geophysical Research, $117, \mathrm{C} 12020$

Neumann G (1969) Seasonal salinity variations in the upper strata of the western tropical Atlantic ocean-I. Sea surface salinities, Deep-Sea Res. 16: 165-177

Nittrouer CA, Demaster DJ (1986), Sedimentary processes on the Amazon continental shelf: past, present and future research, Continental Shelf Research, 6: 5-30

Obernosterer I, Herndl GJ (2000) Differences in the optical and biological reactivity of the humic and non-humic DOC component in two contrasting coastal marine environments, Limnol. Oceanogr., 45: 1120-1129

Ostapoff F, Tarbeyev Y, Worthem S (1973) Heat Flux and Precipitation Estimates from Oceanographic Observations, Science 180: 960-962.

Palacios SL, Peterson TD, Kudela RM (2009), Development of synthetic salinity from remote sensing for the Columbia River Plume, J. Geophys. Res., 114: C00B05

Perry GD, Duffy PB, Miller NL (1996) An extended data set of river discharges for validation of general circulation models, J. Geophys. Res. 101: 21339-21349

Piterbarg LI, Ostrovskii AG(1997) Advection and Diffusion in Random Media: Implications for Sea Surface Temperature Anomalies. Kluwer Academic, 330 pp.

Piton B, Wacongne S (1985). Unusual amounts of very saline subsurface water in the eastern Gulf of Guinea in May 1984. Tropical Ocean-Amosphere Newsletter 325-8

Price JF (2009) Metrics of hurricane-ocean interaction: Vertically-integrated or verticallyaveraged ocean temperature? Ocean Science 5:351-368.

Reul N, Saux-Picart S, Chapron B, Vandemark D, Tournadre J, Salisbury J (2009), Demonstration of ocean surface salinity microwave measurements from space using AMSR-E over the Amazon plume, Geophys. Res. Letters, 36, L13607

Reul, N, Tenerelli J (2011) SMOS Level 3 SSS Research products - Product Validation Document - Reprocessed Year 2010. CECOS/CNES/IFREMER/CATDS Techn Doc (available from www.catds.fr).

Reul N, Tenerelli J, Boutin J, Chapron B, Paul F, Brion E, Gaillard F, Archer O (2012) Overview of the First SMOS Sea Surface Salinity Products. Part I: Quality 
Assessment for the Second Half of 2010. IEEE Transactions on Geoscience and Remote Sensing 50 (5) : 1636 - 1647

Reverdin G, Kestenare E, Frankignoul C, Delcroix T (2007), Sea surface salinity in the Atlantic Ocean $\left(30^{\circ} \mathrm{S}-50^{\circ} \mathrm{N}\right)$, Prog. Oceanogr., 73: 311-340

Reverdin G, Morisset S, Boutin J, Martin N (2012) Rain-induced variability of near seasurface $T$ and $S$ from drifter data, J. Geophys. Res., 117, C02032

Richardson PL, McKee T (1984) Average seasonal variation of the atlantic equatorial currents from historical ship drifts, Journal of Physical Oceanography, 14(7):1226-1238

Ruf CS, Swift CT, Tanner AB, Le Vine DM(1988)Interferometric synthetic aperture microwave radiometry for the remote sensing of the Earth.IEEE Transactions on Geoscience and Remote Sensing, 26, pp. 597-611.

Salisbury J, Vandemark D, Campbell J, Hunt C, Wisser D, Reul N, Chapron B (2011) Spatial and temporal coherence between Amazon River discharge, salinity, and light absorption by colored organic carbon in western tropical Atlantic surface waters, J.Geophys. Res., 116, C00H02

Schlössel P, Soloviev A, Emery WJ (1997) Cool and freshwater skin of the ocean during rainfall, Boundary-Layer Meteorology 82 (3): 439-474

Schmitt RW(2008) Salinity and the global water cycle, Oceanography 21(1):12-19

Singh A, Delcroix T, Cravatte S (2011) Contrasting the flavors of El Niño-Southern Oscillation using sea surface salinity observations, J. Geophys. Res., 116: C06016

Smith WO, Demaster DJ (1996) Phytoplankton biomass and productivity in the amazon river plume: correlation with seasonal river discharge, Continental Shelf Research, 16(3):291-319

Soloviev A, Lukas R (1996) Observation of spatial variability of diurnal thermocline and rainformed halocline in the Western Pacific warm pool, J. Phys. Oceanogr., 26: $2529-2538$

Steven DM, Brooks AL (1972), Identification of amazon river water at barbados, w. indies, by salinity and silicate measurements, Marine Biology, 14(4): 345-348

Ternon, JF, Oudot C, Dessier A, Diverres D (2000) A seasonal tropical sink for atmospheric $\mathrm{CO}_{2}$ in the atlantic ocean: the role of the amazon river discharge, Marine Chemistry 68(3): 183-201

Terray L, Corre L, Cravatte S, Delcroix T, Reverdin G, Ribes A. (2011) Near-surface salinityas nature's rain gauge to detect human influence on the tropical water cycle, J. Climate, 25:958-977

Twardowski MS, Donaghay PL (2001) Separating in situ and terrigenous sources of absorption by dissolved material in coastal waters, J. Geophys. Res., 106(C2): $2545-2560$ 
UNESCO: The international system of units (SI) in oceanography, UNESCO Technical Papers No. 45, IAPSO Pub. Sci. No. 32, Paris, France, 1985.

Van Bennekom AJ, JagerJE (1978) Dissolved aluminium in the Zaire river plume, Neth. J.Sea Res. 12 (3/4): 358-367.

Van Bennekom AJ, Berger GW (1984), Hydrography and silica Budget of the Angola Basin, Netherlands Journal of Sea Research 17 (2-4): 149-200

Vangriesheim A, Pierre C, Aminot A, Metzl N, Baurand F, Caprais JC (2009) The influence of Congo river discharges in the surface and deep layers of the gulf of guinea, Deep Sea Re- search Part II: Topical Studies in Oceanography56(23): 2183-2196

Vialard J, Delecluse P (1998a) An OGCM Study for the TOGA Decade. Part I : Role of Salinity in the Physics of the Western Pacific Fresh Pool. Journal of Physical Oceanography, 28: $1071-1088$

Vialard J, Delecluse P (1998b) An OGCM Study for the TOGA Decade. Part II : Barrier Layer Formation and Variability. Journal of Physical Oceanography, 28:1089 -1106

Vizy EK, Cook KH (2010) Influence of the Amazon/Orinoco Plume on the summertime Atlantic climate, J. Geophys. Res., 115, D21112

Vörösmarty CJ, Fekete B, Tucker BA(1998) River dischargeDatabase, Version 1.1 (RivDIS v1.0 supplement). Institute forthe Study of Earth, Oceans, and Space, University of NewHampshire, Durham, $\mathrm{NH}$

Wang X, Han G, Qi, Y, Li W (2011) Impact of barrier layer on typhoon-induced sea surfacecooling, Dynamics of Atmospheres and Oceans, 52, 3: 367-385

Wauthy B (1977) - Révision de la classification des eaux de surface du golfe de Guinée. Cah.O.R.S.T.O.M., sér.Océanogr., 15 (3) : 279-295.

Wijesekera HW, Paulson CA, Huyer A (1999) The effect of rainfall onthe surface layer during a westerly wind burst in the western equatorialPacific, J. Phys. Oceanogr., 29: $612-632$

Wisser D, Fekete BM, Vörösmarty CJ, Schumann AH (2010) Reconstructing 20th century global hydrography: A contribution to the Global Terrestrial Network-Hydrology (GTN-H), Hydrol. Earth Syst. Sci., 14: 1-24

Yamashita Y, Tanoue E (2004), In situ production of chromophoric dissolved organic matter in coastal environments, Geophys. Res. Lett. 31: L14302

Yin X, Boutin J, Martin N, Spurgeon P (2012) Optimization of L-Band Sea Surface Emissivity Models Deduced From SMOS Data, IEEE Transactions on Geoscience and Remote Sensing 50: 1414-1426

Yoo JM, Carton JA (1988), Spatial Dependence of the Relationship between Rainfall and Outgoing Longwave Radiation in the Tropical Atlantic., Journal of Climate, 1: 1047- 1056 
1613 Yu L, Weller RA (2007) Objectively Analyzed air-sea heat Fluxes (OAFlux) for the global

1614 ocean, Bull. Am. Meteorol. Soc., 88(4): 527-539

1615 Yu L (2010) On Sea Surface Salinity Skin Effect Induced by Evaporation and Implications

1616 for Remote Sensing of Ocean Salinity, Journal of Physical Oceanography 40 (1) 85

1617 Yu L (2011) A global relashionship between the ocean water cycle and near-surface 1618 salinity,Journal of geophysical Research, 116: C10025

1619 Yu L, McPhaden MJ (2011) Ocean pre-conditioning of Cyclone Nargis in the Bay of 1620 Bengal:Interaction between Rossby waves, surface fresh waters, and sea surface 1621 temperatures. J. Phys. Oceanogr., 41, 1741-1755.

1622 Yueh SH, West R, Wilson WJ, Li FK, Njoku EG, Rahmatsamii Y (2001), Error sources and feasibility for microwave remote sensing of ocean surface salinity. IEEE Transactionson Geoscience and Remote Sensing, 39: 1049-1060

Zhang Y, Zhang X (2012) Ocean haline skin layer and turbulent surface convections, J. 